WSRC-TR-2003-00308

KEYWORDS:

Sludge Suspension

Computational Approach

Slurry Jet Model

Maximum Clearing Distance

\title{
SLUDGE HEEL REMOVAL ANALYSIS FOR SLURRY PUMPS OF TANK 11
}

SAVANNAH RIVER TECHNOLOGY CENTER

Si Young Lee

July 2003

Westinghouse Savannah River Company

Savannah River Site

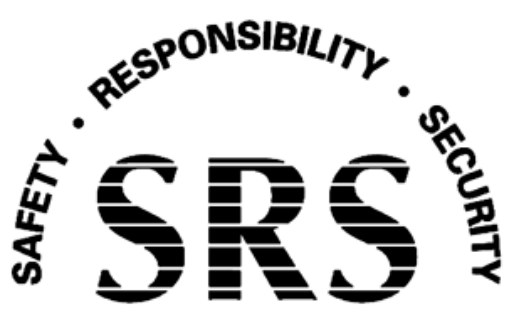

Aiken, SC 29808 
This document was prepared in conjunction with work accomplished under Contract No. DE-AC09-96SR18500 with the U. S. Department of Energy.

\section{DISCLAIMER}

This report was prepared as an account of work sponsored by an agency of the United States Government. Neither the United States Government nor any agency thereof, nor any of their employees, makes any warranty, express or implied, or assumes any legal liability or responsibility for the accuracy, completeness, or usefulness of any information, apparatus, product or process disclosed, or represents that its use would not infringe privately owned rights. Reference herein to any specific commercial product, process or service by trade name, trademark, manufacturer, or otherwise does not necessarily constitute or imply its endorsement, recommendation, or favoring by the United States Government or any agency thereof. The views and opinions of authors expressed herein do not necessarily state or reflect those of the United States Government or any agency thereof.

This report has been reproduced directly from the best available copy.

Available for sale to the public, in paper, from: U.S. Department of Commerce, National Technical Information Service, 5285 Port Royal Road, Springfield, VA 22161, phone: (800) 553-6847, fax: (703) 605-6900

email: orders@ntis.fedworld.gov

online ordering: http://www.ntis.gov/help/index.asp

Available electronically at http://www.osti.gov/bridge

Available for a processing fee to U.S. Department of Energy and its contractors, in paper, from: U.S. Department of Energy, Office of Scientific and Technical Information, P.O. Box 62, Oak Ridge, TN 37831-0062,

phone: (865)576-8401,

fax: (865)576-5728

email: $\underline{\text { reports@ adonis.osti.gov }}$ 
WSRC-TR-2003-00308

\section{Nomenclature}

$$
\begin{aligned}
& A=\operatorname{area}\left(\mathrm{ft}^{2} \text { or } \mathrm{m}^{2}\right) \\
& \mathrm{C}=\text { constant in eq. (9) (--) } \\
& \mathrm{d}=\text { branch diameter or solid particle size in slurry (ft or } \mathrm{m} \text { ) } \\
& \mathrm{D}=\text { main pipe diameter ( } \mathrm{ft} \text { or } \mathrm{m} \text { ) } \\
& \mathrm{g}=\text { gravity }\left(\mathrm{m} / \mathrm{sec}^{2}\right) \\
& \mathrm{H}=\text { tank liquid level ( } \mathrm{ft} \text { or } \mathrm{m} \text { ) } \\
& \mathrm{I}=\text { turbulence intensity (--) } \\
& \mathrm{K}=\text { constant in eq. (3) } \\
& \mathrm{m}=\text { particle mass flowrate }(\mathrm{kg} / \mathrm{sec}) \\
& \mathrm{P}=\text { pressure }(\mathrm{Pa}) \\
& r=\text { radial distance perpendicular to the jet axis ( } \mathrm{ft} \text { or } \mathrm{m} \text { ) } \\
& \mathrm{R}=\text { curvature radius of elbow or droplet radius ( } \mathrm{ft} \text { or } \mathrm{m} \text { ) } \\
& \operatorname{Re}=\text { Reynolds number, } d \rho u / \mu \text { or } d \rho U / \mu \\
& \mathrm{t}=\text { time }(\text { second }) \\
& \mathrm{U}=\text { slurry velocity at nozzle exit (ft/sec or } \mathrm{m} / \mathrm{sec} \text { ) } \\
& \mathrm{u}=\text { component velocity in } \mathrm{x} \text {-direction ( } \mathrm{ft} / \mathrm{sec} \text { or } \mathrm{m} / \mathrm{sec} \text { ) } \\
& u^{\prime}=\text { local turbulent velocity fluctuation in } \mathrm{x} \text {-direction (ft/sec or } \mathrm{m} / \mathrm{sec} \text { ) } \\
& \mathrm{v}=\text { local flow velocity or component velocity in } \mathrm{y} \text {-direction ( } \mathrm{ft} / \mathrm{sec} \text { or } \mathrm{m} / \mathrm{sec} \text { ) } \\
& v^{\prime}=\text { local turbulent velocity fluctuation in y-direction (ft/sec or } \mathrm{m} / \mathrm{sec} \text { ) } \\
& \mathrm{V}=\text { average velocity magnitude (ft/sec or } \mathrm{m} / \mathrm{sec} \text { ) } \\
& \mathrm{w}=\text { component velocity in z-direction ( } \mathrm{ft} / \mathrm{sec} \text { or } \mathrm{m} / \mathrm{sec} \text { ) } \\
& w^{\prime}=\text { local turbulent velocity fluctuation in z-direction (ft/sec or } \mathrm{m} / \mathrm{sec} \text { ) } \\
& \mathrm{x}=\text { local position along the } \mathrm{x} \text {-direction under Cartesian coordinate system ( } \mathrm{ft} \text { or } \mathrm{m} \text { ) } \\
& \mathrm{y}=\text { local position along the } \mathrm{y} \text {-direction under Cartesian coordinate system ( } \mathrm{ft} \text { or } \mathrm{m} \text { ) } \\
& \mathrm{z}=\text { local position along the } \mathrm{y} \text {-direction under Cartesian coordinate system ( } \mathrm{ft} \text { or } \mathrm{m} \text { ) }
\end{aligned}
$$


Page: $\quad 4$ of 71

WSRC-TR-2003-00308

\section{Greek}

$\rho=$ density $\left(\mathrm{kg} / \mathrm{m}^{3}\right)$

$\kappa=$ turbulent kinetic energy $\left(=\frac{1}{2}\left(u^{\prime 2}+v^{\prime 2}+w^{\prime 2}\right)_{\text {avg }}\right)$

$\varepsilon=$ rate of dissipation of turbulent kinetic energy $\left(\mathrm{m}^{2} / \mathrm{sec}^{3}\right)$

$\Delta=$ difference

$\nabla=$ gradient operator

$\eta=$ ratio of flow distance to nozzle diameter (--)

$\mu=$ dynamic viscosity $\left(\mathrm{N} \mathrm{sec} / \mathrm{m}^{2}\right)$

$v=$ kinematic viscosity $\left(\mathrm{m}^{2} / \mathrm{sec}\right)$

$\tau=$ shear stress $\left(\mathrm{N} / \mathrm{m}^{2}\right)$

\section{Subscript}

avg = average

$\mathrm{C}=$ critical

$\mathrm{ECR}=$ effective cleaning radius

$f=$ fluid

$\mathrm{m}=$ mean

MCD = maximum clearing distance

$0=$ nozzle exit

$\mathrm{p}=$ particle

$\mathrm{S}=$ solid

$\mathrm{t}=$ turbulent

w or wall $=$ wall surface 


\section{Abstract}

Computational fluid dynamics methods were used to develop and recommend a slurry pump operational strategy for sludge heel removal in Tank 11. Flow patterns calculated by the model were used to evaluate the performance of various combinations of operating pumps and their orientation. The models focused on removal of the sludge heel located at the edge of Tank 11 using the four existing slurry pumps. The models and calculations were based on prototypic tank geometry and expected normal operating conditions as defined by Tank Closure Project (TCP) Engineering.

Computational fluid dynamics models of Tank 11 with different operating conditions were developed using the FLUENT ${ }^{T M}$ code. The modeling results were used to assess the efficiency of sludge suspension and removal operations in the $75-\mathrm{ft}$ tank. The models employed a three-dimensional approach, a two-equation turbulence model, and an approximate representation of flow obstructions. The calculated local velocity was used as a measure of sludge removal and mixing capability.

For the simulations, a series of the modeling calculations was performed with indexed pump orientations until an efficient flow pattern near the potential location of the sludge mound was established for sludge removal. The calculated results demonstrated that the existing slurry pumps running at $1600 \mathrm{rpm}$ could remove the sludge mound from the tank with a 103 in liquid level, based on a minimum sludge suspension velocity of 2.27 $\mathrm{ft} / \mathrm{sec}$. In this case, the only exception is the region within about $2 \mathrm{ft}$ from the tank wall.

Further results showed that the capabilities of sludge removal were affected by the indexed pump orientation, the number of operating pumps, and the pump speed. A recommended operational strategy for an efficient flow pattern was developed to remove the sludge mound assuming that local fluid velocity can be used as a measure of sludge suspension and removal. Sensitivity results showed that for a given pump speed, a higher tank level and a lower pump nozzle elevation would result in better performance in suspending and removing the sludge. The results also showed that the presence of flow obstructions such as valve housing structure were advantageous for certain pump orientations. 
Report: WSRC-TR-2003-00308

Date: $\quad 10 / 6 / 2003$

Page: $\quad 6$ of 71
WESTINGHOUSE SAVANNAH RIVER COMPANY

SLUDGE HEEL REMOVAL ANALYSIS FOR SLURRY PUMPS OF TANK 11

(This Page Intentionally Left Blank) 


\section{Introduction}

Tank 11 is a 0.75 million-gallon, single-wall, Type I waste tank located in the H-Tank Farm area. The tank was placed into service as a receiver of high heat wastes. The tank is a $75 \mathrm{ft}$ diameter, flat-bottomed, cylindrical carbon steel tank with a height of about $24.5 \mathrm{ft}$. There are cooling coils, a valve housing to control coolant flow in the cooling coils, and structural supports internal to the tank. The waste in the tank consists of salt and sludge. The salt was removed by dissolution in water and transferred to other tanks for storage. The remaining sludge mound settled near the bottom, west wall of the tank will then be hydraulically mobilized and transferred to other tanks.

To suspend and mobilize the sludge mound, water will be added to Tank 11 as a slurry medium. Tank 11 has four slurry pumps manufactured by the Lawrence Company [1] available for sludge removal operations. Each pump has a suction inlet at the bottom and two opposing discharge nozzles, $1.5 \mathrm{in}$. in diameter. The pump is normally submerged to approximately the level of the sludge, allowing a recirculating mixture of sludge and water to serve as the feed flow. The pump nozzle can not be placed lower than about 17 inches above the tank bottom [1,2]. The minimum nozzle elevation corresponds to about 11 inches from the tank floor to the bottom of the pump suction screen as shown in Fig. 1. All pumps are located at a $16.5 \mathrm{ft}$ radial distance from the tank wall as shown schematically in Fig. 1. Each pump can rotate between 0.2 and 0.5 rpm using a variable frequency drive. The cleaning pattern generated on the tank bottom defines the effective cleaning radius (ECR) when the pump rotates. The ECR has been one of the measures or indicators of the cleaning ability of a mixing pump. After the mixer suspends the sludge, waste transfers from Tank 11 to another tank will be performed. Detailed design information for the slurry pump is shown in Table 1.

In previous work [5], a three-dimensional computational fluid dynamics (CFD) model for a prototypic tank was developed and benchmarked against TNX test data. The test data were obtained from a mixing experiment conducted in a full tank mockup in the TNX area. The test tank was $85 \mathrm{ft}$ in diameter and $8 \mathrm{ft}$ high. The advanced mixing pump of Tank 18, which had similar design characteristics to the Tank 11 mixing pumps, was used to suspend a kaolin clay slurry in the tank. Its long shaft was enclosed in a 16 in nominal pipe diameter casing. It was located $16 \mathrm{ft}$ from the tank wall with a discharge elevation 27 in above the tank bottom. Kaolin clay slurries were used to simulate the actual sludge in the waste tanks [5].

The primary objective of the present work is to provide a recommended operational strategy for sludge heel removal in Tank 11. The flow patterns calculated by the model will be used to evaluate the capabilities of the slurry mixers under various combinations of number of operating pumps and their nozzle discharge orientation. A schematic layout and dimensions of the sludge mound heel located at the corner of the tank are shown in Fig. 2. Figure 3 shows the typical flow development and evolution of a jet flow discharged by a slurry mixer obtained from previous modeling results $[4,5]$ and literature information [11].

The analysis results will be used to evaluate hydraulic cleaning capabilities for waste removal. This information will also assist in the operating plan for the Tank 11 waste removal and in identifying special operation requirements for the suspension and removal of the tank sludge. 


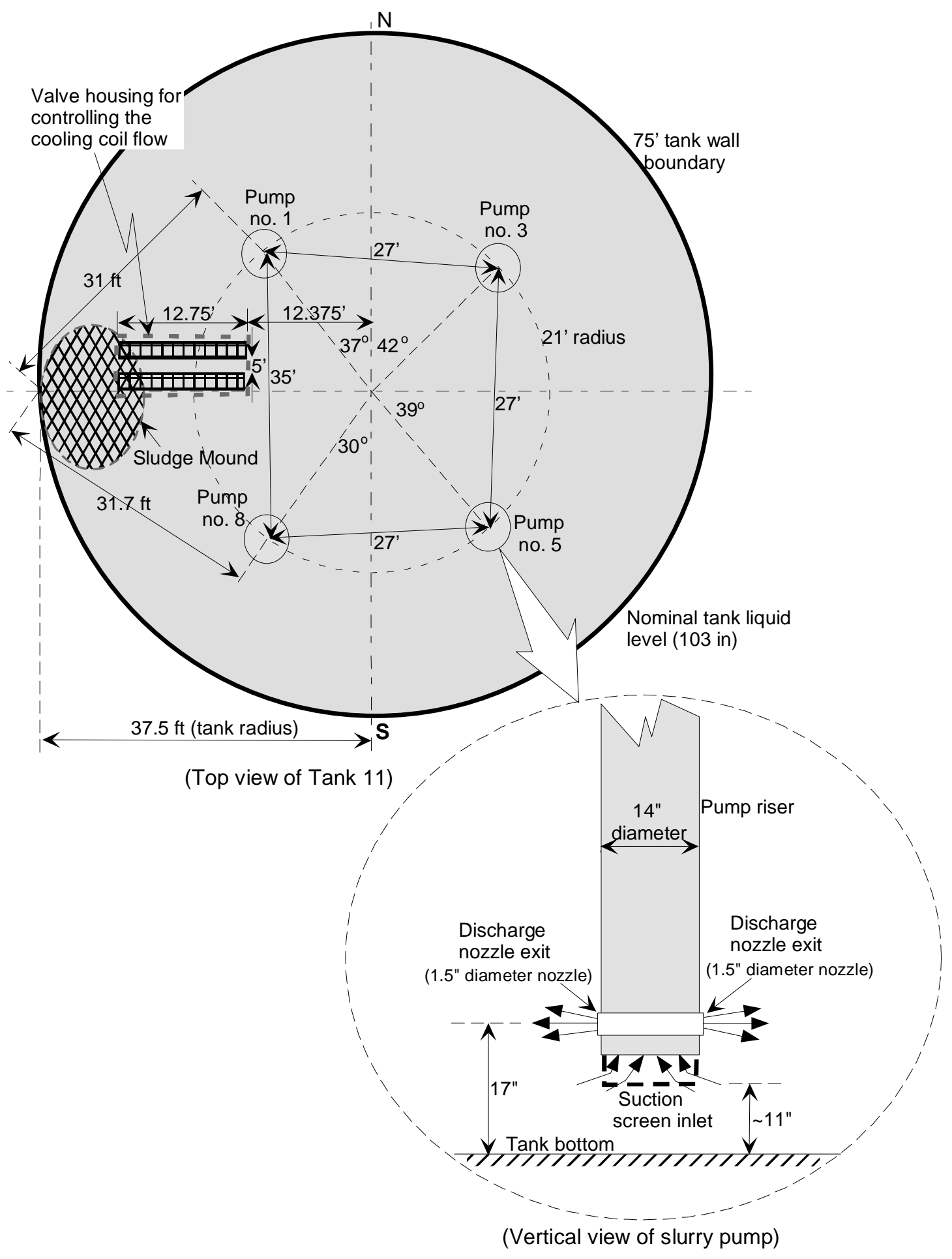

Figure 1. Schematic of Tank 11 layout with major flow obstructions of valve housing and four slurry mixing pumps. 


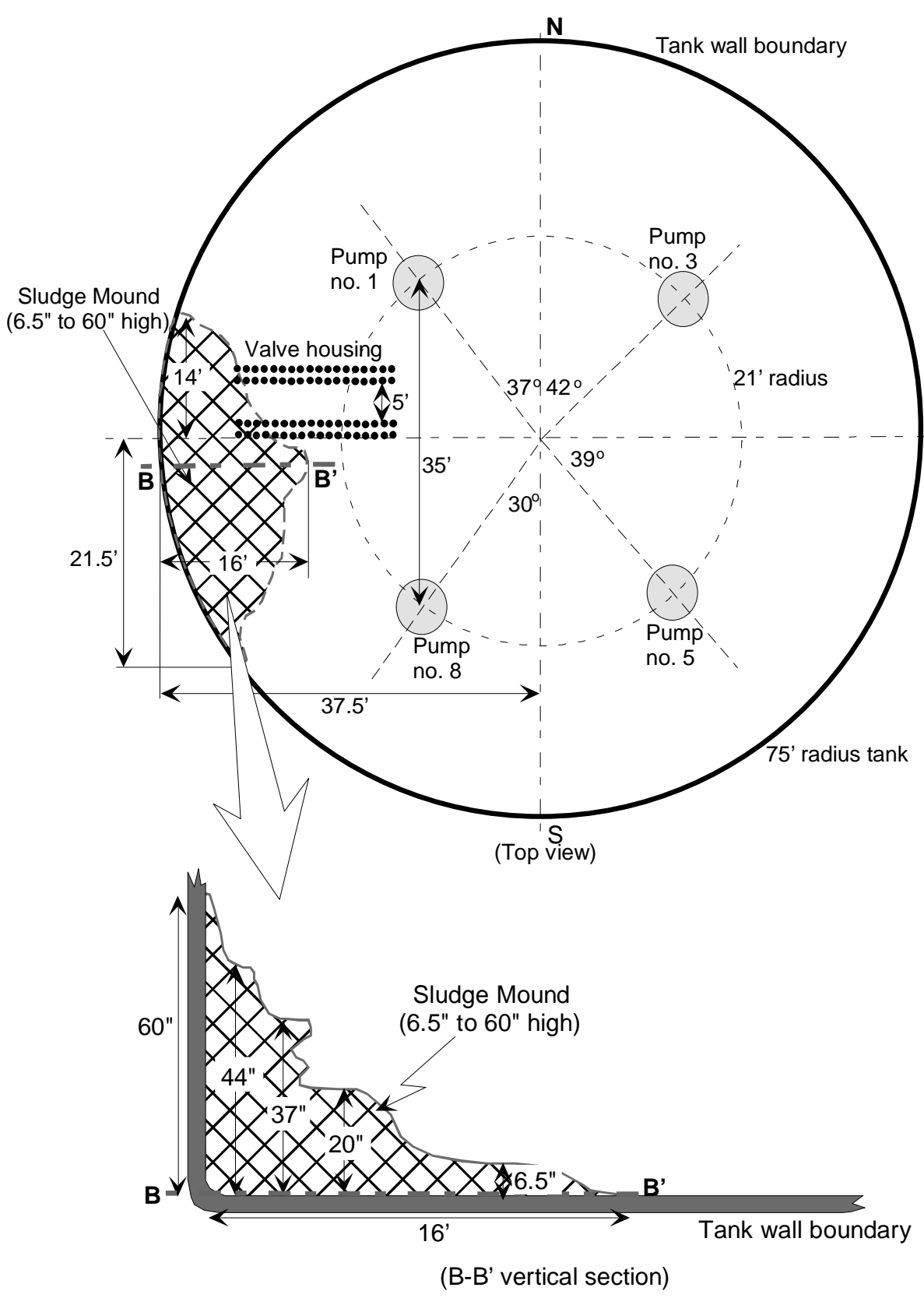

Figure 2. Dimensions of sludge mound heels and mapping of four slurry mixing pumps. 
Report: WSRC-TR-2003-00308

Date: $\quad 10 / 6 / 2003$

Page: $\quad 10$ of 71
WESTINGHOUSE SAVANNAH RIVER COMPANY

SLUDGE HEEL REMOVAL ANALYSIS FOR SLURRY PUMPS OF TANK 11

Table 1. Specifications of Tank 11 slurry pump used for the present analysis.

\begin{tabular}{|c|c|}
\hline Design Parameters & Slurry Pump \\
\hline Horsepower, hp & 150 \\
\hline Pump casing diameter, inches & 22.5 \\
\hline Pump column diameter, inches & 14 \\
\hline $\begin{array}{c}\text { Number of discharge nozzles } \\
\text { (flow directions) }\end{array}$ & $2\left(180^{\circ}\right.$ apart and opposite flow direction $)$ \\
\hline $\begin{array}{c}\text { Nozzle diameter, inches } \\
\text { Pump suction location }\end{array}$ & 1.5 \\
\hline Suction diameter, inches & Bottom of pump \\
\hline Flowrate per nozzle, gpm & $549^{*}$ \\
\hline \multirow{2}{*}{$\begin{array}{c}\text { Flow velocity at pump } \\
\text { discharge nozzle, ft/sec }\end{array}$} & About $109(1200 \mathrm{gpm}$ at $1800 \mathrm{rpm})$ \\
\cline { 2 - 3 } & About $99.6(1097 \mathrm{gpm} \text { at } 1600 \mathrm{rpm})^{*}$ \\
\hline
\end{tabular}

Note: *Reference operating conditions 


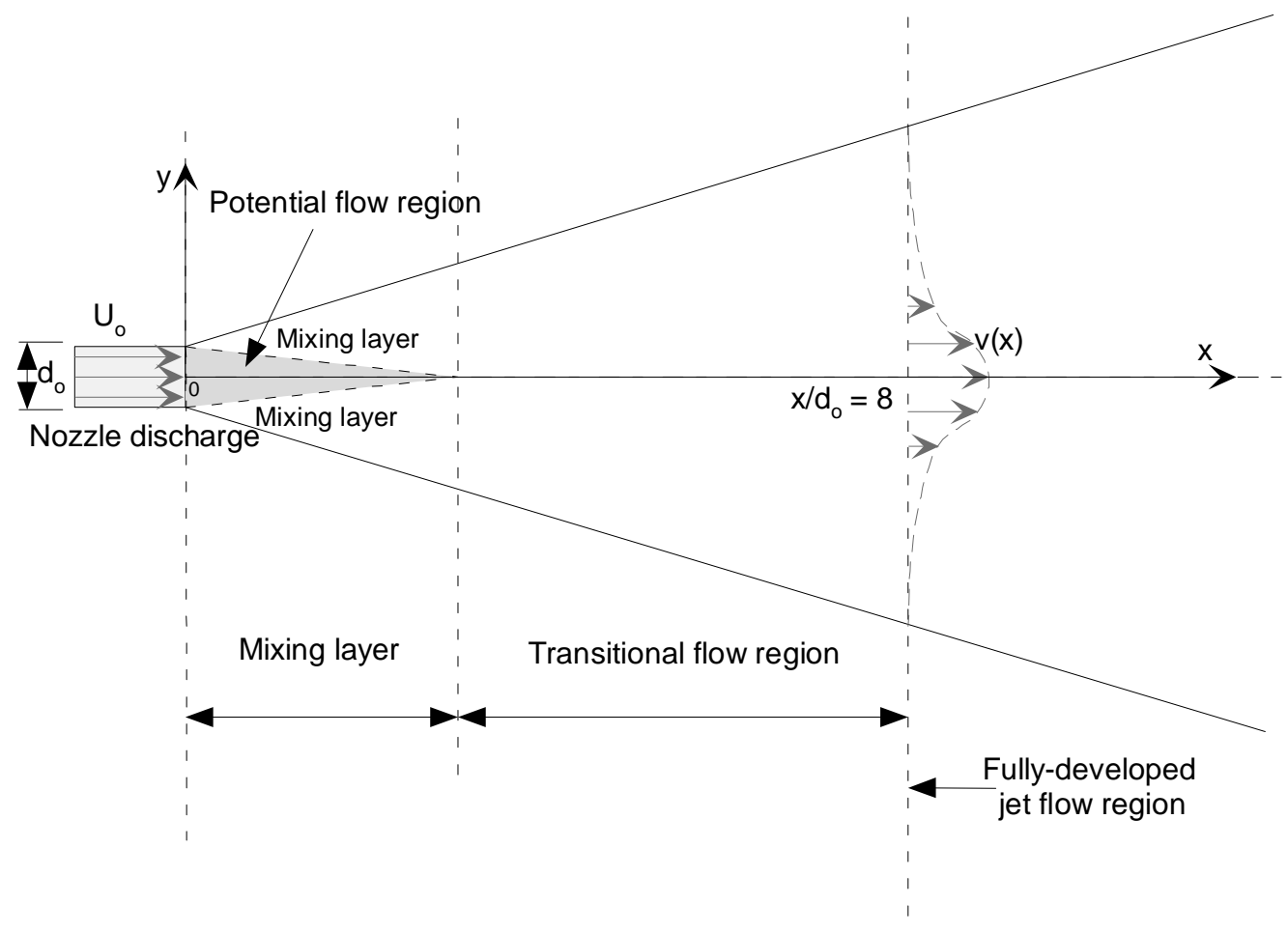

(Two-dimensional jet flow at the discharge plane)

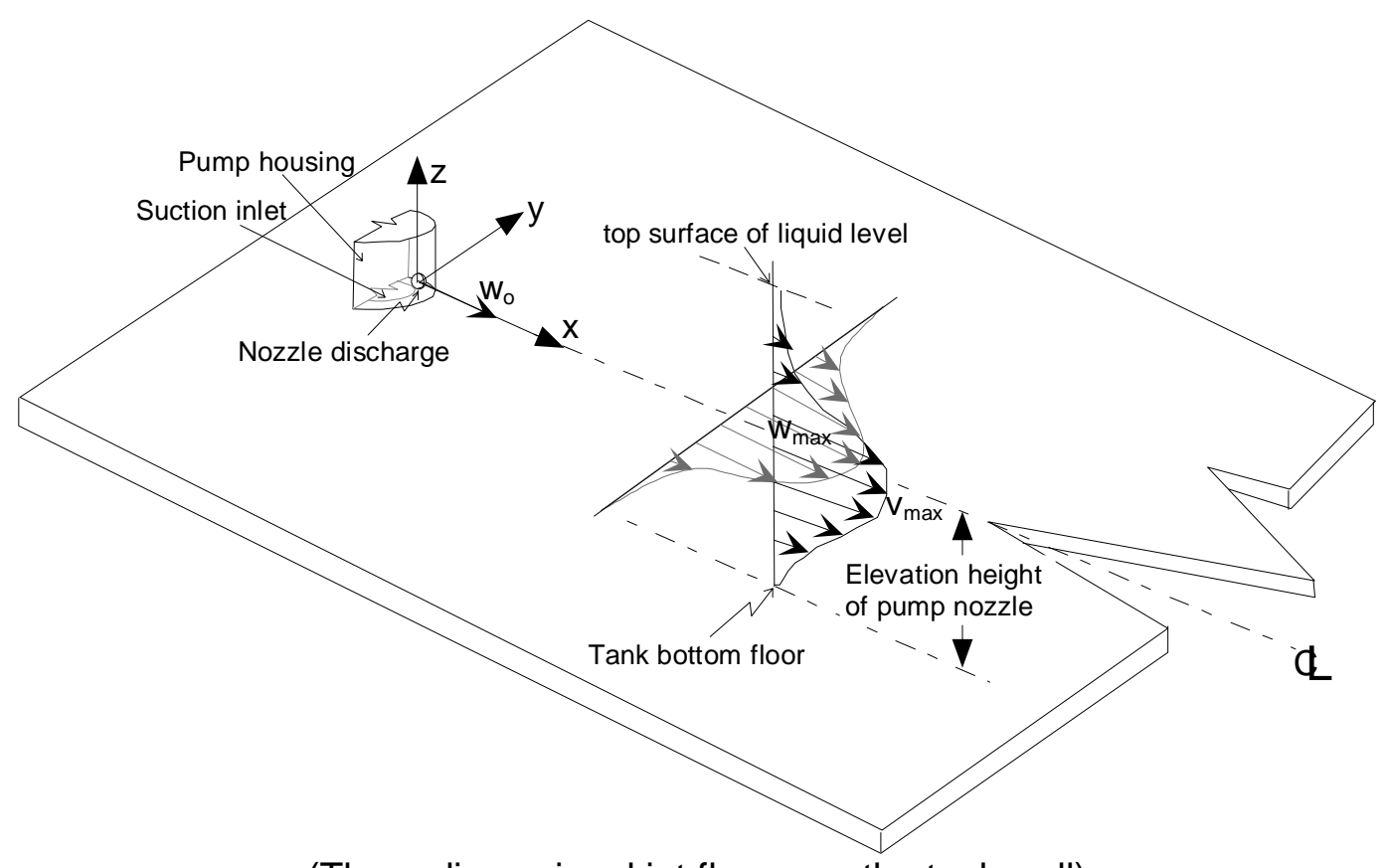

(Three-dimensional jet flow near the tank wall)

Figure 3. Typical flow dissipation and evolution of a jet flow along the discharge direction 
Page: 12 of 71

\section{Modeling Approach and Analysis}

In previous analyses [4, 5, 8], a three-dimensional CFD approach was used to calculate flow patterns for the sludge removal operations of Tank 8 and to evaluate sludge removal capabilities for Tank 18. The calculation results were benchmarked against both TNX and literature data [5]. The model predictions were in good agreement with test data and operational observations. The same finite volume CFD code, FLUENT [7], was used here to perform the Tank 11 modeling and analysis. A prototypic geometry is modeled with a non-orthogonal and hexahedral mesh.

The decay rate of the jet axial velocity and the evolution of flow patterns are potentially important phenomena affecting sludge suspension and removal operations. They result from the interaction of the submerged turbulent jet with the tank wall, internal solid obstructions, and free surface. The ability to shear the sludge layer is also directly related to the local velocity. Hence, flow velocity of the discharge jet is considered one of the key parameters governing the degree of sludge suspension and turbulent mixing for the present work.

The present models consider flow obstructions such as key pump support structures and the valve housing, but they do not model the presence of the sludge mound, 12 roof supporting columns, and cooling coils. Modeling a moving solid boundary as the sludge heel erodes is beyond the capability of the present code. Instead, the flow velocity in the vicinity of the sludge mound is used as an indicator of the ability of the flow to suspend sludge and remove the heel.

\subsection{Flow Criterion for Sludge Removal}

Before establishing the flow criterion for a quantitative estimation of sludge heel removal, decay characteristics of a submerged jet flow and assessment of the slurry flow regime need to be discussed briefly using literature information and our previous analyses. Detailed discussions are provided below.

\section{Characterization of the jet flow generated by a slurry pump of Tank 11}

When a turbulent jet of fluid is discharged from a nozzle with a diameter $d_{o}$, it both entrains fluid and expands as shown in Fig. 3 [6, 10,11]. Most mixing action and entrainment takes place in the region of fully-developed flow which begins at a distance of approximately eight nozzle diameters from the discharge plane. The non-dimensional velocity distribution $\varphi_{v}$ along the jet axis of this region for a homogeneous fluid jet is given by [11]

$$
\varphi_{v}=\left(\frac{v(x)}{U_{o}}\right)=C_{o}\left[\frac{x}{d_{o}}\right]^{-1}=C_{o} \eta^{-1}
$$

In eq. (1), $C_{o}$ is a constant determined by the turbulence characteristics of the jet, $U_{o}$ the nozzle exit velocity, $v(x)$ the local velocity at a point $x$, and $x$ the distance from nozzle. Abramovich (1963) correlated the experimental data for a free turbulent jet submerged in fluid using the non-dimensional form provided by eq. (1). From his work, the proportional constant $C_{o}$ in eq. (1) was determined to be 6.3158. 
Equation (1) shows that the velocity at any point in the region of established flow is directly proportional to the product, $d_{o} U_{o}$. Thus, the one-dimensional entraining distance corresponding to the minimum entrainment velocity can be estimated theoretically when nozzle size and pumping flowrate are provided.

However, the fluid region for the present work has both a solid boundary and a free surface boundary as the jet expands into the downstream region and then the flow recirculates in the tank. The spreading fluid is retarded by the frictional resistance of the wall. The inner part of the flow may be expected to show a certain structural similarity to a boundary layer, whereas entrainment of quiescent fluid occurs near the outer edge of the flow, which accordingly is likely to resemble a free jet in character.

When a solid structure or wall surface is present near the jet nozzle, the jet flow will feel a three-dimensional interaction from the wall boundary and free surface. The literature [6] has shown that the flow region of the jet up to 40 nozzle diameters, $\eta=40$ in eq. (1), is not affected by the presence or absence of a wall near the nozzle.

\section{Assessment of Tank Flow Regime}

Average flow velocity, particle size and density, and slurry flow regime are key important parameters in determining the transport patterns of particles in a slurry [14], which are closely related to the erosion phenomena. In this case, the critical velocity is defined as the minimum velocity that can initiate the movement of the solids deposited near the bottom of the tank. Graf [14] correlated the critical velocity $V_{c}$ empirically in terms of geometrical dimensions and the ratio of particle to fluid densities using data available in the literature.

$$
V_{c}=\left(\frac{d}{H}\right)^{-0.1} \sqrt{2.5 g d\left(\frac{\rho_{s}}{\rho_{f}}-1\right)}
$$

In eq. (2) $d$ and $H$ are the particle diameter and tank liquid level, respectively. As seen in Fig. 4 , when the average flow velocity is much larger than the critical velocity, $V_{c}$, the literature results show that solid particles in a continuous flow field are homogeneously distributed [14]. When the flow velocity required for sludge transport and removal is exceeded, the solid-laden flow can be treated as a homogeneous fluid. Thus, once sludge particles are suspended by the continuous flow, the conditions of the first of the three typical slurry flow fields shown in Fig. 4 are satisfied. The present flow calculations are based on a homogeneous single-phase fluid flow. Table 2 shows minimum velocities of particle pickup and suspension for various diameters of 2.0 specific gravity particles in water. The flow criterion for sludge removal will be established next. 
Report: WSRC-TR-2003-00308

Date: $\quad 10 / 6 / 2003$

Page: $\quad 14$ of 71

Table 2. Minimum velocities of particle suspension and transport/removal for the various particle sizes in water (particle density=2.0SG)

\begin{tabular}{|c|c|c|c|}
\hline $\begin{array}{c}\text { Tank } \\
\text { level } \\
\text { (inches) }\end{array}$ & $\begin{array}{l}\text { Particle } \\
\text { size } \\
\text { (microns) }\end{array}$ & $\begin{array}{c}\text { Minimum velocity }\left(V_{c}\right) \text { required } \\
\text { to initiate movement of particle } \\
\text { deposited from horizontal wall } \\
\text { surface computed by eq. (2) } \\
\text { (ft/sec) }\end{array}$ & $\begin{array}{l}\text { Typical minimum velocity } \\
\text { used for particle suspension } \\
\text { and transport for Tank } 11 \\
\text { sludge removal operations } \\
\text { (ft/sec) }\end{array}$ \\
\hline \multirow{3}{*}{103} & 5 & 0.136 & \multirow{6}{*}{$\begin{array}{c}2.27^{*} \text { (for sludge removal) } \\
\text { [Refs. 2, 3] }\end{array}$} \\
\hline & 10 & 0.179 & \\
\hline & 20 & 0.236 & \\
\hline \multirow{3}{*}{74} & 5 & 0.131 & \\
\hline & 10 & 0.173 & \\
\hline & 20 & 0.228 & \\
\hline
\end{tabular}

Note: * The average velocity used in this analysis, $2.27 \mathrm{ft} / \mathrm{sec}$, is much larger than the minimum critical velocity $\left(V_{c}\right)$ to initiate movement of particle deposited at the surface of cohesive sludge mound. This case corresponds to Case a in Fig. 4. 


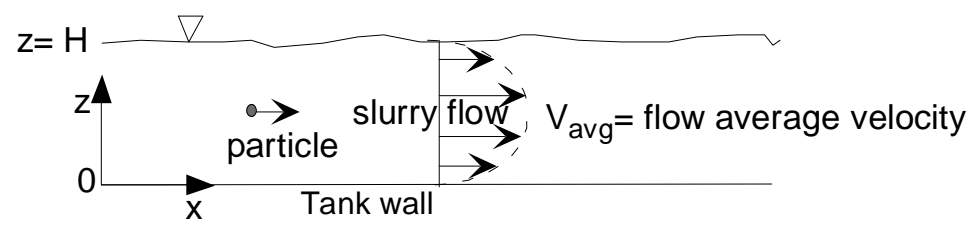

Case a: For homogeneous flow regime $\left(\mathrm{V}_{\mathrm{avg}}>\mathrm{V}_{\mathrm{C}}\right.$ : the present case)

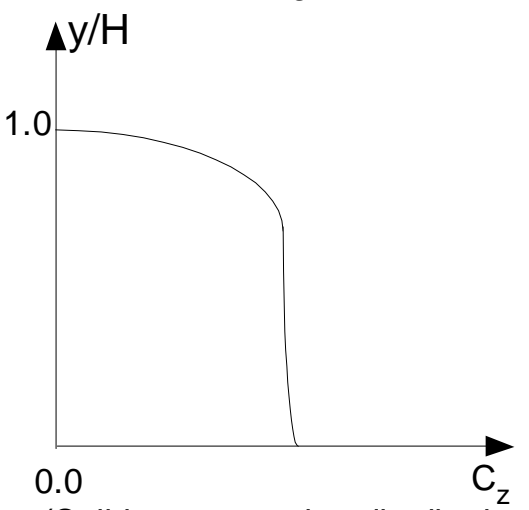

(Solid concentration distribution)

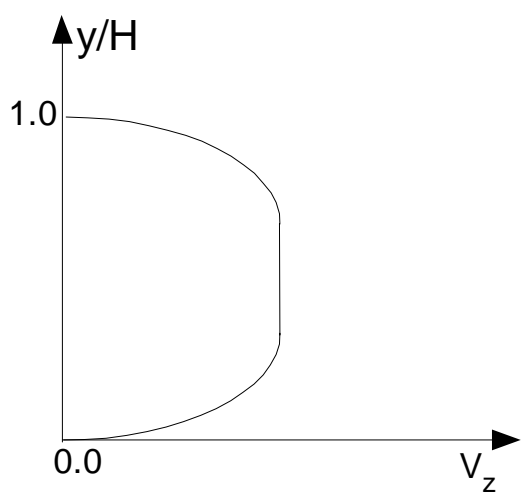

(Flow velocity distribution)

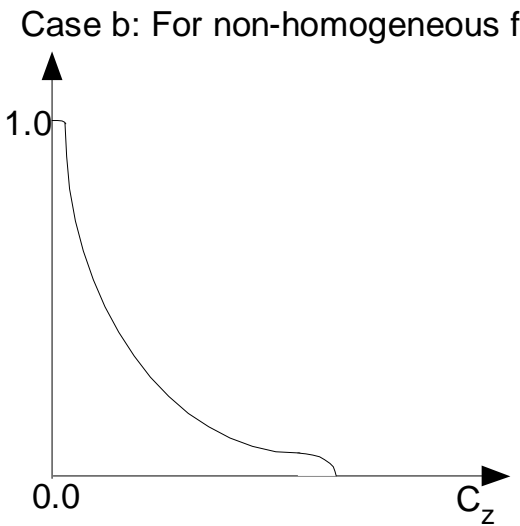

(Solid concentration distribution)

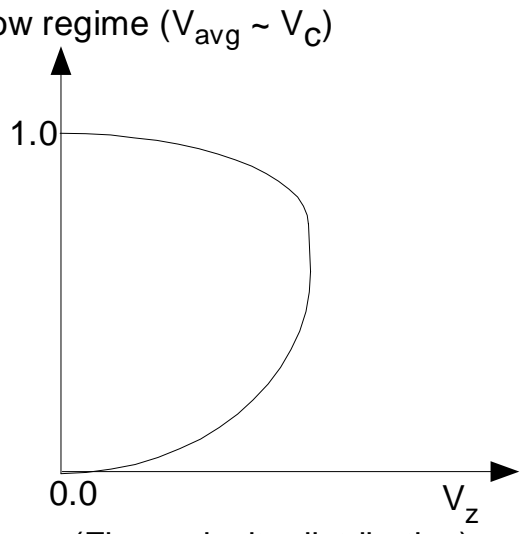

(Flow velocity distribution)

Case c: For non-homogeneous flow regime with solid particle deposit $\left(\mathrm{V}_{\mathrm{avg}}<\mathrm{V}_{\mathrm{C}}\right)$

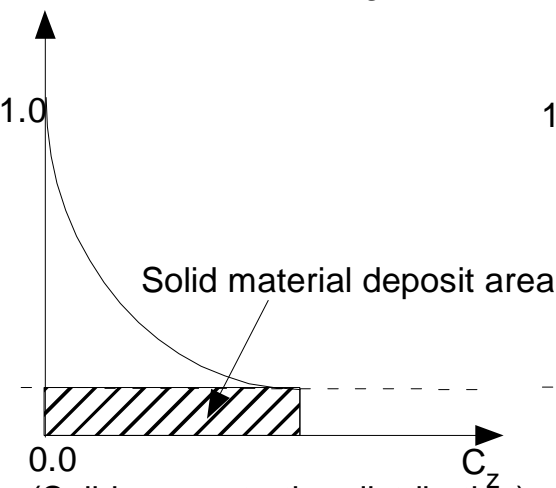

(Solid concentration distribution)

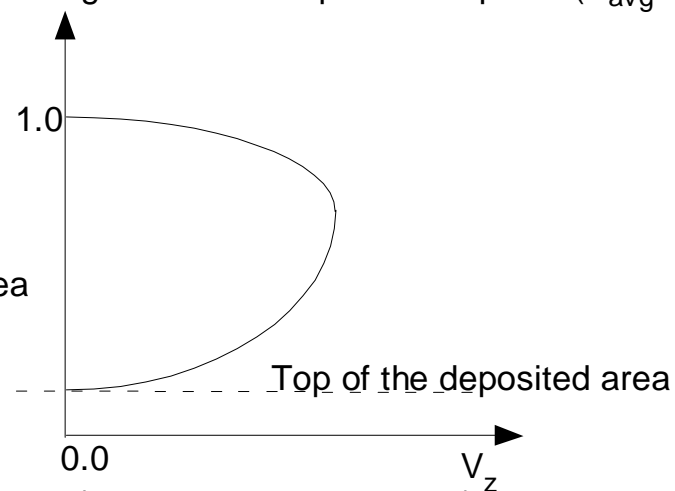

(Flow velocity distribution)

Figure 4. Schematic representation of solid concentration and velocity distributions for various flow regimes of solids-laden slurry $\left(\mathrm{V}_{\mathrm{c}}\right.$ is a minimum velocity to initiate the movement of particle from the deposit area.) 
Page: 16 of 71

\section{Establishment of Flow Criterion Required for Sludge Heel Removal}

The flow patterns calculated in the previous Tank 8 analysis [2] can be used to estimate the effectiveness of sludge removal operations and the amount of the sludge mound that would be left behind in Tank 11. The flow calculations will be assessed for the sludge removal in terms of the ECR of the pump. Observations and measurements from Tank 8 [3] were used to quantify the flow criterion and to interpret the mixing performance calculations for Tank 18 [5].

The dissipation of a turbulent jet flow through a nozzle is shown schematically in Fig. 3 . Using the notation provided in the figure, the axial velocity distribution along the jet axis is described as follows:

$$
v(x, z=0)=v_{c}(x)=K\left(\frac{U_{o} d_{o}}{x}\right)
$$

Since the pump discharge flow is affected by the bottom of the tank, the constant $K$ is evaluated from the Tank 18 calculations rather than classical free jet theory. It was found to be 4.874 [5]. The maximum axial velocity at any axial position $x$ can be estimated using eq. (3).

From the previous works $[5,8]$, the minimum suspension velocity for the cohesive sludge mound was established to be $2.27 \mathrm{ft} / \mathrm{sec}$. This value is consistent with the experimental observations in Tank 18 [8]. Therefore, the present work will use this velocity as the flow criterion in providing a recommended operational strategy for sludge heel removal in Tank 11.

It is important to recognize that the suspension velocity determined from the Tank 8 observations is not a precise measure because it is primarily dependent on the material characteristics of cohesive sludge mound, but it is in reality affected by the uncertainty in evaluating the ECR. The value of $2.27 \mathrm{ft} / \mathrm{sec}$ is used in this report as a nominal criterion against which calculated flow patterns can be assessed. It should not be interpreted as having three-digit accuracy, but rather as being an appropriate evaluation criterion. The uncertainty in the flow pattern evaluations, and especially the ability of the flow to suspend sludge at large distances from the pump nozzle, is directly related to the uncertainty in the suspension velocity found from the ECR analysis.

When liquid flow passes over a stationary cohesive sludge mound containing solid particles, the flowing liquid is responsible for hydrodynamic forces being exerted on the individual particle of the mound. In this case the initial movement of the top layer of the mound is called critical or incipient condition of erosion. The degree of erosion resistance for a given particle size to the hydrodynamic forces of flowing fluid depends on the cohesion and adhesion forces. In this case, a further increase in the fluid momentum causes an increase in the magnitude of hydrodynamic forces. Hence, for a particular stationary sludge mound, a condition is eventually reached at which particles in the movable bed are not able to resist the hydrodynamic forces and, thus, solids of a given size resting in the top layer start to be eroded. The flow condition corresponding to this condition is referred to as the critical or minimum scouring velocity. The detailed analyses for the scouring phenomena were performed in the previous works $[5,8]$.

The present case to estimate the incipient minimum scouring velocity considers a stationary bed consisting of cohesive solid particles of uniform size, and liquid flowing 
over it. The literature data show that large particles are more easily eroded by streams than smaller ones. This phenomenon becomes more pronounced with small particles since the cohesion forces existing between the particles increase as the latter decrease in size. Dallavalle [9] cited the equation for the incipient velocity of silting erosion

$v_{e c}=\frac{0.00656}{d_{p}}$

where $v_{e c}$ is the incipient eroding velocity in $\mathrm{ft} / \mathrm{sec}$, and $d_{p}$ the diameter of the particles in $\mathrm{mm}$. Incipient erosion velocities provided by eq. (4) are applicable to silting material, which contains small sizes of particles ranging from 5 (larger than clay) to 50 microns (close to very fine sand) in diameter.

Graf (1971) [14] presented the literature data for the incipient erosion velocity as shown in Fig. 5. As can be seen in Fig. 5, there exists for each grain size a certain velocity below which it will experience sedimentation, while above a certain velocity, called critical scour velocity, it will be eroded. Fluid velocity between these two velocities will suspend or transport solids for each solid size. The results show that the current velocity $2.27 \mathrm{ft} / \mathrm{sec}$ will erode the sludge layer for the particle sizes larger than clay material (about 5 microns). Equation (2) shows that fluid velocity, particle size, specific gravity of particle, and tank liquid level are key parameters associated with particle suspension. It should be emphasized that the incipient velocity of erosion is actually dependent on the critical shear stress at which incipient sediment begins to move. The critical shear stress of actual cohesive materials contained in Tank 11 depends on the composition of the different sludge material, the particle-size distribution, particle shape, and the packing.

Table 3 demonstrates reasonable agreement between the literature information and the present velocity criterion used for the suspension and removal operations of Tank 11. Minimum fluid velocity for suspending the sludge of Tank 18 in Savannah River Site (SRS) has been established as $2.27 \mathrm{ft} / \mathrm{sec}$ for the previous analysis [5, 8]. In addition, the current velocity criterion for the sludge suspension is compared with the literature data as shown in Table 4. Thus, local fluid velocity at any distance from the nozzle is employed as a measure of the slurrying and mixing efficiency of the slurry mixer in Tank 11. 
Report: WSRC-TR-2003-00308

Date: $\quad 10 / 6 / 2003$

Page: $\quad 18$ of 71

Table 3. Minimum velocities of particle pickup and removal for the various particle sizes (fluid density=1.2SG, particle density=2.0SG)

\begin{tabular}{|c|c|c|c|c|}
\hline $\begin{array}{c}\text { Tank } \\
\text { level } \\
\text { (inches) }\end{array}$ & $\begin{array}{c}\text { Particle } \\
\text { size } \\
\text { (microns) }\end{array}$ & $\begin{array}{c}\text { Minimum velocity } \\
\text { required to pick up } \\
\text { particle from } \\
\text { horizontal wall } \\
\text { surface computed } \\
\text { by eq. (2) (ft/sec) }\end{array}$ & $\begin{array}{c}\text { Minimum velocity } \\
\text { required to erode the } \\
\text { sludge mound } \\
\text { composed of uniform } \\
\text { sizes of solids (ft/sec) } \\
{[14]}\end{array}$ & $\begin{array}{c}\text { Velocity criterion } \\
\text { used for particle } \\
\text { suspension and } \\
\text { transport for Tank } \\
11 \text { operations }\end{array}$ \\
\hline \multirow{2}{*}{103} & 5 & 0.136 & 2.953 & \\
\cline { 2 - 4 } & 10 & 0.179 & 1.969 & $\begin{array}{c}2.27 \mathrm{ft} / \mathrm{sec} \\
\text { (for sludge } \\
\text { removal) }\end{array}$ \\
\cline { 2 - 5 } & 20 & 0.236 & 1.312 & \\
\hline
\end{tabular}

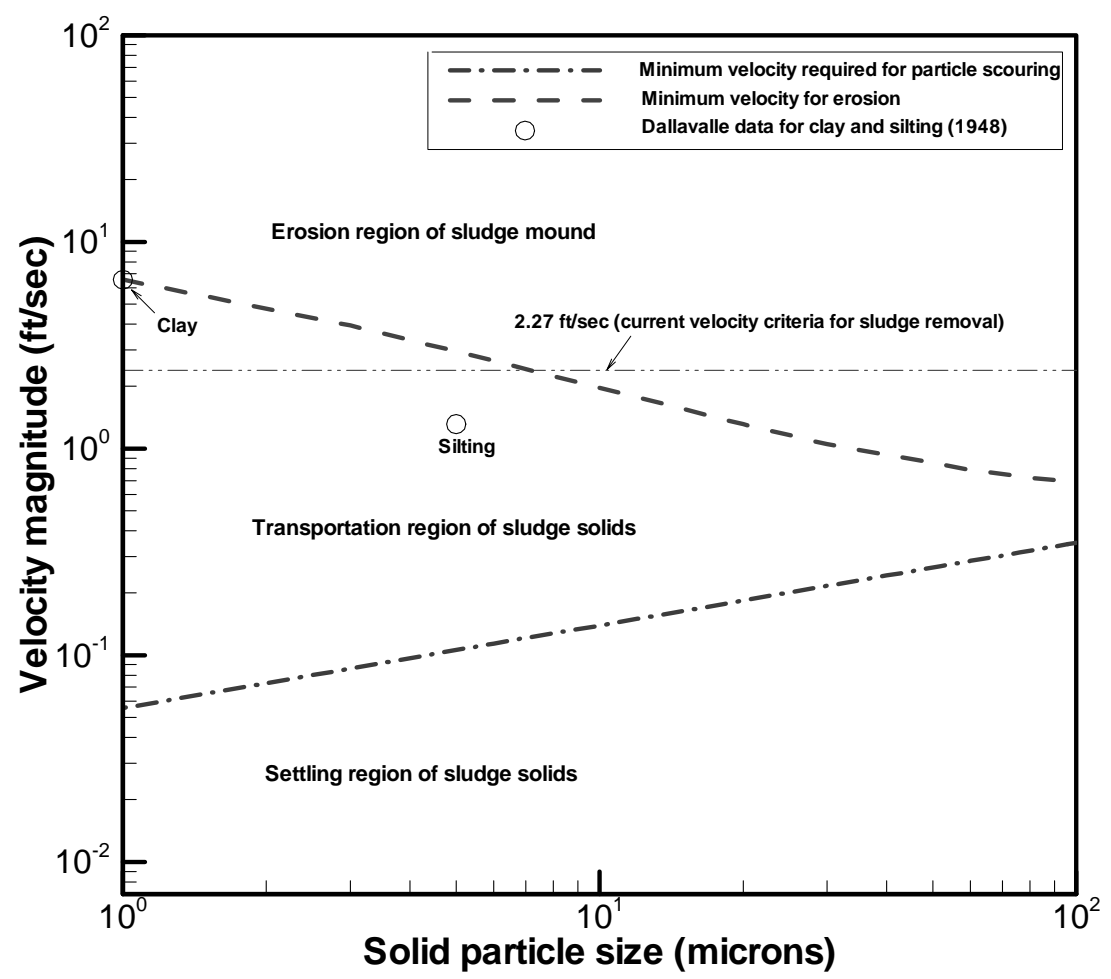

Figure 5. Velocity criteria for deposition, scouring, and erosion of sludge solids for the present operating conditions based on Graf's correlation (1971) [14] and Dallavalle's data (1948) [9] 
Table 4. Comparison of minimum eroding velocities available in the literature [9] and the present criterion for cohesive mounds composed of certain particle sizes in water

\begin{tabular}{|c|c|c|c|}
\hline $\begin{array}{l}\text { Class of particles in } \\
\text { cohesive bed }\end{array}$ & $\begin{array}{l}\text { Average } \\
\text { particle } \\
\text { size } \\
\text { (microns) }\end{array}$ & $\begin{array}{l}\text { Minimum velocity }\left(V_{c}\right) \\
\text { required to initiate } \\
\text { erosion of particle } \\
\text { deposited from horizontal } \\
\text { wall surface (ft/sec) }\end{array}$ & $\begin{array}{l}\text { Minimum velocity required } \\
\text { for particle suspension } \\
\text { and transport for Tank } 11 \\
\text { sludge removal } \\
\text { operations }(\mathrm{ft} / \mathrm{sec})\end{array}$ \\
\hline $\begin{array}{l}\text { Fine gravel to } \\
\text { coarse sand }\end{array}$ & 1000 & 0.0066 & \multirow{6}{*}{$\begin{array}{c}2.27^{*} \text { (for sludge removal) } \\
\text { [Refs. } 3,4]\end{array}$} \\
\hline $\begin{array}{l}\text { Fine sand to very } \\
\text { fine sand }\end{array}$ & 100 & 0.066 & \\
\hline Very fine sand to silt & 50 & 0.13 & \\
\hline Silt to clay & 5 & 1.31 & \\
\hline Clay & 1 & 6.56 & \\
\hline Colloids & 0.1 & --- & \\
\hline
\end{tabular}

Note: * The average velocity used in this analysis, $2.27 \mathrm{ft} / \mathrm{sec}$, is the critical velocity $\left(V_{c}\right)$ to initiate movement of particles larger than clay material (1 micron) deposited at surface of cohesive sludge mound.

The test results presented in Table 4 show that the critical flow velocity required to pick up a solid particle larger than 1 micron diameter in a clear fluid is very small compared with the flow criterion determined from sludge suspension observations $[3,4,8]$. The present flow criterion for the suspension and removal operations of the sludge in Tank 11 is supported by the values established from the recent sludge removal operations of Tank 18 [8]. For the present analysis, local fluid velocity at any distance from the pump nozzle is compared to the flow criterion of $2.27 \mathrm{ft} / \mathrm{sec}$ as a measure or indicator for sludge removal in Tank 11.

\subsection{Modeling Approach Method}

The FLUENT ${ }^{\mathrm{TM}}$ [7] code, which was validated against velocity measurements in the fulltank facility located in TNX [5], was used to calculate waste flow patterns for the slurry mixers of Tank 11 to estimate the ability to suspend and remove sludge under potential operating conditions illustrated in Figs. 1 and 2 . The slurry pump jet provides flow circulation within the 75-ft tank. The pump suction is located at the bottom of the jet pump as shown in Fig. 1. A three-dimensional CFD analysis was used to evaluate the impact of physical parameters such as tank level, pump elevation, and internal flow obstructions on the circulation patterns within the tank. The pump was assumed to be stationary, and the rotational effects of the pump on sludge removal were found to be 
small from the previous work [5]. The flow circulation patterns are directly related to the suspension and removal of the sludge mound located near the west corner of the tank.

In previous work [5], the ability of the Fluent code to capture important flow phenomena associated with the flow mixing behavior of a submerged jet was demonstrated. The previous results showed that two-dimensional models generally overestimate the magnitude of the flow velocity by more than $40 \%$ when compared to the TNX tests. This important result stems partly from neglecting the presence of the tank bottom, and partly from the two-dimensional model not having the capability to capture vertical flow rotation. With only one degree of freedom for rotational motion, the two-dimensional model cannot dissipate the jet as rapidly as a more realistic three-dimensional representation. Detailed discussions and results are provided in the previous documents [4, 5]. Therefore, the present analysis is based on a three-dimensional modeling approach. Table 5 provides the primary purposes of CFD modeling approaches taken for the present analysis.

The present analysis considers several basic cases with different boundary conditions to investigate how sensitive the velocity profiles are to different tank levels, indexed pump positions, and pump nozzle elevations for each of the indexed-pump operations. The present work consists of two fundamental models. One is to perform the best estimate model with the reference design and operating conditions as provided by the customer [2]. The other is to study the baseline cases with different tank levels and pump elevations to evaluate the sensitivities of flow circulation patterns due to the change of the operational conditions of the tank. The best estimate model was used to estimate effective cleaning distance under steady-state operational conditions with a fixed pump position, and to develop an operational strategy for removal of the sludge heel located in the corner of Tank 11 as shown in Fig. 2. In addition, the extent of the slurry mixing zone is estimated for a slurry mixer submerged at one of the four corners of the tank for given reference design conditions. Steady-state flow simulations are considered using the CFD modeling approach to estimate flow patterns for two different tank levels in terms of slurry flow evolution. Detailed modeling domain and operating conditions are provided in Fig. 6 and Table 6 . The model geometry was created using body-fitted coordinates and unstructured multi-block grids to include internal solid structures of the tank. Reference design conditions for slurry pump of Tank 11 are shown in Table 1.

Detailed wave motion of the free surface at the top of the tank was neglected for computational efficiency. That behavior does not have a significant impact on the flow patterns inside the fluid region in a deep tank since the ratio of liquid height above the nozzle to nozzle diameter is at least about 38 , which is much larger than the critical ratio of 2.5 found in the literature [6]. The fluid properties of water were evaluated at $50^{\circ} \mathrm{C}$ temperature. The flow conditions were assumed to be fully turbulent since Reynolds numbers for typical operating conditions were in the range of $10^{6}$ based on the pump nozzle inlet conditions. A standard two-equation turbulence model, the $\kappa-\varepsilon$ model [7], was used, since previous work [5] showed that the two-equation model predicts the flow evolution of turbulent jet in a large stagnant fluid domain with reasonable accuracy. This model specifies the turbulent or "eddy" viscosity, $\mu_{t}$, by the empirical equation,

$$
\mu_{t}=\left(\frac{C_{\mu} \rho_{f} k^{2}}{\varepsilon}\right)
$$


Table 5. Primary purposes of CFD modeling approaches taken for the present analysis.

\begin{tabular}{|c|c|c|}
\hline $\begin{array}{l}\text { Analysis } \\
\text { Models }\end{array}$ & $\begin{array}{l}\text { Modeling } \\
\text { Approaches }\end{array}$ & Primary Purposes \\
\hline $\begin{array}{c}\text { Tank } 11 \text { model } \\
\text { with internal } \\
\text { obstructions }\end{array}$ & $\begin{array}{c}\text { Three- } \\
\text { dimensional } \\
\text { steady-state }\end{array}$ & $\begin{array}{l}\text { - To evaluate steady state flow patterns for Tank } \\
11 \text { with the slurry mixers located at the four } \\
\text { corners and } 103 \text { in liquid level in establishing } \\
\text { effective cleaning distance } \\
\text { - To investigate the efficient performance of } \\
\text { sludge clearance and to develop an operational } \\
\text { strategy for Tank } 11 \text { sludge heel removal using } \\
\text { the four existing slurry pumps located at the four } \\
\text { corners of the tank under the reference } \\
\text { operating conditions } \\
\text { To perform the sensitivity analysis to evaluate } \\
\text { what physical parameters are most sensitive for } \\
\text { the efficient performance of sludge suspension } \\
\text { and removal }\end{array}$ \\
\hline
\end{tabular}

In eq. (5) $C_{\mu}$ is an empirical constant. In the present calculations, its value is 0.09 . The turbulent viscosity is computed by solving two transport equations for $k$ (turbulent kinetic energy) and $\varepsilon$ (rate of dissipation of turbulent energy). The governing equations to be solved for the present work are composed of one continuity equation, three momentum equations for the three component directions ( $x, y$, and $z$ directions), and two constitutive equations for the turbulence descriptions. Detailed descriptions for the governing equations and computational methods are provided in previous work [5].

\subsection{Tank 11 Model and Assumptions}

Tank 11 is cylindrical, $75 \mathrm{ft}$ in diameter, and $24.5 \mathrm{ft}$ high. For the reference conditions, the tank liquid level was kept 103 in high as shown in Table 6. The model also considered a 74-in liquid level to investigate the impact of tank level on the circulation pattern. The tank has four, $150 \mathrm{hp}$ slurry pumps available to suspend and remove the sludge mound. Each pump has two horizontal discharge nozzles, each 1.5 in diameter. A total discharge flowrate of $1200 \mathrm{gpm}$ corresponds to a pump speed of $1800 \mathrm{rpm}$. There is a single suction at the bottom of the pump. The mixer is located about $16.5 \mathrm{ft}$ away from the tank wall and about 17 in above the tank bottom as shown in Fig. 1. The modeling domain contains the internal flow obstructions representing the valve housing to control cooling coil flow. The valve housing consists of two banks of 2 -in diameter tubes as shown in Fig. 7. Detailed dimensions and pump layouts as modeled in the present work are illustrated in the figure. The model is a full three-dimensional representation of the entire tank to capture significant phenomena related to the turbulent behavior of the jet flow.

As mentioned earlier, two basic modeling approaches are taken for the present analysis. One is the best estimate model with the reference operating conditions as shown in Table 6. This model is used to estimate effective cleaning distance under steady-state operational conditions with an indexed pump position, and to develop an operational 
strategy for removal of the sludge heel located in the west corner of Tank 11 as shown in Fig. 2. The other is the baseline model with different tank levels and pump elevations to evaluate the sensitivities of flow circulation patterns due to the change of the operational conditions of the tank. In this case water was used to simulate the fluid in the tank. Previous sensitivity results $[4,5]$ showed that flow pattern impacts due to fluid property differences were negligibly small. Detailed geometrical and operating conditions are provided in Table 6 . Based on nozzle diameter and water properties, flow near the nozzle is clearly turbulent since the Reynolds number for the reference operating conditions is about $1.15 \times 10^{6}$. The flow for the entire computational domain is assumed to be turbulent to give a reasonable representation of the liquid jet leaving the pump nozzle.

As discussed previously, the standard $\kappa-\varepsilon$ model was used for the turbulence calculations. A three-dimensional model was run in steady-state mode for the operating conditions of Tank 11 as provided in Table 6 . Angular position of the slurry pump with two discharge jets was fixed so that one of the two discharge jets for each pump was pointed directly to the corner of the Tank 11 aiming at the site of the sludge mound, while the other nozzle jet was pointed to the opposite wall. Geometrical configurations and layout for the model are illustrated in Fig. 6. The calculations were performed for a fixed position of the jet nozzle when a steady-state mixing flow pattern in the tank was established.

The calculations consisted of several different cases to simulate various operating conditions for Tank 11 and to examine the sensitivities of the operating parameters with respect to the efficiency of sludge suspension. The three-dimensional model was run in a steady-state mode for the fixed pumps to allow the jet flow to develop a flow pattern. For instance, when two pumps are used for the present Tank 11 model, the pumps are in a fixed orientation to maximize flow streams aimed at the sludge heel located near the corner of the tank. Both discharge jets are located at a horizontal plane 17 in above the tank bottom. For the modeling analysis, the pump speed was $1600 \mathrm{rpm}$ for the reference conditions and $1800 \mathrm{rpm}$ and $2000 \mathrm{rpm}$ for the sensitivity studies. Figure 8 shows three-dimensional geometrical configurations as modeled in the CFD environment for the multi-pump simulations including the internal flow obstructions shown in Fig. 7. For the simulations, a series of the modeling calculations will be performed in a fixed pump orientation until an optimized flow pattern near the potential location of the sludge mound is established.

Geometrical simplifications and physical model assumptions are listed as follows:

- There are no solid obstructions in the tank other than the pump support structure, nozzle housing, and valve housing as shown in Fig. 7 or Fig. 8.

- Two discharge nozzles are $180^{\circ}$ apart, aligned in straight and opposite directions.

- The pump nozzle is stationary, although in reality, the pump has a slight oscillation.

- $\quad$ The working liquid is water at $50^{\circ} \mathrm{C}$.

- The liquid region is bounded by a free surface at constant atmospheric pressure.

- The model is isothermal. No energy equation is calculated.

- $\quad$ The flow in the entire model domain is assumed to be turbulent to give a reasonable representation of the liquid jet leaving the pump nozzle. 
Page:

23 of 71

- The wavy motion of the free surface due to the interaction with the discharge jet is neglected. Literature data [6] show that the surface wave effect is negligible when the ratio of liquid height above the nozzle to nozzle diameter is larger than 2.5. For a slurry mixer in Tank 11, the minimum ratio is about 38 for the 74 in liquid level case.

Three-dimensional numerical simulations are made for the Tank 11 modeling analysis. About a quarter million nodes for the three-dimensional computational domain shown in Fig. 6 have been established from the sensitivity studies of computational meshes. Typical hexahedral, non-uniform meshes for the best estimate model of the Tank 11 model are shown in Fig. 9.

Table 6. Reference design and operating conditions of Tank 11 used for the present analysis.

\begin{tabular}{|c|c|c|}
\hline \multicolumn{2}{|c|}{ Parameters } & Conditions \\
\hline \multirow{2}{*}{ Tank dimensions } & Diameter & $75 \mathrm{ft}$ \\
\hline & Tank liquid level & 103 in $^{*}$ or 74 in high \\
\hline \multicolumn{2}{|c|}{ Mixing pump } & Lawrence slurry pump \\
\hline \multicolumn{2}{|c|}{ Number of pumps } & 1 to 4 pumps \\
\hline \multicolumn{2}{|c|}{ Pump nozzle diameter } & $1.5 \mathrm{in}$ \\
\hline \multirow{2}{*}{$\begin{array}{l}\text { Pump positions inside } \\
\text { the tank }\end{array}$} & $\begin{array}{l}\text { Vertical } \\
\text { elevations }\end{array}$ & $\begin{array}{l}17 \mathrm{in}^{*} \text { and } 26 \text { in (from the center of pump } \\
\text { discharge nozzle to tank bottom) }\end{array}$ \\
\hline & $\begin{array}{l}\text { Horizontal } \\
\text { locations }\end{array}$ & See Fig. 2 \\
\hline \multicolumn{2}{|c|}{ Tank fluid temperature } & $50^{\circ} \mathrm{C}$ \\
\hline \multicolumn{2}{|c|}{ Tank fluid } & Slurry $^{+}$(density: 1.2 SG, viscosity: $2 \mathrm{cp}$ ) \\
\hline \multirow{3}{*}{$\begin{array}{l}\text { Nozzle flowrate for } \\
\text { each nozzle } \\
\text { [fluid speed] }\end{array}$} & $1600^{*} \mathrm{rpm}$ & $\begin{array}{l}549^{*} \mathrm{gpm} \\
{[99.6 \mathrm{ft} / \mathrm{sec}]}\end{array}$ \\
\hline & 1800 rpm & $\begin{array}{c}600 \mathrm{gpm} \\
{[109 \mathrm{ft} / \mathrm{sec}]}\end{array}$ \\
\hline & 2000 rpm & $\begin{array}{l}651 \mathrm{gpm} \\
{[118 \mathrm{ft} / \mathrm{sec}]}\end{array}$ \\
\hline
\end{tabular}

Note:* Reference operating conditions as provided by the customer [2]

+ Water $\left(50^{\circ} \mathrm{C}\right)$ was used as a simulant for the present analysis, but slurry was used in the sensitivity analysis. 
Report: WSRC-TR-2003-00308

Date: $\quad 10 / 6 / 2003$

Page: $\quad 24$ of 71
WESTINGHOUSE SAVANNAH RIVER COMPANY

SLUDGE HEEL REMOVAL ANALYSIS FOR SLURRY PUMPS OF TANK 11

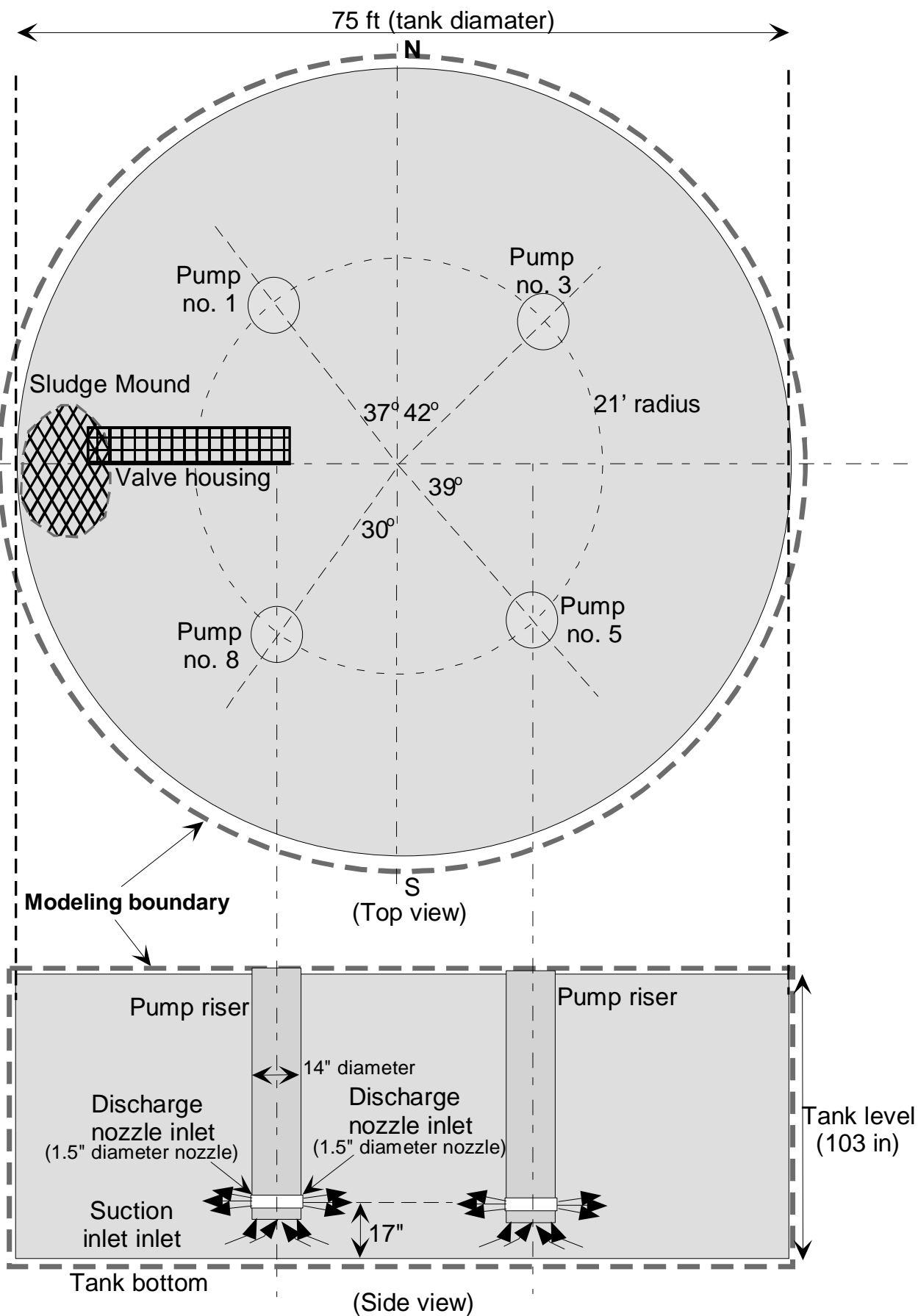

Figure 6. Three-dimensional modeling boundary for Model-I in the present analysis of the Tank 11 facility with four slurry pumps 


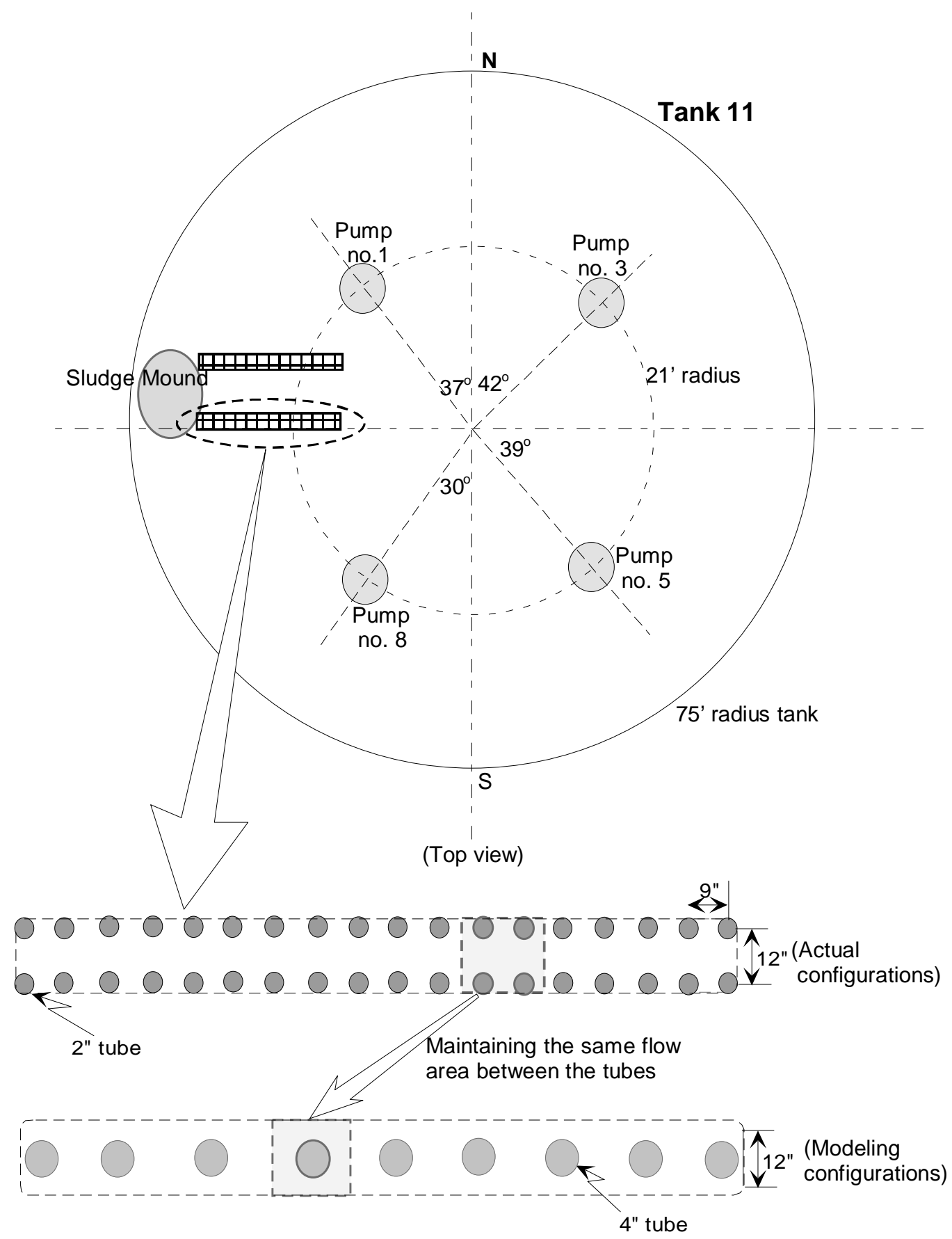

Figure 7. Schematic illustrations for the modeling boundary of Tank 11 with four slurry pumps including flow obstructions representing valve housing for cooling-coil flow control. 
Date: $\quad 10 / 6 / 2003$

Page: 26 of 71

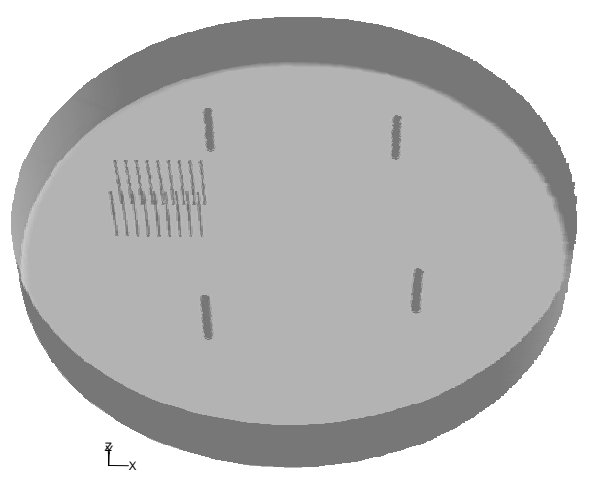

Figure 8. Three-dimensional geometry of Tank 11 CFD model with four mixing pumps considering solid obstruction effects of valve housing consisting of 18 cooling pipes.

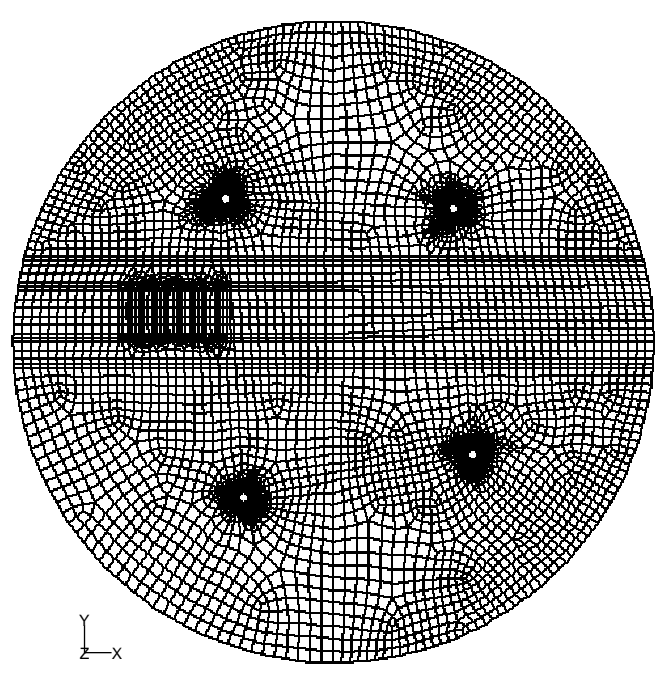

Figure 9. Hexahedral meshes on the $x-y$ computational domain for a three-dimensional CFD model of Tank 11 with four mixing pumps. 


\section{Results and Discussions}

CFD models have been developed and analyses performed to estimate circulation flow patterns within Tank 11 to evaluate the ability of the four slurry pumps to remove the sludge mound remaining in the tank. The mixing pumps are assumed to be stationary, since the previous result [5] showed that rotational effects on flow patterns were negligible. A flow velocity criterion will be used as the primary indicator of the ability to suspend sludge.

Two basic models were developed, including several different cases for the modeling calculations with internal flow obstructions such as pump riser and valve housing inside the tank. One is the best estimate model simulated with the reference operating conditions as provided by the customer [2], and it is mainly to evaluate flow circulation patterns and Effective Cleaning Radius (ECR) to develop an operational strategy for the sludge removal operations of Tank 11. The other is the baseline model, and its primary objective is to perform sensitivity analyses for operational parameters such as pump speed, liquid level, and pump elevation. Reference design and operating conditions of Tank 11 used for the present analysis are provided in Table 6.

As shown in Fig. 2, the sludge mound is located near the west corner of the tank, where the valve housing to control cooling coil flow stands. This sludge mound is based on the past experience of Tank 7 and Tank 8 . Because of the distance from the nearest slurry pump to the sludge mound, as well as the apparent obstruction to the slurry jet flow formed by the valve housing, major questions are the optimum number of operating pumps and the most effective discharge direction of each pump to remove the sludge heel. The location and dimensions of the sludge mound are shown in Fig. 2.

When various numbers of operating pumps are aimed at the sludge mound, Figure 10 shows the calculation results for velocity magnitude along the centerline through the sludge heel area using the best estimate model. The results show that maximum velocity magnitude for a single pump operation (pump no. 1) is about $140 \%$ higher at the wall region near the sludge mound corner compared to a three-pump operation (pump no. 1 , no. 3 , and no. 8) for the same nozzle elevation. It is noted that the most effective flow pattern to remove the sludge occurs when one pump (pump no. 1) is aiming at the near-wall region of the sludge mound, all other operating parameters fixed.

Figure 11 compares the results of flow patterns between one-pump and two-pump operations in terms of performance of sludge removal when a sludge mound locates between the corner of valve housing and tank wall. In this case the single pump run is more efficient than the two-pump run in removing the sludge mound located adjacent to the tank wall as shown in Fig. 12. In this case it is noted that velocities near the tank center are very small because of the major flow directions of the pump nozzles aiming at the corner of the sludge mound. However, when pumps are operated aiming at the sludge mound located behind the sludge mound, two-pump run (using pump no. 8 and no. 5) has better performance than one-pump run (using pump no. 8) does as graphically presented in Fig. 13. The results for flow velocities along the centerline of Tank 11 crossing the sludge mound are quantitatively compared between the two cases in Fig. 14. These results are mainly due to the interference effect of hydraulic jets and the solid obstruction effects of fluid flow. Thus, it is not necessary or advantageous to operate all four pumps simultaneously for efficient removal of the sludge mound. The detailed operating strategy for sludge removal will be developed here in terms of 
numbers of operating pumps and aiming angles of indexed pump nozzle directions using the best estimate model.

The Tank 11 model with the reference conditions of Table 6 was used to estimate the distance at which the sludge removal velocity was maintained under three pump operations. The three pumps are pump no. 3, no. 5, and no. 8, and they are stationary. The present calculations used $2.27 \mathrm{ft} / \mathrm{sec}$ as the minimum velocity for the sludge removal, which was estimated earlier using the previous works [4, 5, and 8]. The results showed that the effective distance for the sludge removal was about $27.2 \mathrm{ft}$ from the nozzle of pump no. 5 along the principal discharge direction $A^{\prime}-A$ under the multi-pump conditions. This result is in reasonable agreement with the measurement data [3]. As shown in the velocity contour plot in Fig. 15, flow velocity at $29 \mathrm{ft}$ away from the nozzle exit of pump no. 5 start to increase due to the combined effect of the pump no. 1 discharge, which is stationed at the downstream side of pump no. 5 .

The best estimate model with the reference operating conditions shown in Table 6 was used for the performance evaluation of the tank sludge removal operations since the model included the potential operating conditions provided by the customer [2] and vertical obstructions representing valve housing structures to control cooling coil flow. The model results were also used to provide recommended operational scenarios for number of pumps, nozzle orientations, and pump speeds to suspend and transfer the remaining sludge. A detailed mapping of the four slurry pump locations, valve housing structure, and the sludge heel dimensions are shown in Fig. 2.

From the graphical results shown in Fig. 16, a single pump operation with pump no. 1, designated as Case- $\mathrm{A}$, was taken as the first configuration. The most efficient direction of the pump no. 1 nozzle was found to be $38^{\circ}$ toward the sludge mound from the modeling predictions. The previous results [4] demonstrated that internal obstructions helped guide the flow into the zone of the sludge mound; the flow velocity increased about $10 \%$ compared to the model without flow obstructions. The maximum velocity at the estimated location of the sludge mound was about $2.5 \mathrm{ft} / \mathrm{sec}$ about $10 \%$ higher than the sludge removal velocity $(2.27 \mathrm{ft} / \mathrm{sec})$. The results for the velocity distributions on the exit plane of the pump nozzle are shown in Fig. 16. In the figure the red zone has the velocity magnitude higher than the minimum flow velocity required for sludge removal. As shown in Fig. 17, flow jetted by pump nozzle is mainly dissipated by turbulent flow fluctuations due to the presence of solid boundary. The degree of turbulent dissipation is measured by turbulent intensity. It can be used as an indicator of local mixing associated with vortex eddy motion since solid boundary creates fluid vorticity. The turbulence intensity $I$ is defined as the ratio of the root-mean-square of the velocity fluctuations to mean flow velocity. That is,

$$
I=\frac{\sqrt{\frac{1}{3}\left(u^{\prime 2}+v^{\prime 2}+w^{\prime 2}\right)_{a v g}}}{V} \approx 0.8165 \frac{\sqrt{k}}{V}
$$

In eq. (6) $u^{\prime}, v^{\prime}$, and $w^{\prime}$ are local velocity fluctuations in the $\mathrm{x}, \mathrm{y}$, and $\mathrm{z}$ directions and $V$ is the mean velocity magnitude. The turbulence intensity is proportional to the square root of the turbulent kinetic energy $k$ for a given mean fluid velocity. From the results shown in Figs. 16 and 17, the velocity reduction rate along the discharge direction increases with increasing turbulence intensity. This is mainly related to the increased radial dispersion of fluid momentum, which leads to diminished axial velocity of the nozzle 
discharge flow. Most efficient flow patterns for the sludge removal with a single pump run (Case-A) are shown in Fig. 18.

As a second case (Case-B), two pumps were used to increase the flow enough to mobilize and transport the sludge, since the Case-A results showed that one-pump run could not attain the sludge removal velocity at the south side of the valve housing area. In this case, pump no. 5 was added to the operation of pump no. 8 so that two pumps could operate simultaneously. The best combinations of the two nozzle directions were $22^{\circ}$ for pump no. 5 and $43^{\circ}$ for pump no. 8 . The results showed that local velocity at the location of the sludge mound region was $2.7 \mathrm{ft} / \mathrm{sec}$ at maximum, exceeding the minimum the sludge removal velocity. Velocity contour plots for Case-B are shown in Fig. 19.

For Case-C, two pumps were selected to mobilize the north side portion of the sludge mound just behind the valve housing structures (about $2 \mathrm{ft}$ away from the tank wall boundary). For this case pump no. 1 and pump no. 3 were operated at the same time. Local flow velocities between about $2 \mathrm{ft}$ and $11 \mathrm{ft}$ away from the tank wall near the sludge mound were found to be higher than the minimum speed of the sludge removal $2.27 \mathrm{ft} / \mathrm{sec}$. The graphical results for the flow patterns of Case-C are shown in Fig. 20. Velocity contour plots for horizontal pump discharge and vertical planes are shown in Fig. 21.

For Case-D, the simultaneous operation of three pumps was taken to remove the front side of the sludge mound as well as peripheral sides of the sludge mound around the valve housing. The results showed that north side of the sludge mound adjacent to the valve housing area could be mobilized. Figure 22 shows the results for the velocity contour plot.

Lastly, as Case-E, computational simulations for the simultaneous operation of all pumps available in Tank 11 were made to stir up the entire sludge area around the valve housing. Two-dimensional flow patterns on the discharge plane of the four pump nozzles are shown in Fig. 23. Velocity contour plots at the same plane are presented in Fig. 24 showing that the red zone is higher than the sludge removal velocity of 0.69 $\mathrm{m} / \mathrm{sec}(2.27 \mathrm{ft} / \mathrm{sec})$. Although all the cases evaluated here are for a fixed sludge mound, Case-E can be combined with the previous four cases to form a suggested pump operating cycle for mobilizing and removing the sludge. Detailed results for all five cases are summarized in Table 7 . Flow velocity results of the five cases under the reference conditions (1600 rpm pump speed) along the centerline crossing the potential sludge mound are shown in Fig. 25. As another scenario of the sludge removal operation, the simulation runs with higher pump speeds, $1800 \mathrm{rpm}$ and $2000 \mathrm{rpm}$, were made using the same operating conditions as the reference case of $1600 \mathrm{rpm}$. The results for the reference pump speed showed that sludge mound near the tank wall boundary could not be removed in terms of the minimum velocity criterion required for the sludge removal. The detailed results for the higher pump speeds are shown in Figs. 26 and 27. 
Report: WSRC-TR-2003-00308

Date: $\quad 10 / 6 / 2003$

Page: $\quad 30$ of 71
WESTINGHOUSE SAVANNAH RIVER COMPANY

SLUDGE HEEL REMOVAL ANALYSIS FOR SLURRY PUMPS OF TANK 11

Table 7. Pump nozzle orientations for efficient indexed operation of sludge heel removal under the reference operating conditions shown in Table 6

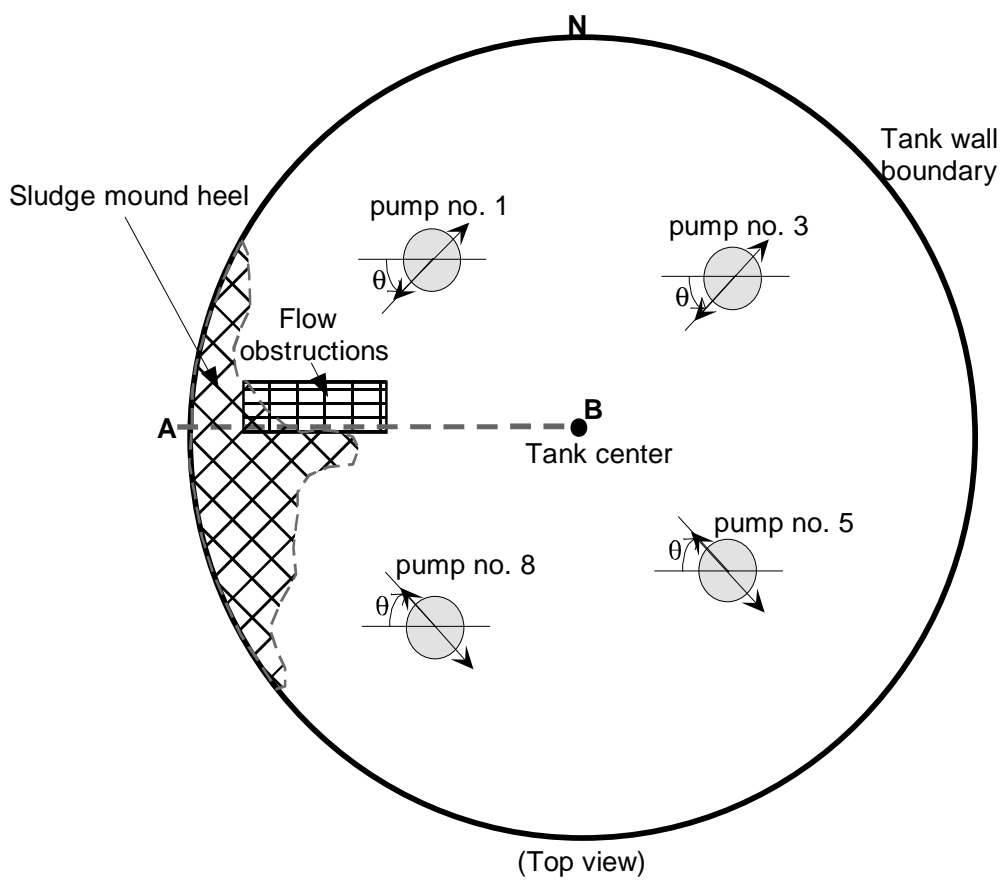

\begin{tabular}{|c|c|c|c|c|c|}
\hline \multirow[t]{2}{*}{ Cases } & \multirow{2}{*}{$\begin{array}{c}\text { Number of } \\
\text { operating pumps } \\
\begin{array}{c}\text { (angle } \theta \text { as shown } \\
\text { above) }\end{array}\end{array}$} & \multicolumn{4}{|c|}{$\begin{array}{l}\text { Pump identifications } \\
\text { (as shown above) }\end{array}$} \\
\hline & & no. 8 & no. 5 & no. 3 & no. 1 \\
\hline \multirow[b]{2}{*}{ Case-A } & 1 & off & off & off & operation \\
\hline & (aiming angle, $\theta^{*}$ ) & -- & -- & -- & $38^{\circ}$ \\
\hline \multirow[b]{2}{*}{ Case-B } & 2 & operation & operation & off & off \\
\hline & (aiming angle, $\theta^{*}$ ) & $43^{\circ}$ & $22^{\circ}$ & -- & -- \\
\hline \multirow[b]{2}{*}{ Case-C } & 2 & off & off & operation & operation \\
\hline & (aiming angle, $\theta^{*}$ ) & -- & -- & $16^{\circ}$ & $38^{\circ}$ \\
\hline \multirow[b]{2}{*}{ Case-D } & 3 & operation & off & operation & operation \\
\hline & (aiming angle, $\theta^{*}$ ) & $54^{\circ}$ & -- & $16^{\circ}$ & $38^{\circ}$ \\
\hline \multirow[b]{2}{*}{ Case-E } & 4 & operation & operation & operation & operation \\
\hline & (aiming angle, $\theta^{*}$ ) & $65^{\circ}$ & $22^{\circ}$ & $16^{\circ}$ & $38^{\circ}$ \\
\hline
\end{tabular}


Note: * Angle $\theta$ represents the angle made by the discharge flow direction of each pump nozzle and the horizontal line A-B aiming at the west corner of Tank 11 (sludge mound corner) as shown in the figure.

It is important to recognize that local velocity is not the only parameter affecting the ability of the liquid stream to suspend and transport sludge. The length of time that the sludge is exposed to the liquid stream is also important, and this effect is quantified in the present analysis by using the previous empirical approach [8]. A longer exposure time, as would be the case for an indexed pump rather than a continuously rotating pump, could reasonably be expected to result in greater erosion of the sludge layer at a given position. Thus, exposure time for an indexed pump position is determined by the previous experimental results and observations of Tank 16 [13].

From the previous results for Tank 16 operations with $0.25 \mathrm{rpm}$ of average rotational slurry pump [13], the pump operating time of about 500 hours was required to get cleaning radius of 37.5 feet. These data are applied to the present Tank 11 operations with fixed pump orientation since the CFD simulation results show that the steady-state cleaning distance covers the sludge mound area for the potential operating conditions. In this case, the main assumption was that material characteristics of Tank 11 sludge is similar to that of Tank 16 sludge.

The mixing time for the pump operation with the fixed pump orientation aiming at the sludge mound was estimated using the Tank 16 data [13]. From the present modeling results, the jetted spread angle was found to be about $14^{\circ}$. For the present operating conditions with indexed slurry pump, the pump operating time can be estimated by the equation. That is,

$t=t_{t k 16}(x)\left(\frac{\theta}{360}\right) N_{n}$

In eq. (7) $t_{t k 16}(x)$ is the pump operating time at the cleaning radius of $x \mathrm{ft}$, which can be obtained from Tank 16 data [3]. $\theta$ and $N_{n}$ are jet spread angle and number of discharge nozzles for each pump, respectively. When the current indexed operating condition of Tank 11 slurry pump is given as $\theta=14^{\circ}$, and $t_{t k 16}(x=37.5 f t) \approx 500 \mathrm{hrs}$ is provided to eq. (7) by the previous data [13], about 40 hours' pump operation time is required for each indexed pump orientation in order to suspend cohesive sludge materials.

The primary aim of the sensitivity studies is to determine what operational conditions result in better cleaning capability of the sludge using the existing waste removal equipment. Therefore, it is important to quantify the maximum sludge cleaning distance of each mixer for different operating conditions.

As discussed earlier, a flow velocity criterion has been used as the primary indicator to assess the sludge removal capability for various different operating conditions. Flow patterns were evaluated for three different pump speeds with all other parameters used by the reference conditions. The reference pump speed was $1600 \mathrm{rpm}$ as provided in Table 6. A couple of higher pump speeds were used for the sensitivity runs, assuming that the nominal speed of $1600 \mathrm{rpm}$ could increase up to $2000 \mathrm{rpm}$ if necessary. The results of flow velocities for the near-wall regions of sludge mound around the valve housing are compared among three different pump speeds in Figs. 28 through 31 . Flow patterns at the corner regions adjacent to the wall boundary are more active than in the central region of the tank because of fluid vortices generated due to the presence of the 
Page: 32 of 71

tank wall boundary. It is noted that the higher pump speed is generally more efficient than the lower in terms of sludge removal capability, but it is about the same in terms of flow circulation patterns as shown in Figs. 30 and 31 . Table 8 shows quantitative comparison of the calculated ECR values between the two speeds, $1600 \mathrm{rpm}$ and 1800 rpm. The results show that the effective cleaning distance increases by about $5 \%$ with respect to the reference speed of $1600 \mathrm{rpm}$ when pump speed increases from $1600 \mathrm{rpm}$ to $1800 \mathrm{rpm}$.

Table 8. Sensitivity results for different tank levels in the Tank 11 model under the reference operating conditions except for pump speed in terms of maximum clearing distance (MCD)

\begin{tabular}{|c|c|c|c|c|}
\hline Cases & $\begin{array}{c}\text { Pump } \\
\text { speed }\end{array}$ & $\begin{array}{c}\text { Pump } \\
\text { elevation from } \\
\text { tank bottom }\end{array}$ & $\begin{array}{c}\text { Nozzle exit } \\
\text { velocity } \\
\text { (ft/sec) }\end{array}$ & $\begin{array}{c}\text { Max. Clearing } \\
\text { Distance* }(\mathbf{2 . 2 7} \mathbf{f t} / \mathbf{s e c} \\
\text { or } \mathbf{0 . 6 9} \mathbf{~ m} / \mathbf{s e c})\end{array}$ \\
\hline \multirow{2}{*}{$\begin{array}{c}\text { Tank 11 } \\
\text { Model }\end{array}$} & $1600 \mathrm{rpm}^{* *}$ & $17 \mathrm{in}^{* *}$ & $99.6^{* *}$ & $27.2 \mathrm{ft}$ \\
\cline { 2 - 5 } & $1800 \mathrm{rpm}$ & $17 \mathrm{in}^{* *}$ & $109 \mathrm{ft} / \mathrm{sec}$ & $28.4 \mathrm{ft}$ \\
\hline
\end{tabular}

Note: ${ }^{*}$ MCD was defined as the distance from the nozzle exit of the pump to the point at which local velocity reaches minimum suspension (or specified) velocity of 2.27 $\mathrm{ft} / \mathrm{sec}$.

${ }^{* *}$ Reference operating conditions defined in Table 6.

Flow patterns were evaluated for two different tank levels with all other parameters fixed. The reference tank level was 103 in as shown in Table 6. A lower tank level of 74 in was selected for the sensitivity analysis of tank level, since the tank level after the first waste transfer might be reduced to 74 in according to the Tank 11 operational plan [2]. Figure 32 compares velocity magnitudes at the nozzle exit plane and top surface for one-pump operation (pump no. 1) between the two different tank levels. Flow patterns at the corner regions adjacent to the wall boundary are more active than in the central region of the tank because of fluid vortices generated due to the presence of the tank wall boundary. In Fig. 33 flow velocities along the centerline of the pump exit plane for the one-pump operation are compared between the two liquid levels. In the figure maximum velocity for the reference tank level (103 in) are found to be about $14 \%$ higher than the 74 in tank level. Flow velocities for the four-pump run are compared at the planes of pump exit and top surface in Fig. 34. Velocity distributions corresponding to the velocity contour plots of Fig. 34 are compared along the specific direction as shown in Fig. 35. The sensitivity results show that the lower tank level case has higher dissipation of fluid momentum than the other case since turbulent dissipation rate increases along the discharge direction as tank level decreases. These results are consistent with the previous modeling results $[4,5]$ and operational experience of Tank 18 [8]. Quantitative comparison for the two different tank levels of Tank 11 is made in terms of maximum cleaning distance as shown in Table 9. Based on the nozzle orientation map of selected pumps for efficient operations of sludge heel removal as 
developed under the reference operating conditions, the calculation results for the 74-in tank level corresponding to those of Fig. 25 are shown in Fig. 36.

Table 9. Sensitivity results for different tank levels in the Tank 11 model under the reference operating conditions except for liquid level in terms of maximum clearing distance (MCD)

\begin{tabular}{|c|c|c|c|c|}
\hline Cases & $\begin{array}{c}\text { Tank liquid } \\
\text { level }\end{array}$ & $\begin{array}{c}\text { Pump } \\
\text { elevation } \\
\text { from tank } \\
\text { bottom }\end{array}$ & $\begin{array}{c}\text { Nozzle exit } \\
\text { velocity } \\
\text { (ft/sec) }\end{array}$ & $\begin{array}{c}\text { Max. Clearing } \\
\text { Distance }(\mathbf{2 . 2 7} \mathbf{f t} / \mathbf{s e c} \\
\text { or } \mathbf{0 . 6 9} \mathbf{~ m} / \mathbf{s e c})\end{array}$ \\
\hline \multirow{2}{*}{$\begin{array}{c}\text { Tank 11 } \\
\text { Model }\end{array}$} & $103 \mathrm{in}^{* *}$ & $17 \mathrm{in}^{\star *}$ & $99.6^{* *}$ & $27.2 \mathrm{ft}$ \\
\cline { 2 - 5 } & $74 \mathrm{in}$ & $17 \mathrm{in}^{* *}$ & $99.6^{* *}$ & $25.1 \mathrm{ft}$ \\
\hline
\end{tabular}

Note: * MCD was defined as the distance from the nozzle exit of the pump to the point at which local velocity reaches minimum suspension (or specified) velocity of 2.27 $\mathrm{ft} / \mathrm{sec}$.

${ }^{* *}$ Reference operating conditions defined in Table 6.

Flow patterns were evaluated for two different pump elevations with all other parameters fixed by the reference conditions. The reference pump elevation was 17 in as shown in Table 6. A higher pump elevation of 26 in was used, since the nozzle cannot be lowered below 17 in and it can only be raised [2]. The results are compared in Table 10. It is noted that the higher pump elevation is generally less efficient than the lower in terms of sludge removal capability, but it is only slightly different in terms of flow circulation. The results for different tank levels and pump elevations under the onepump (pump no. 1) operating condition are compared in Fig. 37. These results are consistent with those of the previous works [4, 5, and 8] 
Page: $\quad 34$ of 71

Table 10. Sensitivity results for different pump elevations in the Tank 11 model under the reference operating conditions except for pump elevation in terms of maximum clearing distance (MCD)

\begin{tabular}{|c|c|c|c|c|}
\hline Cases & $\begin{array}{c}\text { Tank liquid } \\
\text { level }\end{array}$ & $\begin{array}{c}\text { Pump elevation } \\
\text { from tank } \\
\text { bottom }\end{array}$ & $\begin{array}{c}\text { Nozzle exit } \\
\text { velocity } \\
\text { (ft/sec) }\end{array}$ & $\begin{array}{c}\text { Max. Clearing } \\
\text { Distance } \\
\text { (2.27 ft/sec) }\end{array}$ \\
\hline \multirow{2}{*}{$\begin{array}{c}\text { Tank 11 } \\
\text { Model }\end{array}$} & $103 \mathrm{in}^{* *}$ & $26 \mathrm{in}$ & $99.6^{* *}$ & $24.9 \mathrm{ft}$ \\
\cline { 2 - 5 } & $103 \mathrm{in}^{\star *}$ & $17 \mathrm{in}^{* *}$ & $99.6^{* *}$ & $27.2 \mathrm{ft}$ \\
\hline
\end{tabular}

Note: * MCD was defined as the distance from the nozzle exit of the pump to the point at which local velocity reaches minimum suspension (or specified) velocity.

${ }^{* *}$ Reference operating conditions defined in Table 6.

The present analyses have been performed using water as the working fluid. Different fluid properties, which are similar to typical slurry fluids in Tank 11 as shown in Table 6, were used to examine the sensitivity of the flow patterns to these changes. The results show that the flow patterns are not sensitive to changes of fluid properties. At the discharge plane, there are no apparent differences in flow evolution. At the 17 in elevation of the pump exit plane, slurry flow around the horizontal discharge direction of the nozzle dies out slightly more quickly than water since radial diffusion is increased relative to convection when the fluid viscosity is increased from water $(1 \mathrm{cp})$ to slurry $(2$ $\mathrm{cp})$. It is noted that the radial flow behavior induced by the slurry is larger than that for water because of the increased diffusion in the momentum transport. However, when the maximum clearing distance (MCD) is defined as the distance over which the jet velocity exceeds the minimum suspension velocity, differences in the MCD for water and slurry are negligible. This result is consistent with the previous results of the Tank 18 analyses [5]. These results are summarized in Table 11.

Table 11. Sensitivity results for different fluid properties in the Tank 11 model in terms of maximum clearing distance (MCD)

\begin{tabular}{|c|c|c|c|c|}
\hline Cases & $\begin{array}{c}\text { Pump } \\
\text { position } \\
\text { (Liquid level) }\end{array}$ & Tank fluid & $\begin{array}{c}\text { Nozzle } \\
\text { velocity } \\
\text { (ft/sec) }\end{array}$ & $\begin{array}{c}\text { Max. Clearing } \\
\text { Distance* } \\
(2.27 \mathrm{ft} / \mathrm{sec} \text { or } \\
0.69 \mathrm{~m} / \mathrm{sec})\end{array}$ \\
\hline \multirow{2}{*}{$\begin{array}{l}\text { Tank } 11 \\
\text { Model }\end{array}$} & \multirow{2}{*}{$\begin{array}{l}\text { Fixed (or } \\
\text { indexed) } \\
\text { (103 in) }\end{array}$} & Water & 99.6 & $27.2 \mathrm{ft}$ \\
\hline & & $\begin{array}{c}\text { Slurry } \\
\text { (1.2sg and 2cp) }\end{array}$ & 99.6 & $27.1 \mathrm{ft}$ \\
\hline
\end{tabular}

Note: ${ }^{*}$ MCD was defined as the distance from the nozzle exit of the pump to the point at which local velocity reaches minimum suspension (or specified) velocity. 
The modeling results clearly show that fluid velocity for the lower tank level dissipates more quickly than the higher tank level under fixed pump elevation in an indexed mode of operation. It is noted that as soon as the flow exits the nozzle, main circulation cells are generated around the tank, one on each side of the centerline for each nozzle as shown in Figs. 32 and 34 . This circulating flow pattern will help to understand the suspension and removal of waste sludge. The results demonstrate that the higher tank level generates the stronger flow circulating patterns, resulting in a better suspension of sludge.

From the calculation results, it is pointed out that simultaneous operation of all pumps is not needed for an efficient removal of the sludge mound located at a specific position. This stems from the interference effect of pump nozzle flows with different discharge directions as graphically shown Figs. 11 and 13 .

As the modeling results discussed earlier, when fluid velocity is used as a scouring criterion to pick up and suspend sludge, flow fields induced by the slurry pump under the reference operating conditions as defined in Table 6 are adequate for the sludge removal operation of Tank 11. The exception is the region within about $2 \mathrm{ft}$ of the wall, which is located behind the valve housing structure, assuming the minimum velocity required to suspend waste sludge is $2.27 \mathrm{ft} / \mathrm{sec}$. Maximum clearing distance of the slurry mixer from an indexed pump position for the reference operating conditions is found to be about $27 \mathrm{ft}$. Sludge removal domain based on the cleaning distance of $27 \mathrm{ft}$ is illustrated in Fig. 38.

Figure 38 can be used to estimate the amount of cohesive sludge mound in Tank 11 that is beyond the erosion capability of the slurry pump under the reference operating conditions. An engineering estimate is that sludge material would remain in the crosshatched region as shown in the figure. If sludge mound occur differently, it is beyond the scope of the present analysis. Assuming the sludge mound is cohesive, the volume of this region has been evaluated numerically and is approximately 2,610 gal as shown in Table 12. In this calculation, volume of non-cohesive solid material precipitated on the tank floor is not considered. That is, the deposition would be expected to follow behind the rotational motion of the jet, leaving an annular ring at the peripheral region near the tank wall. The particulate would remain there until the opposing jet is passed over that same region.

Table 12. Volume predictions of the sludge mound remaining after the referenced sludge removal operations

\begin{tabular}{|c|c|c|c|}
\hline Pump speed & Tank level & ECR & $\begin{array}{c}\text { Volume of the } \\
\text { sludge mound }\end{array}$ \\
\hline $1600 \mathrm{rpm}$ & $103 \mathrm{in}$ & $27.2 \mathrm{ft}$ & about 2,610 gallons \\
\hline
\end{tabular}

Note: * Numerically calculated assuming that sludge mound height for the crosshatched region in Fig. 38 remains the same as the initial height of 52 inches [2] during pump operations 
Page: $\quad 36$ of 71

The modeling results demonstrate that lower tank level, lower pump speed, and higher pump elevation provide smaller cleaning capabilities with respect to the reference conditions. It is emphasized that the higher tank level is more efficient than the other in terms of sludge removal capability. This is consistent with the previous results $[4,5$, and 8]. This information will assist in the sludge suspension and removal plans for Tank 11 operations. The steady-state flow patterns on the horizontal discharge plane follow a series of parabolic curves similar to that of a free jet $[10,11]$. Vertical velocity profiles are changed from a bell-shaped curve near the exit of the nozzle to a near-uniform velocity near the tank wall boundary. These are in agreement with the previous results $[4,5]$ and the literature data [11]. 


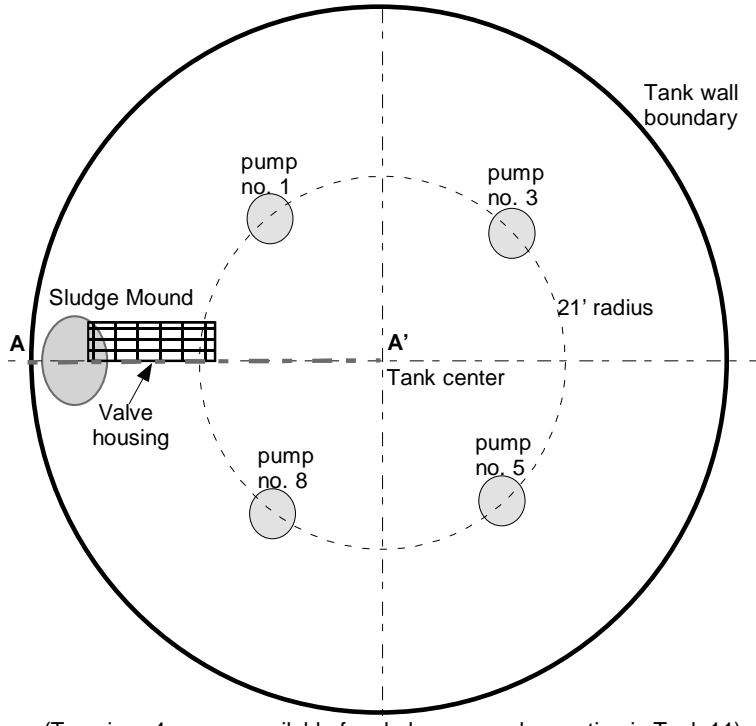

(Top view: 4 pumps available for sludge removal operation in Tank 11)

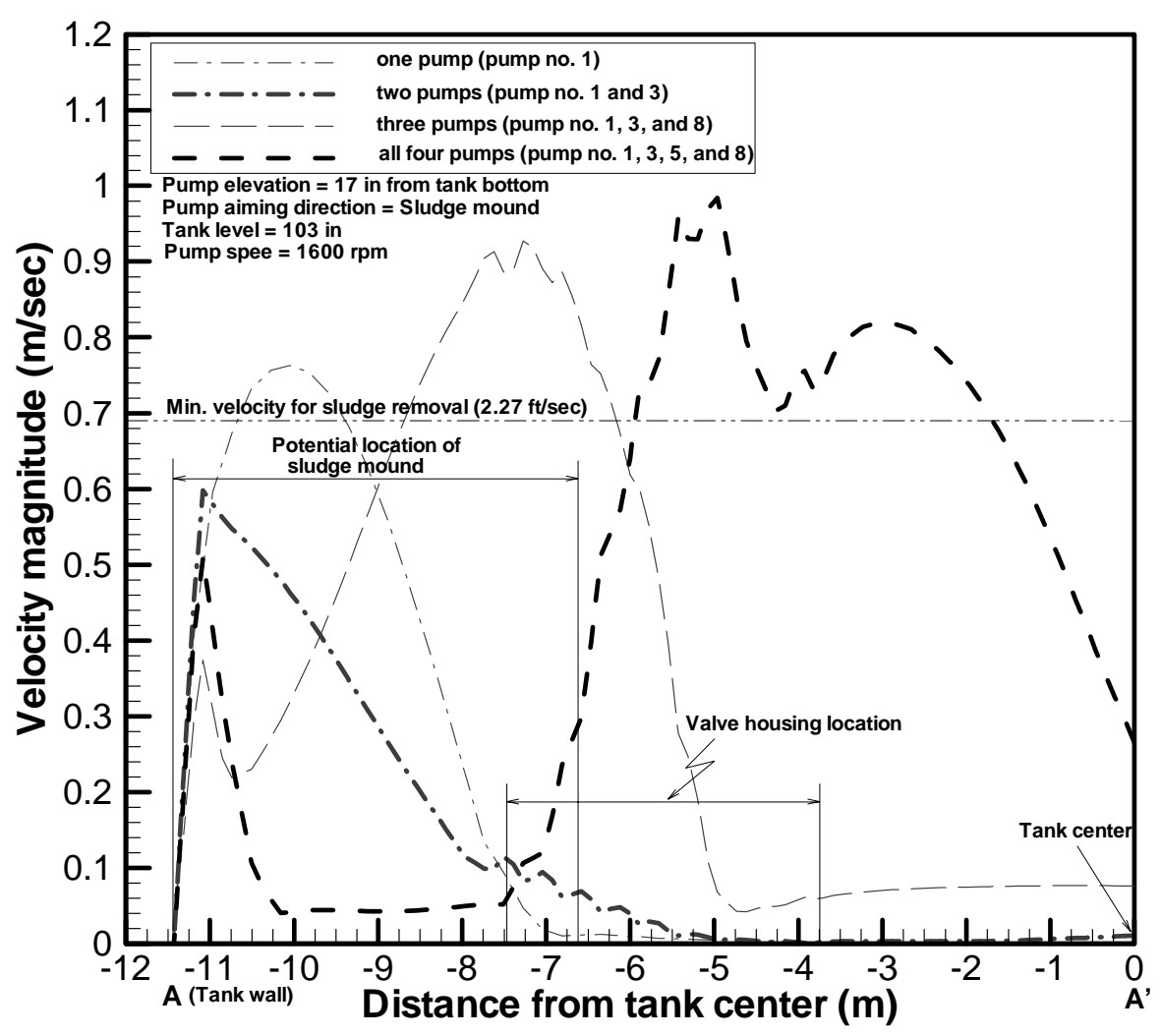

$(1 \mathrm{~m} / \mathrm{sec}=3.28 \mathrm{ft} / \mathrm{sec})$

Figure 10. Flow velocity magnitudes along the centerline $A^{\prime}-A$ of Tank 11 at the discharge elevation of slurry pump for various numbers of operating pumps using the present model. 
Report: WSRC-TR-2003-00308

Date: $\quad 10 / 6 / 2003$

Page: $\quad 38$ of 71
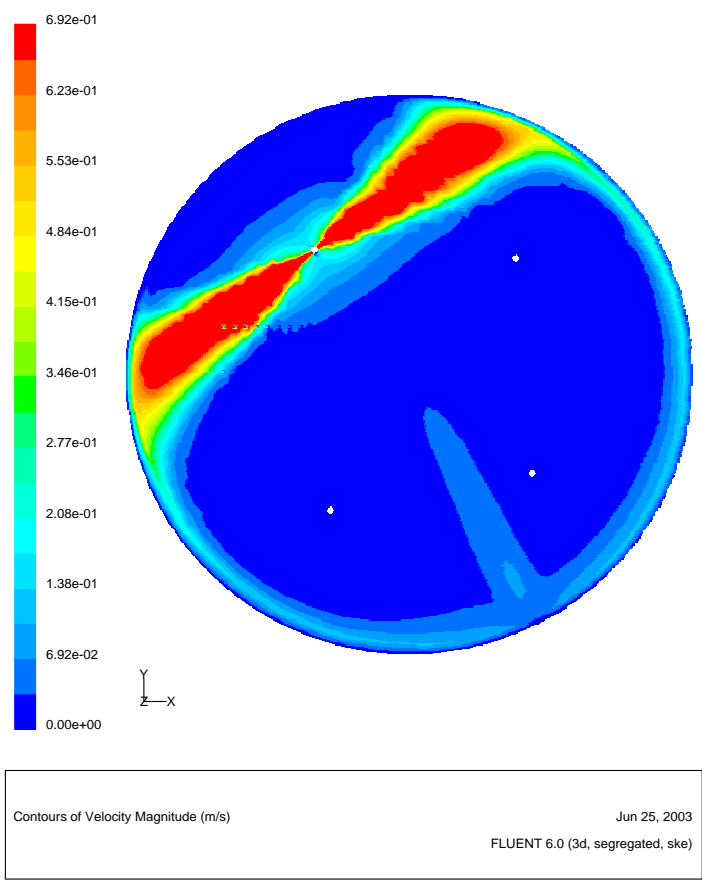

(Single pump operated: pump no. 1)
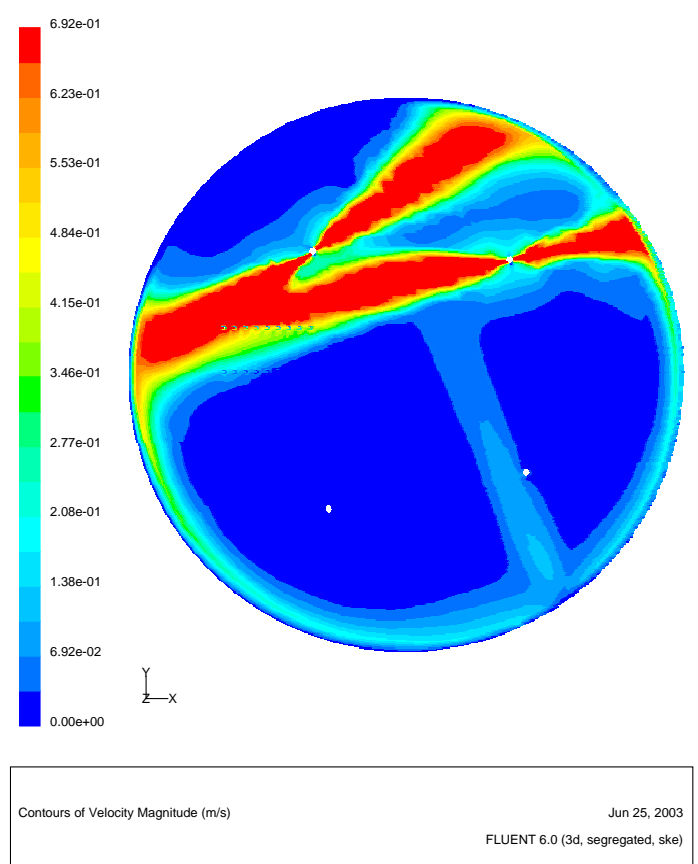

(Two pumps operated: pump no. 1 and 3)

Figure 11. Comparison of velocity contour plots between single-pump (pump no. 1) and two-pump (pump no. 1 and pump no. 3) operations at pump discharge plane using the Tank 11 model under the reference operating conditions shown in Table 6. 

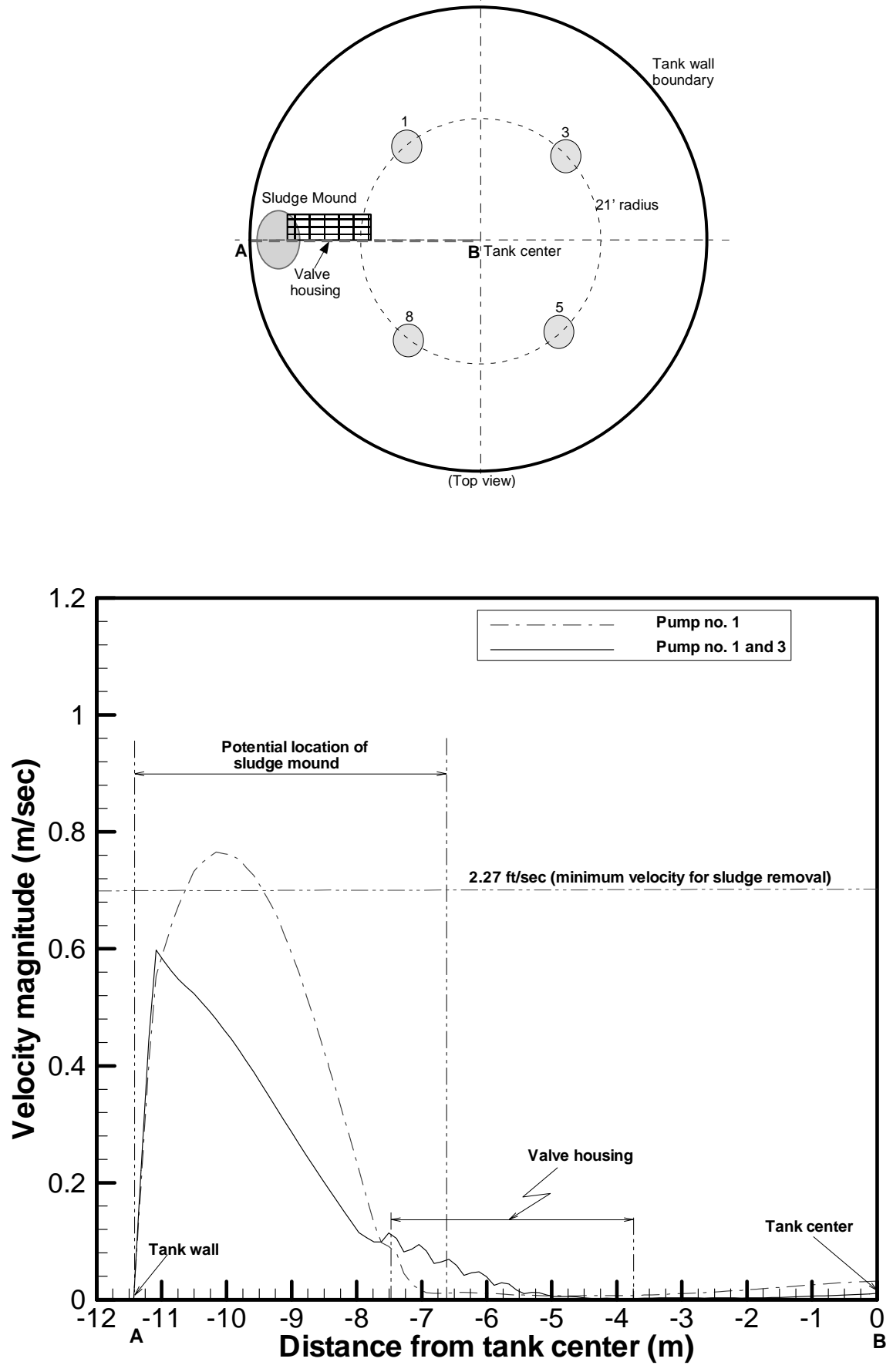

Figure 12. Comparison of velocity magnitudes along the centerline A-B between singlepump (pump no. 1) and two-pump (pump no. 1 and pump no. 3) operations at pump discharge plane using the Tank 11 model under the reference operating conditions shown in Table 6. 
Page: $\quad 40$ of 71
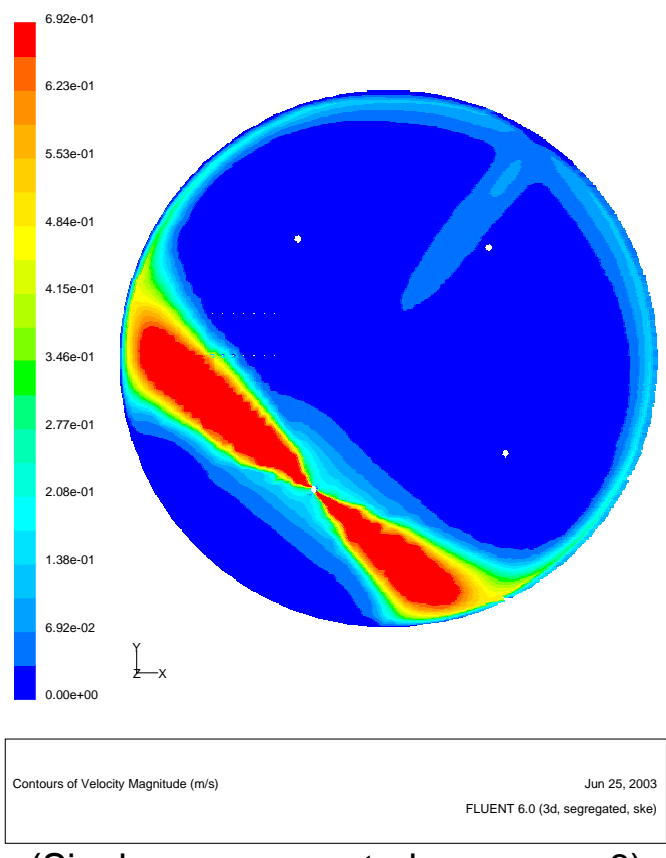

(Single pump operated: pump no. 8)
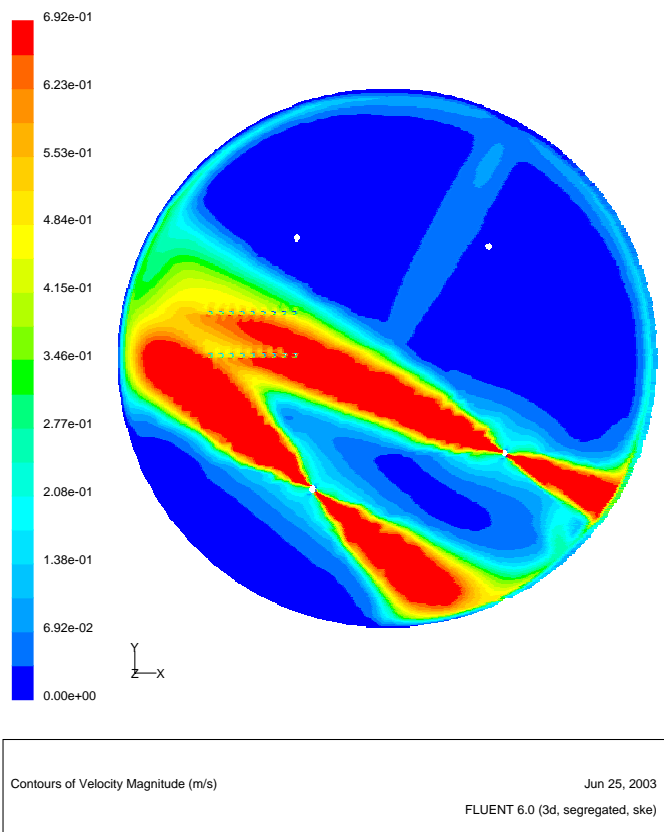

(Two pumps operated: pump no. 5 and 8)

Figure 13. Comparison of velocity contour plots between single-pump (pump no. 8) and two-pump (pump no. 5 and pump no. 8) operations at pump discharge plane using the Tank 11 model under the reference operating conditions shown in Table 6. 

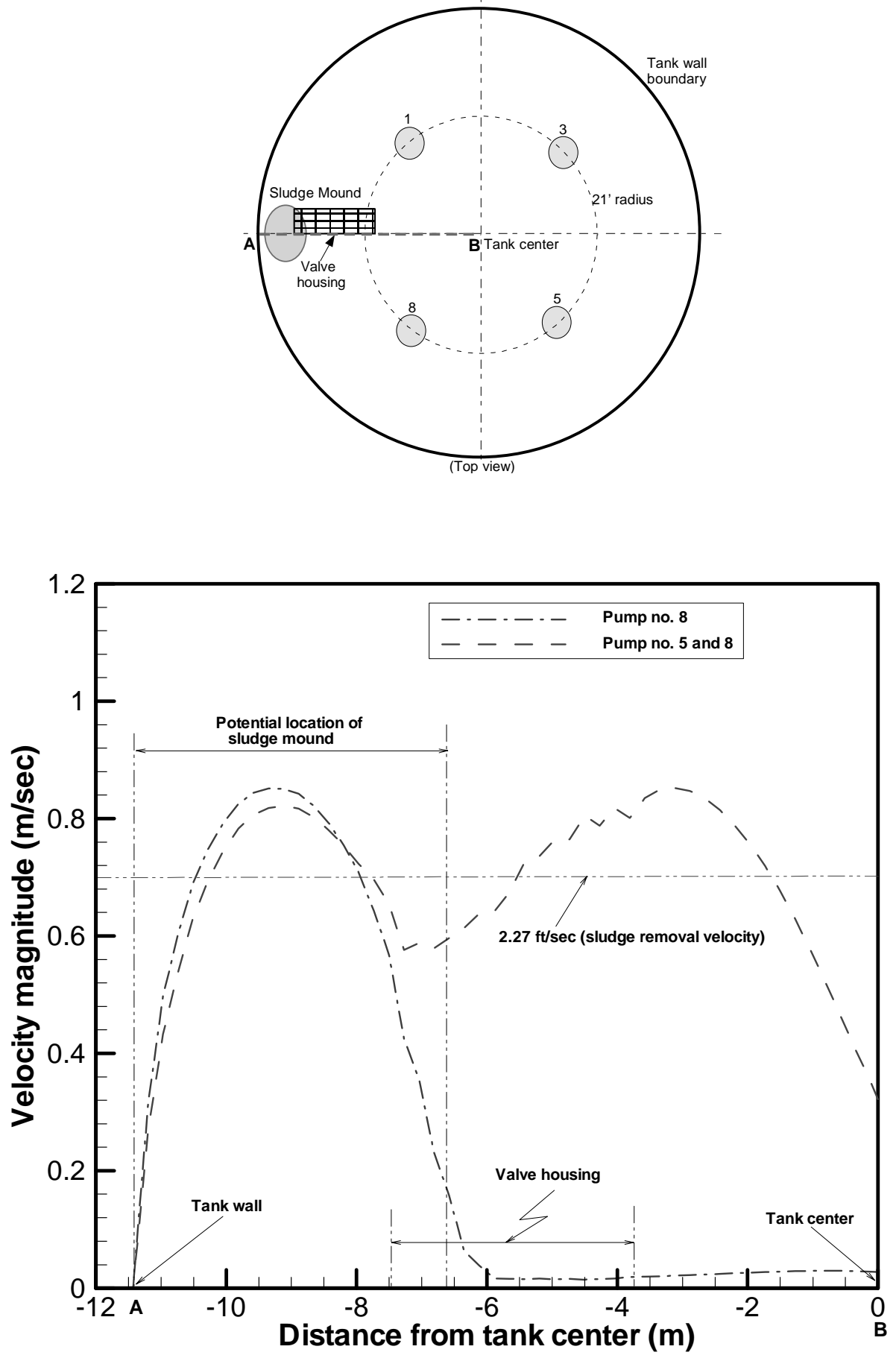

Figure 14. Comparison of velocity magnitudes along the centerline A-B between singlepump (pump no. 8) and two-pump (pump no. 5 and pump no. 8) operations at pump discharge plane using the Tank 11 model under the reference operating conditions shown in Table 6. 
Report: WSRC-TR-2003-00308

Date: $\quad 10 / 6 / 2003$

Page: $\quad 42$ of 71
WESTINGHOUSE SAVANNAH RIVER COMPANY

SLUDGE HEEL REMOVAL ANALYSIS FOR SLURRY PUMPS OF TANK 11

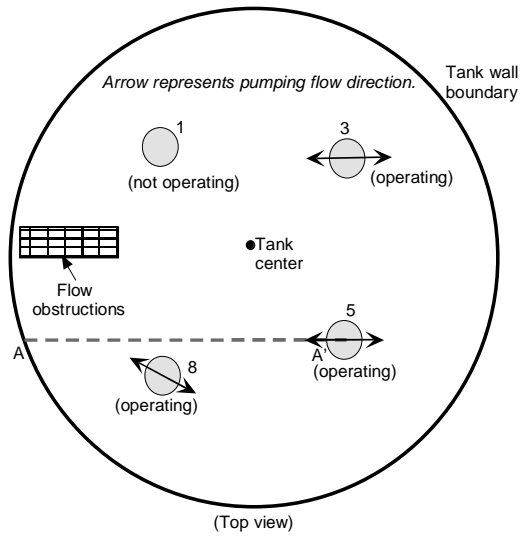

(Orientations of pump operations)

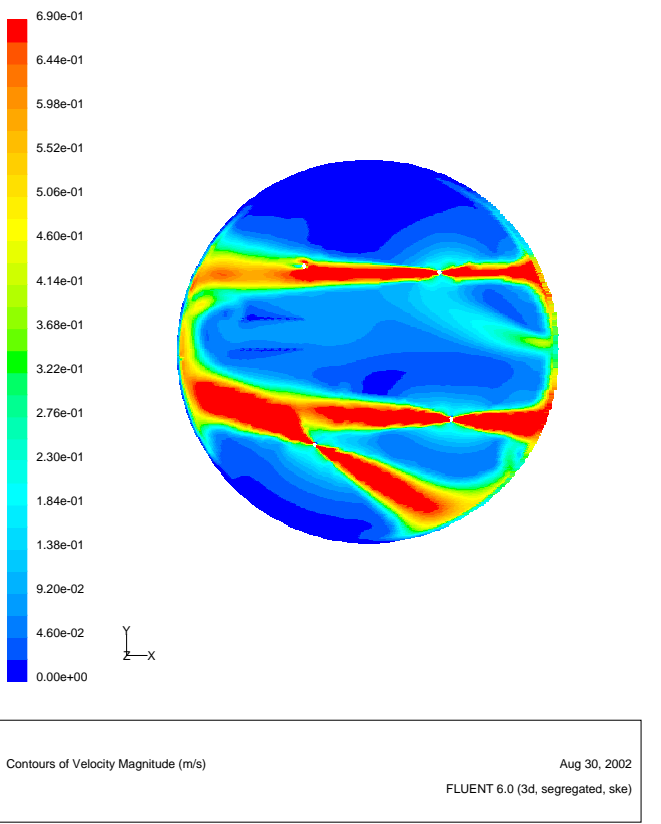

(Flow patterns for three pump operations)

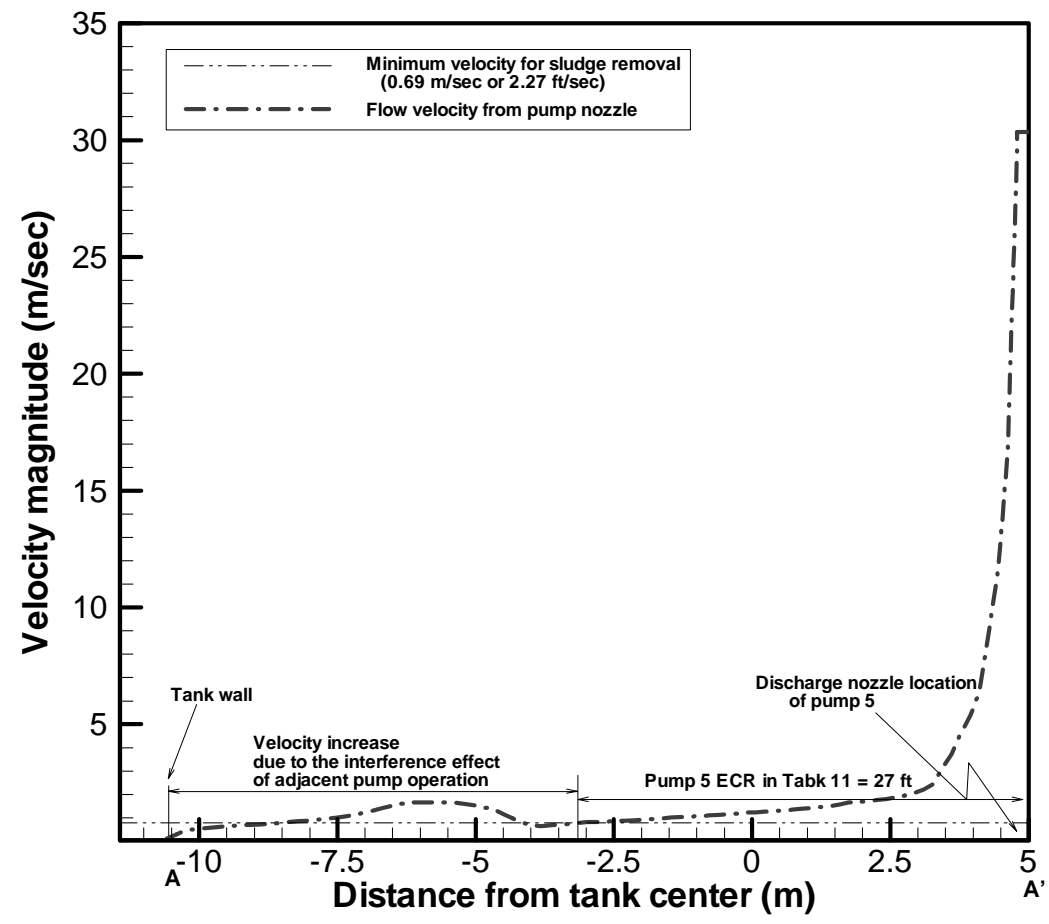

(Flow velocity along the line A'-A of pump discharge direction) $(0.69 \mathrm{~m} / \mathrm{sec}=2.27 \mathrm{ft} / \mathrm{sec})$ 
Figure 14. Flow velocity distributions along the pump discharge line $A^{\prime}-A$ and pump ECR estimation under the reference operating conditions with three pump runs in Tank 11 (pump no. 3, no. 5, and no. 8)
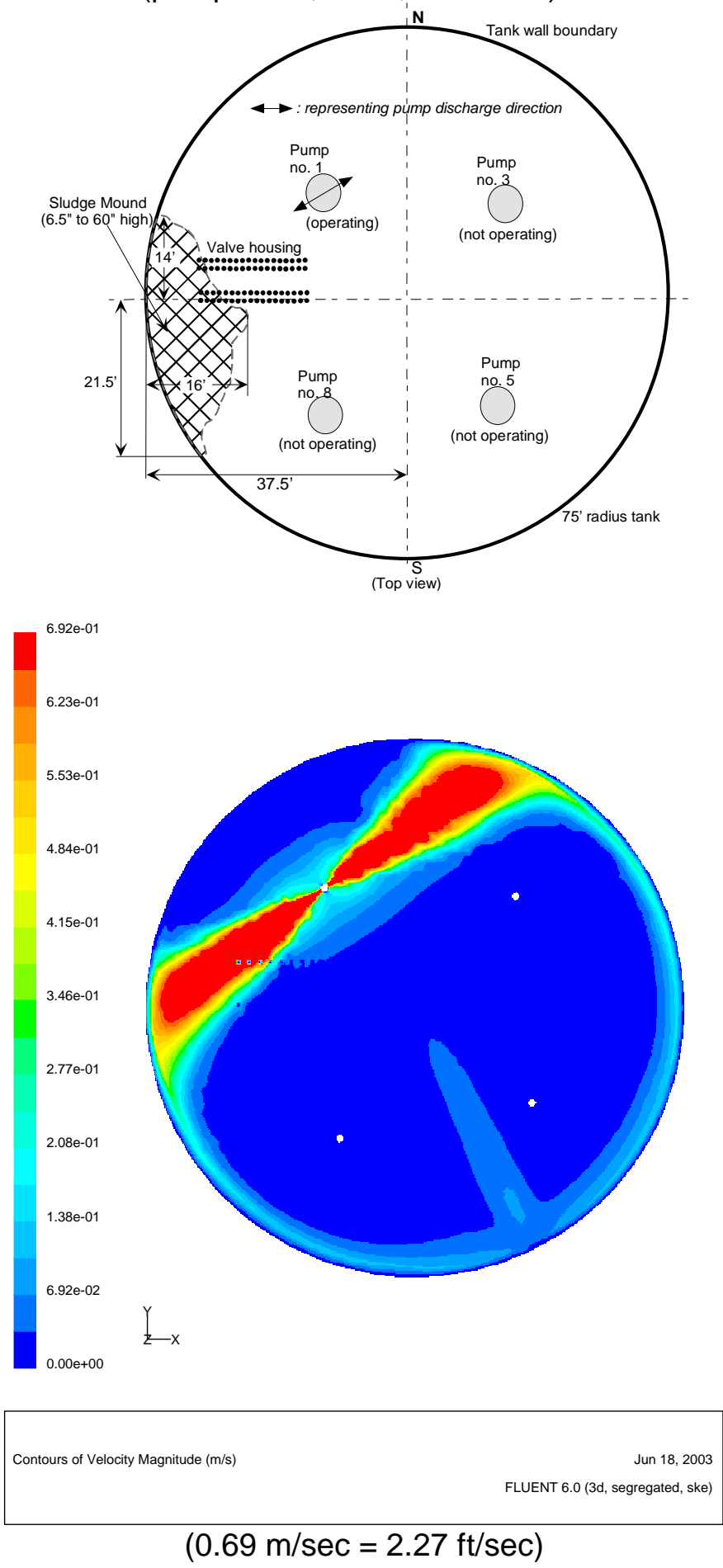

Figure 16. Flow patterns for the pump orientation of one pump operation in association with effectiveness of sludge removal located at the corner of valve housing in Tank 11 (Case-A: pump no. 1 operation) 
Report: WSRC-TR-2003-00308

Date: $\quad 10 / 6 / 2003$

Page: $\quad 44$ of 71
WESTINGHOUSE SAVANNAH RIVER COMPANY

SLUDGE HEEL REMOVAL ANALYSIS FOR SLURRY PUMPS OF TANK 11
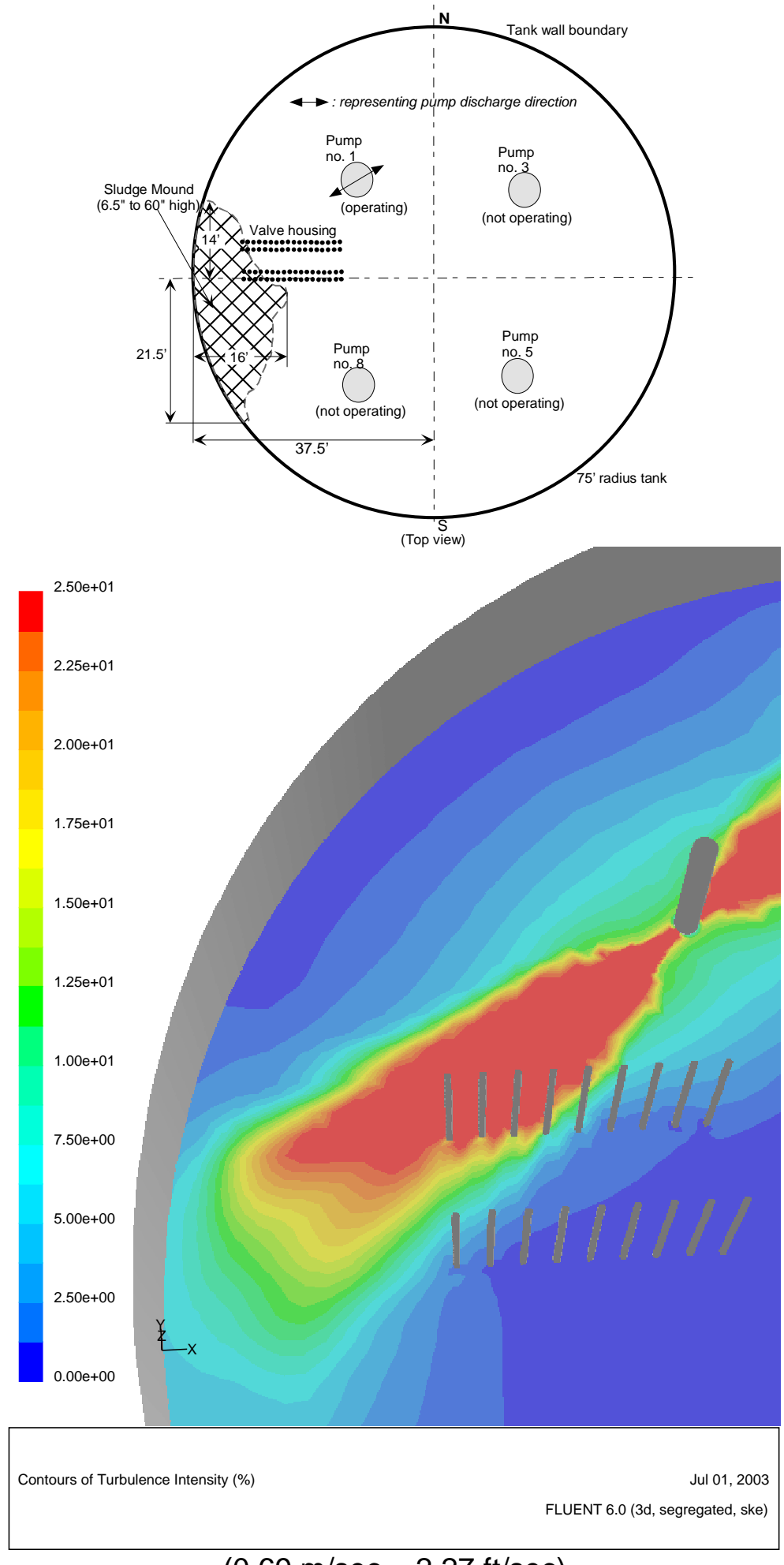

$(0.69 \mathrm{~m} / \mathrm{sec}=2.27 \mathrm{ft} / \mathrm{sec})$

Figure 17. Turbulent intensities for one pump operation in association with effectiveness of sludge removal located at the corner of valve housing in Tank 11 (Case-A: pump no. 1 operation) 


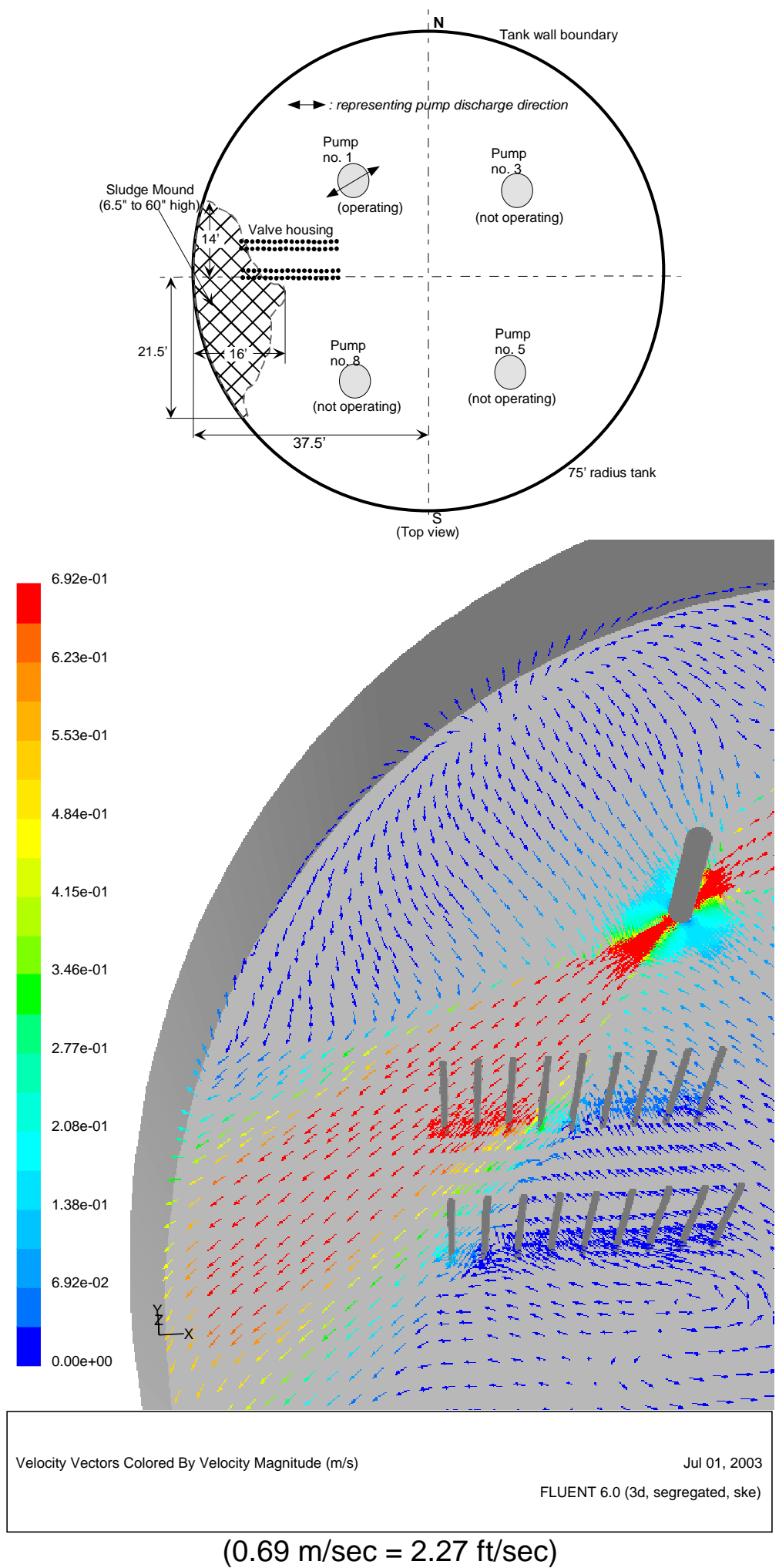

Figure 18. Flow patterns for one pump operation in association with effectiveness of sludge removal located at the corner of valve housing in Tank 11 (Case-A: pump no. 1 operation) 
Report: WSRC-TR-2003-00308

Date: $\quad 10 / 6 / 2003$

Page: $\quad 46$ of 71
WESTINGHOUSE SAVANNAH RIVER COMPANY

SLUDGE HEEL REMOVAL ANALYSIS FOR SLURRY PUMPS OF TANK 11
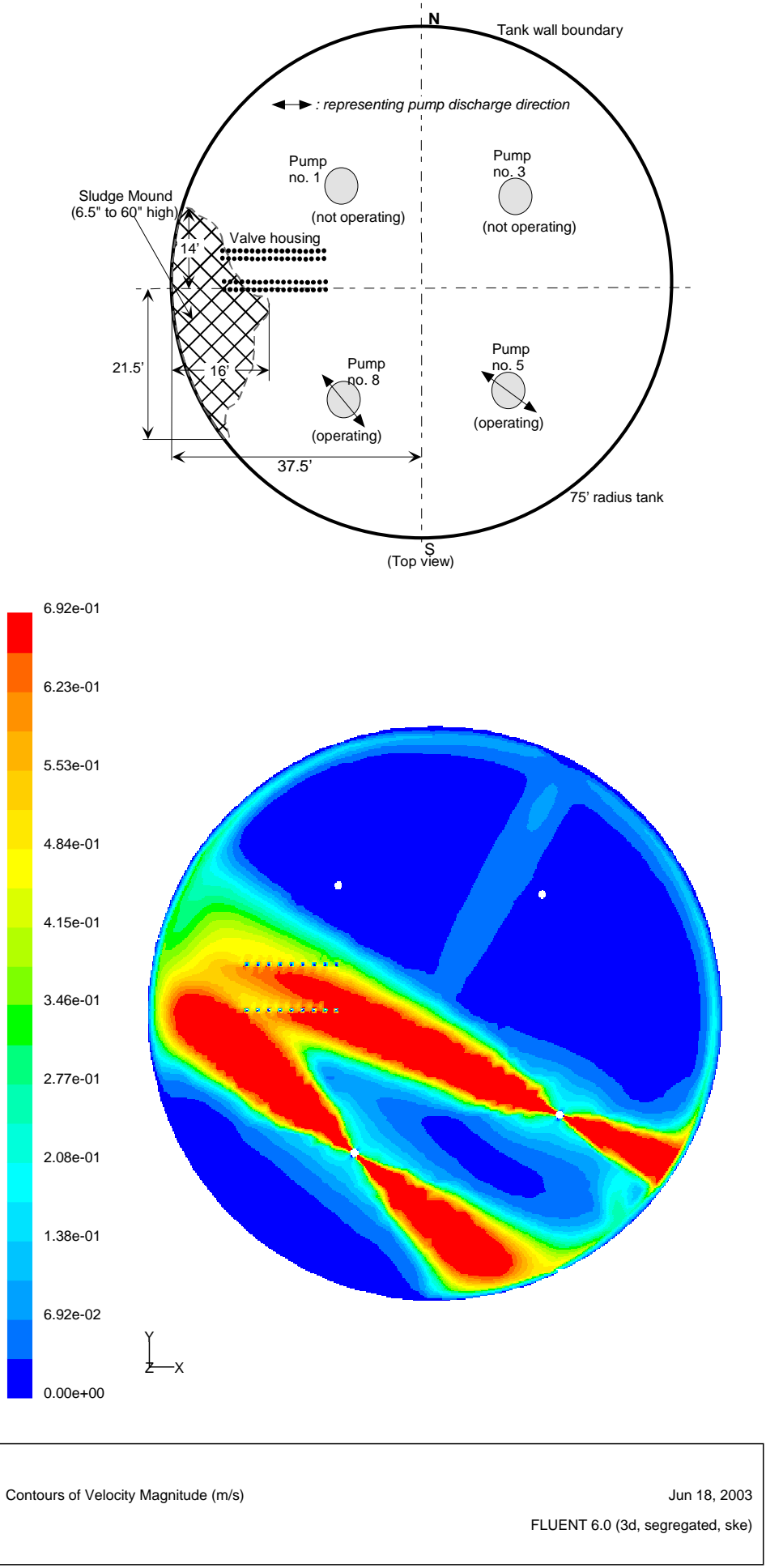

$(0.69 \mathrm{~m} / \mathrm{sec}=2.27 \mathrm{ft} / \mathrm{sec})$

Figure 19. Velocity contour plot for two-pump operation in association with effectiveness of sludge removal located at the corner of valve housing in Tank 11 (Case-B: pump no. 5 and no. 8 operations) 

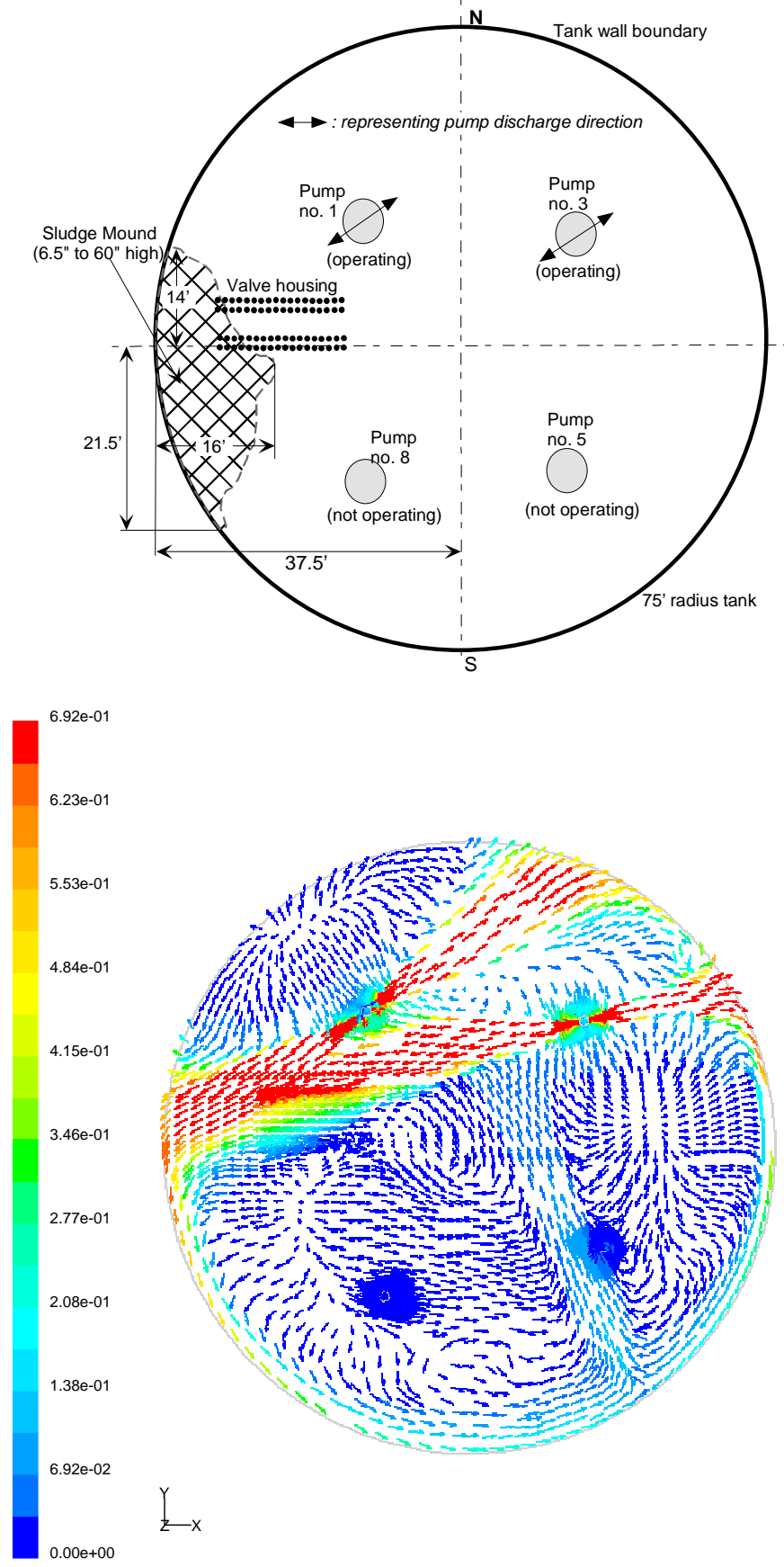

Velocity Vectors Colored By Velocity Magnitude $(\mathrm{m} / \mathrm{s})$

Jun 18,2003

FLUENT 6.0 (3d, segregated, ske)

$(0.69 \mathrm{~m} / \mathrm{sec}=2.27 \mathrm{ft} / \mathrm{sec})$

Figure 20. Flow patterns for the pump orientation of two-pump operation in association with effectiveness of sludge removal located at the corner of valve housing (Case-C: pump no. 1 and no. 3 operations) 
Report: WSRC-TR-2003-00308

Date: $\quad 10 / 6 / 2003$

Page: $\quad 48$ of 71
WESTINGHOUSE SAVANNAH RIVER COMPANY

SLUDGE HEEL REMOVAL ANALYSIS FOR SLURRY PUMPS OF TANK 11
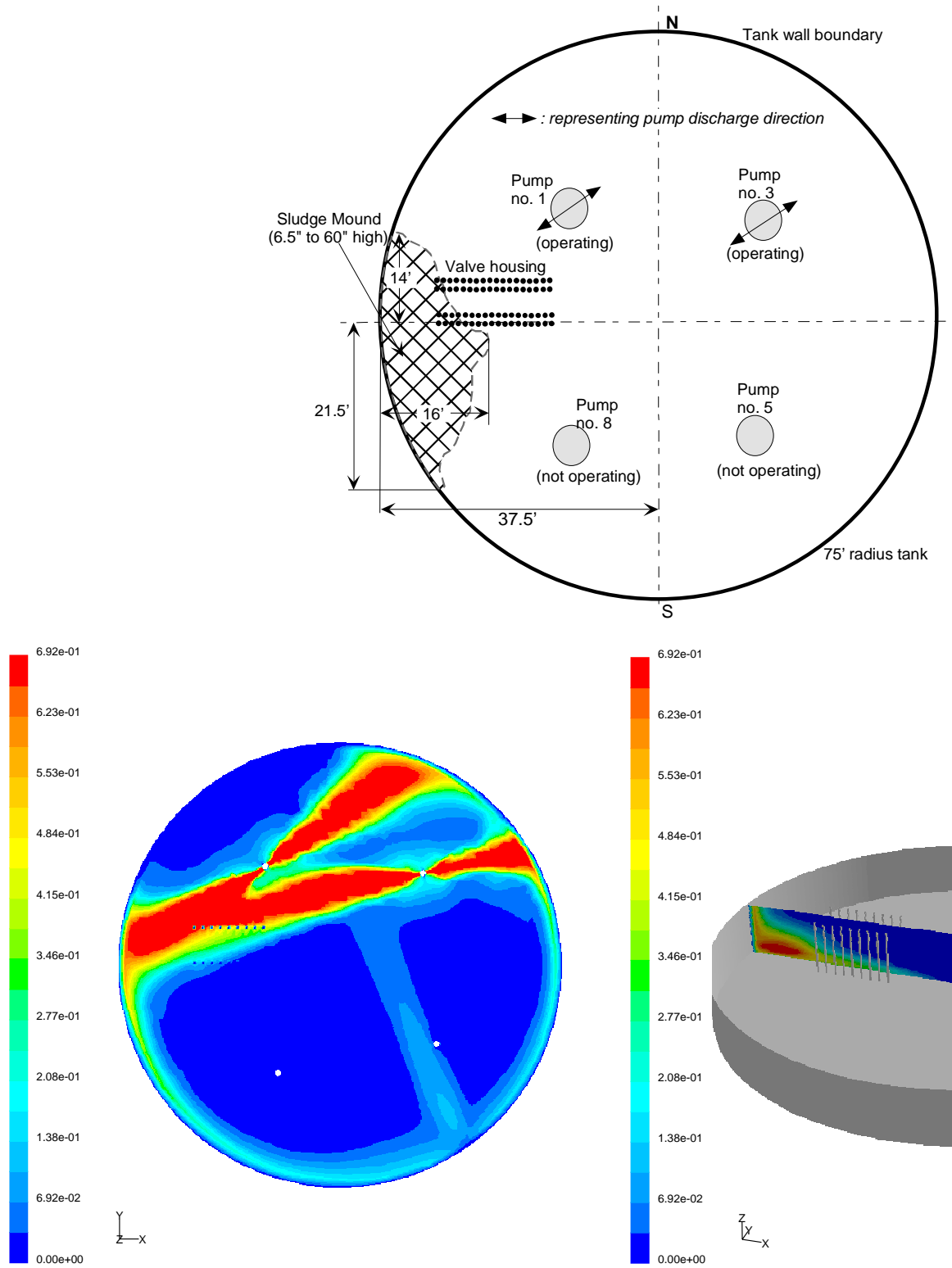

Jun 18,2003

FLUENT 6.0 (3d, segregated, ske)

FLUENT 6.0 (3d, segregated, ske)

(Horizontal plane of pump discharge nozzle) (Vertical plane crossing the valve housing) $(0.69 \mathrm{~m} / \mathrm{sec}=2.27 \mathrm{ft} / \mathrm{sec})$

Figure 21. Velocity contour plots for the two-pump operation in association with effectiveness of sludge removal located at the corner of valve housing (Case-C: pump no. 1 and no. 3 operations) 

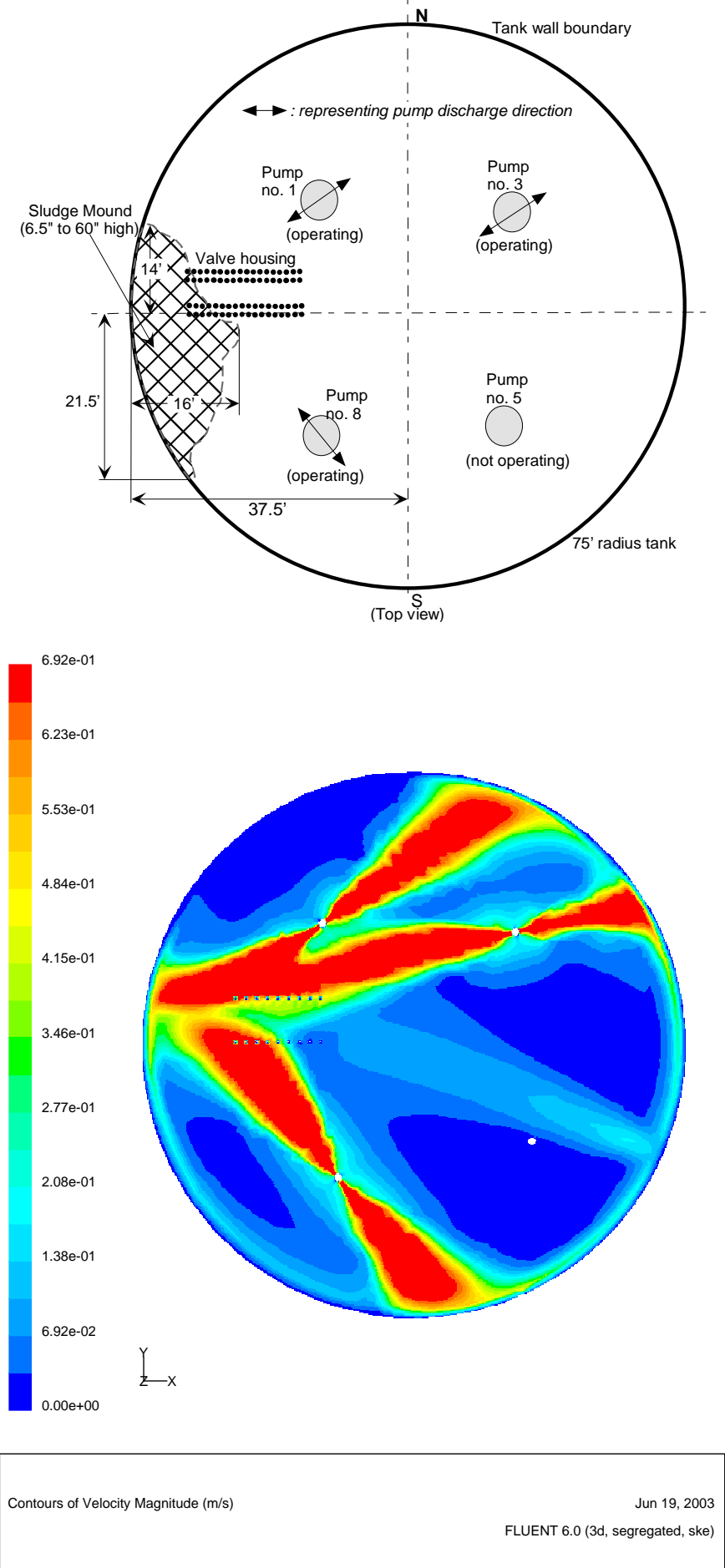

$(0.69 \mathrm{~m} / \mathrm{sec}=2.27 \mathrm{ft} / \mathrm{sec})$

Figure 22. Velocity contour plot for the pump orientation of three-pump operation in association with effectiveness of sludge removal located at the corner of valve housing in Tank 11 (Case-D: pump no. 1, no. 3, and no. 8 operations) 
Report: WSRC-TR-2003-00308

Date: $\quad 10 / 6 / 2003$

Page: $\quad 50$ of 71
WESTINGHOUSE SAVANNAH RIVER COMPANY

SLUDGE HEEL REMOVAL ANALYSIS FOR SLURRY PUMPS OF TANK 11
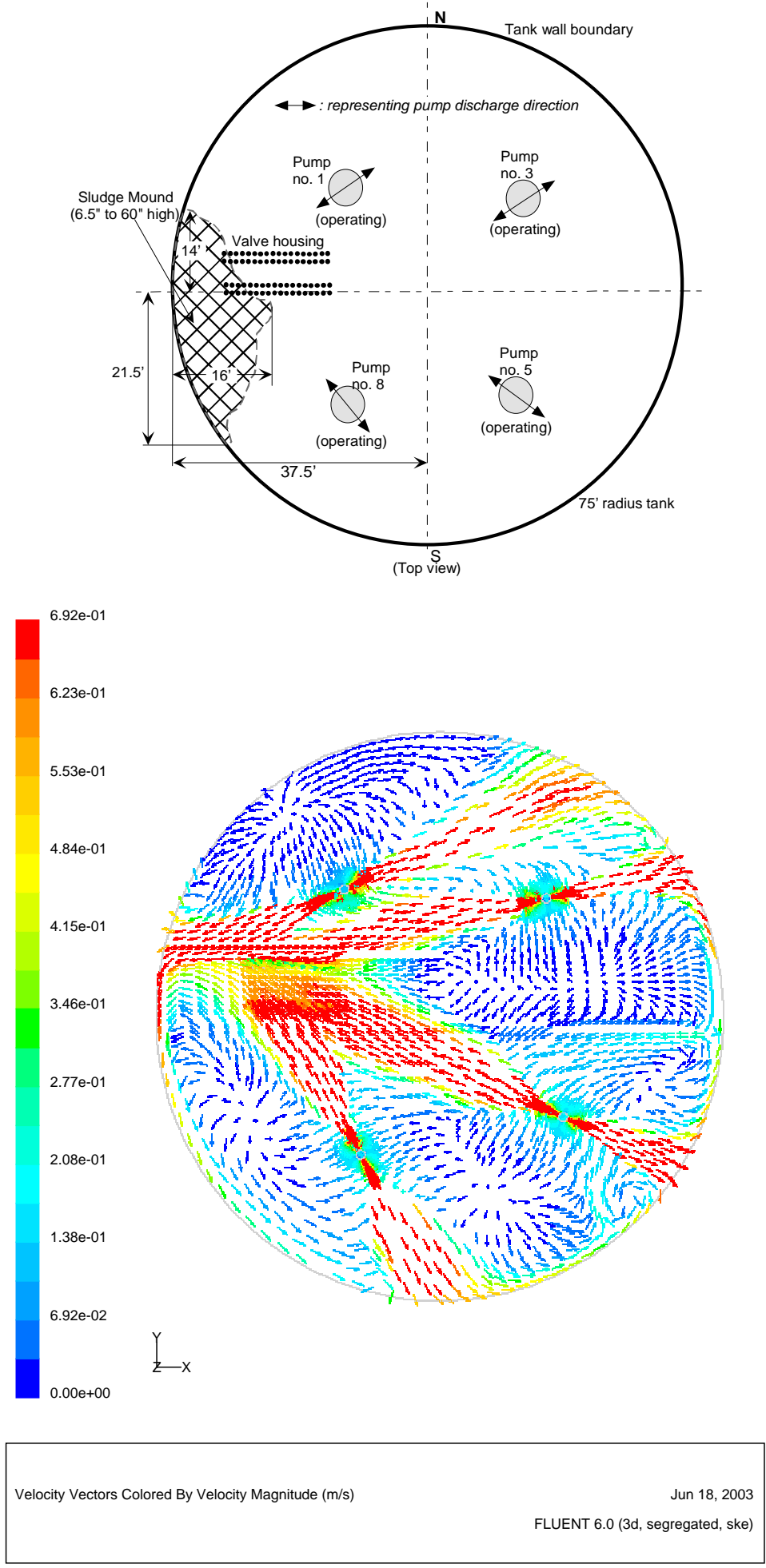

$(0.69 \mathrm{~m} / \mathrm{sec}=2.27 \mathrm{ft} / \mathrm{sec})$

Figure 23. Flow patterns for the four-pump operation in association with effectiveness of sludge removal located at the corner of valve housing in Tank 11 (CaseE: pump no. 1 , no. 3 , no. 5 , and no. 8 operations) 

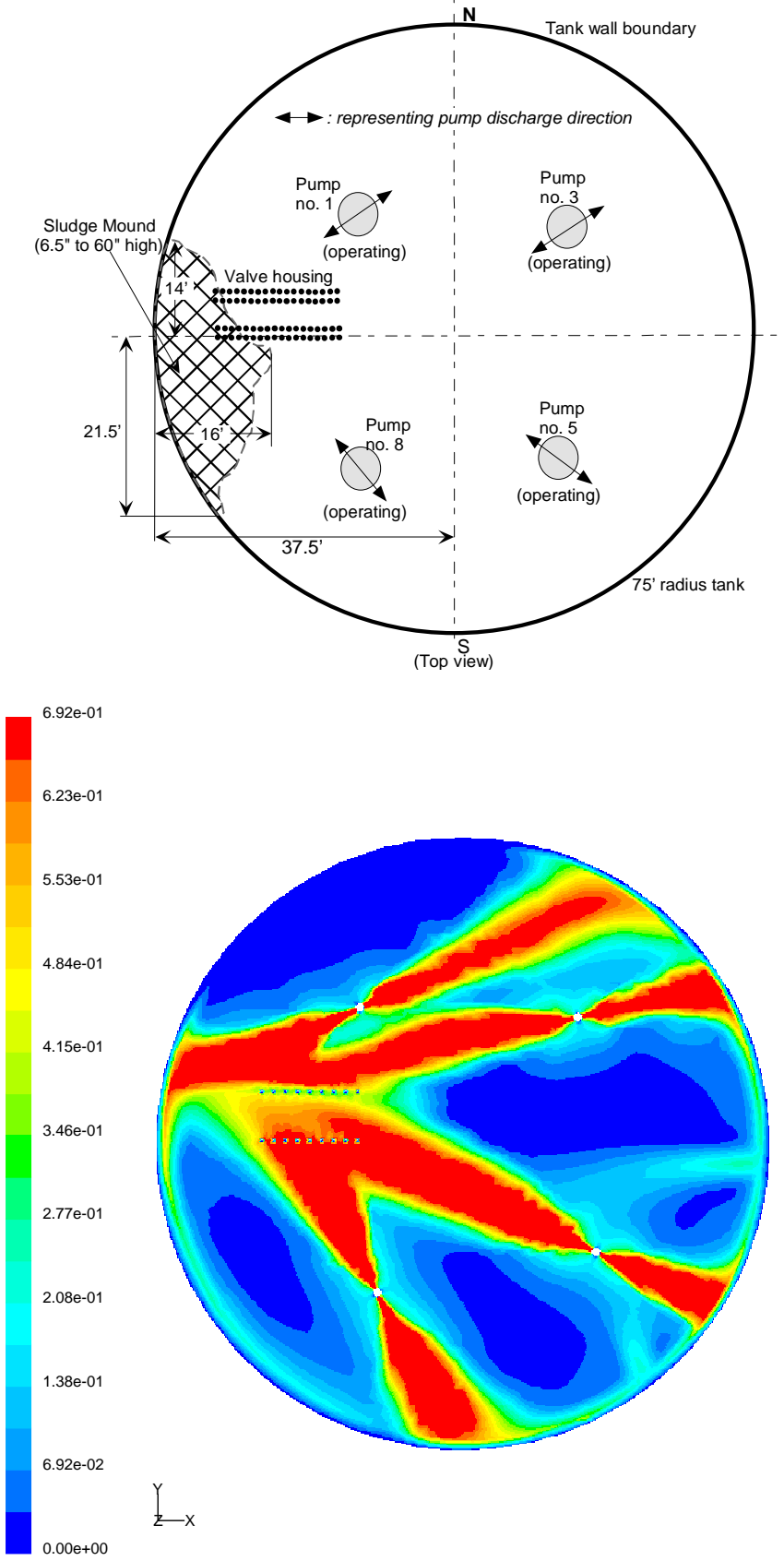

$(0.69 \mathrm{~m} / \mathrm{sec}=2.27 \mathrm{ft} / \mathrm{sec})$

Figure 24. Velocity contour plot for the four-pump operation in association with effectiveness of sludge removal located at the corner of valve housing in Tank 11 (Case-E: pump no. 1, no. 3, no. 5, and no. 8 operations) 

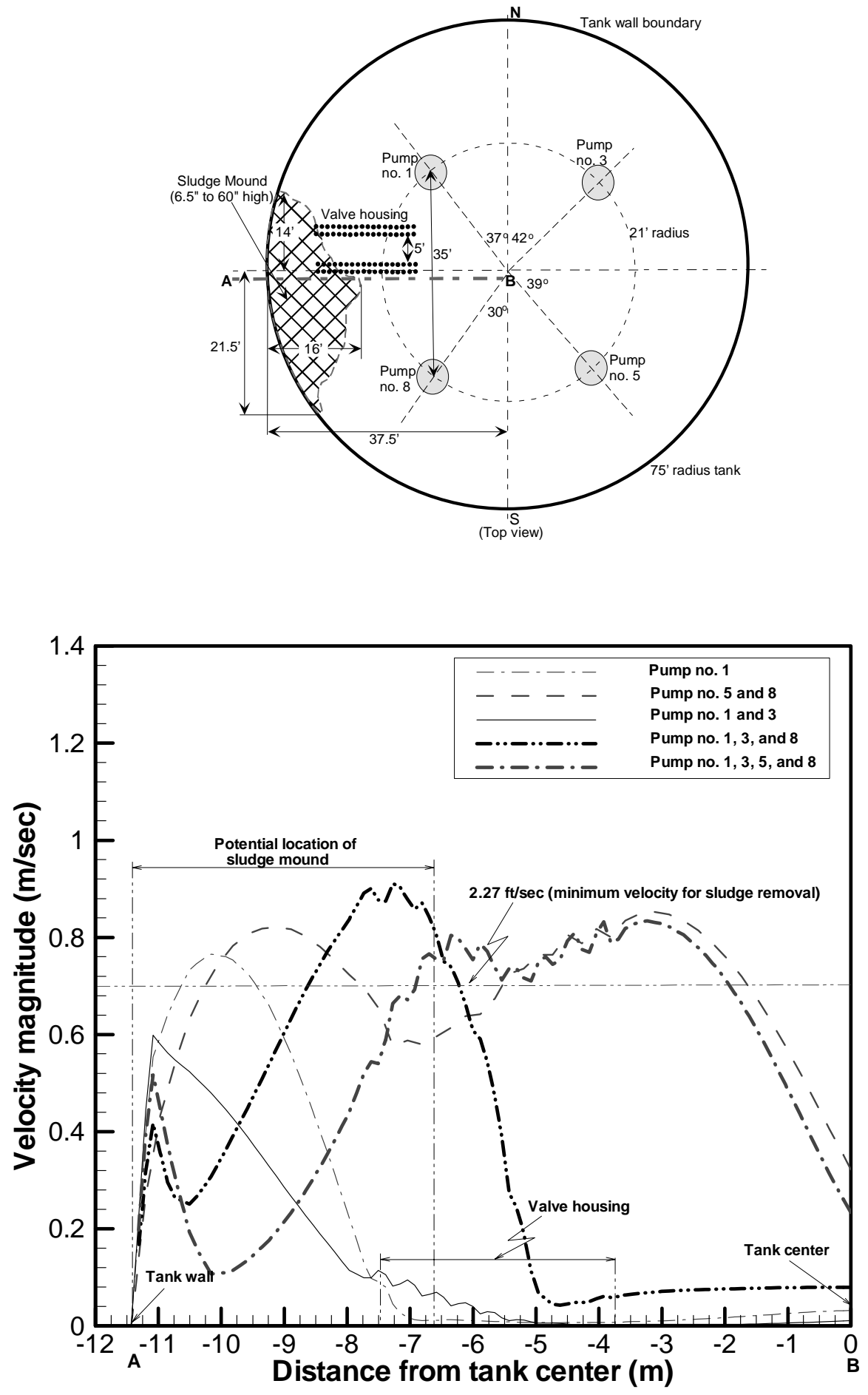

$$
(0.69 \mathrm{~m} / \mathrm{sec}=2.27 \mathrm{ft} / \mathrm{sec})
$$

Figure 25. Flow velocity results along the line A-B near the sludge heel regions using selected numbers of operating pumps and aiming nozzle directions for the reference pump speed (1600 rpm) and operating conditions 

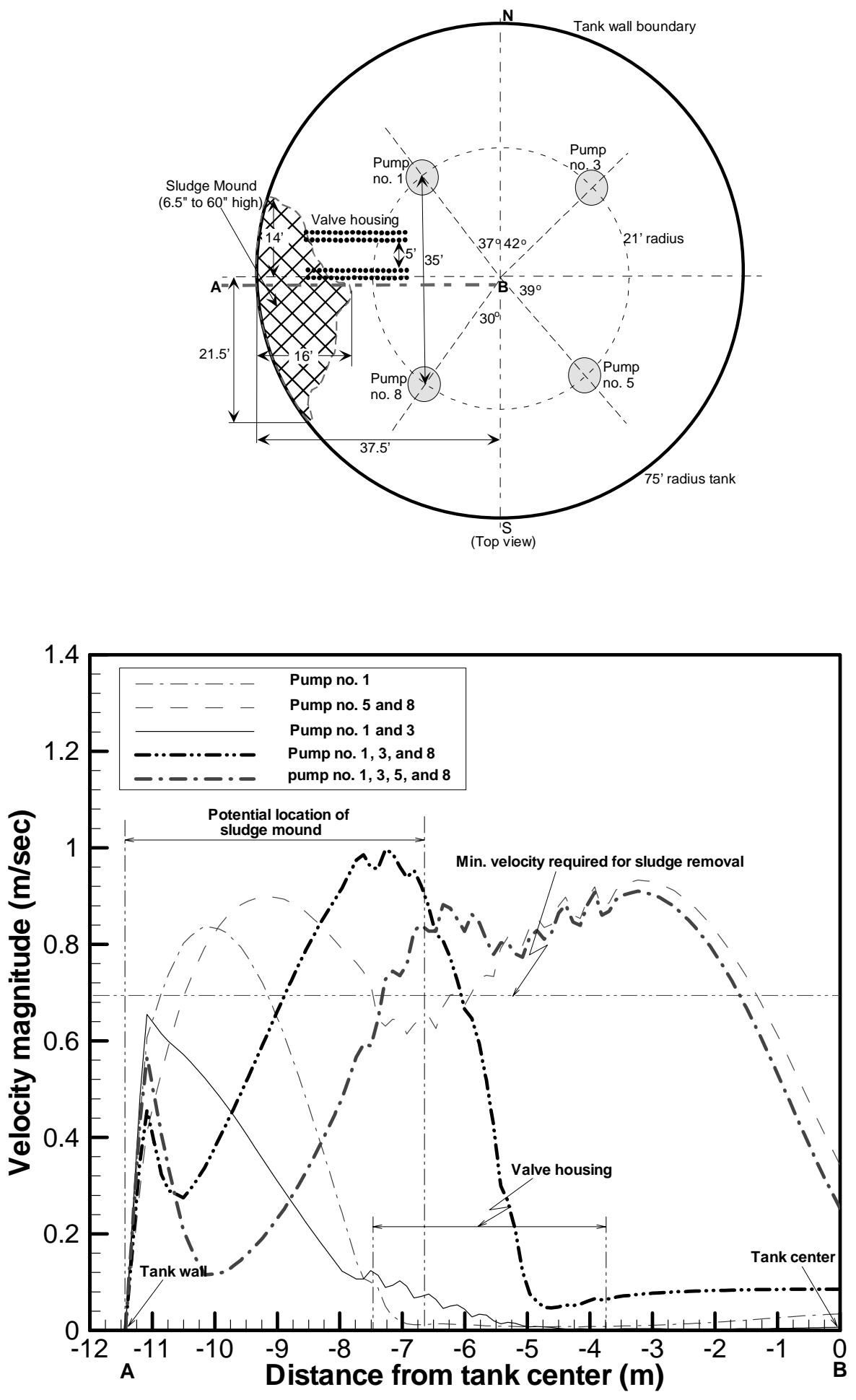

$(0.69 \mathrm{~m} / \mathrm{sec}=2.27 \mathrm{ft} / \mathrm{sec})$

Figure 26. Flow velocity results along the line A-B near the sludge heel regions using selected numbers of operating pumps and aiming nozzle directions for the reference operating conditions other than the pump speed (1800 rpm) 
Report: WSRC-TR-2003-00308

Date: $\quad 10 / 6 / 2003$

Page: $\quad 54$ of 71
WESTINGHOUSE SAVANNAH RIVER COMPANY

SLUDGE HEEL REMOVAL ANALYSIS FOR SLURRY PUMPS OF TANK 11
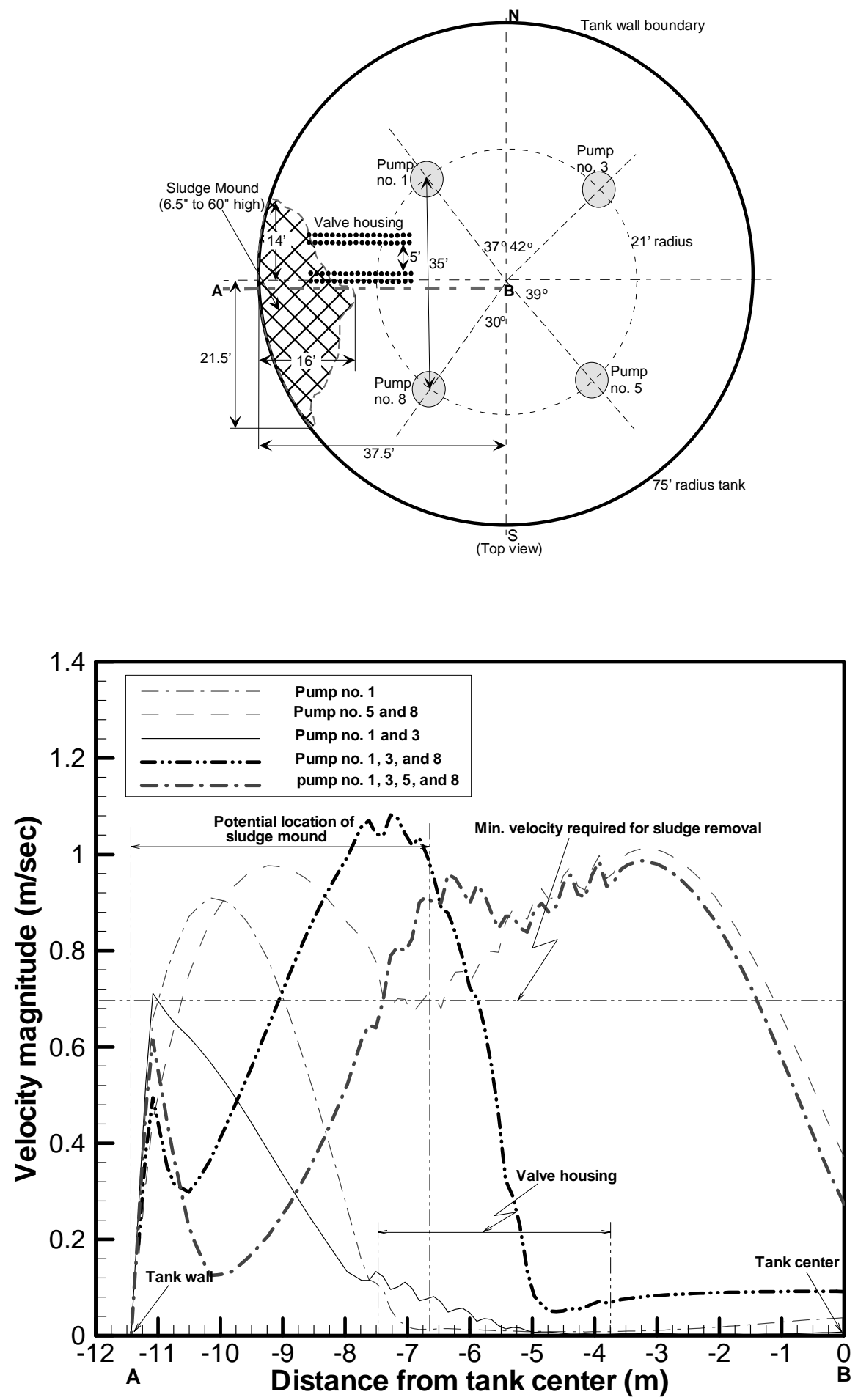

$(0.69 \mathrm{~m} / \mathrm{sec}=2.27 \mathrm{ft} / \mathrm{sec})$

Figure 27. Flow velocity results along the line $A-B$ near the sludge heel regions using selected numbers of operating pumps and aiming nozzle directions for the reference operating conditions other than the pump speed (2000 rpm) 


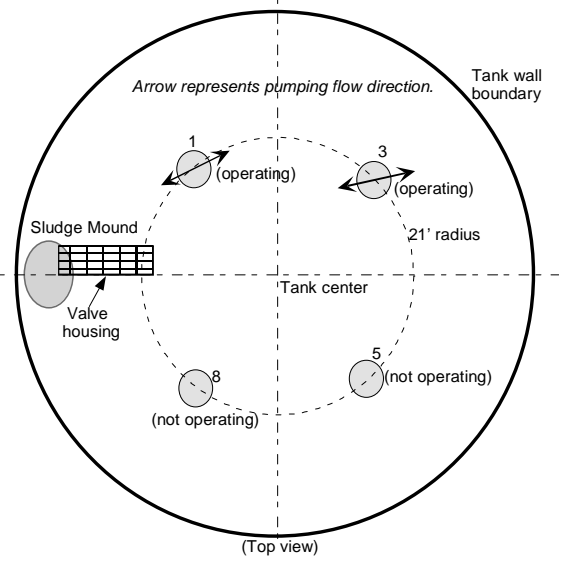

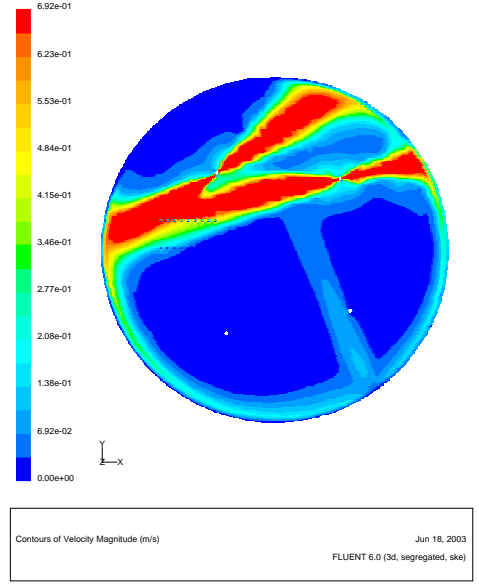

(1600 rpm)

(Nominal reference speed)
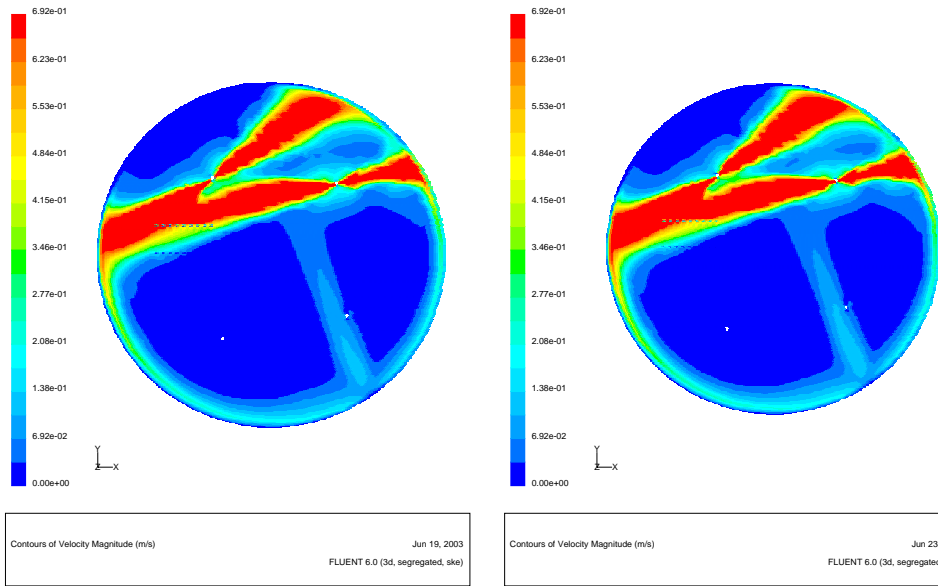

(1800 rpm)

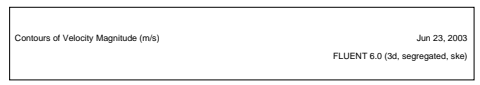

(2000 rpm)

Figure 28. Comparison of velocity contour plots at the pump discharge plane predicted by the present model with two pumps running under the three different pump speeds showing that the red zone is the region higher than the minimum speed of sludge removal $(1 \mathrm{~m} / \mathrm{sec}=3.28 \mathrm{ft} / \mathrm{sec})$. 
Report: WSRC-TR-2003-00308

Date: $\quad 10 / 6 / 2003$

Page: $\quad 56$ of 71
WESTINGHOUSE SAVANNAH RIVER COMPANY

SLUDGE HEEL REMOVAL ANALYSIS FOR SLURRY PUMPS OF TANK 11
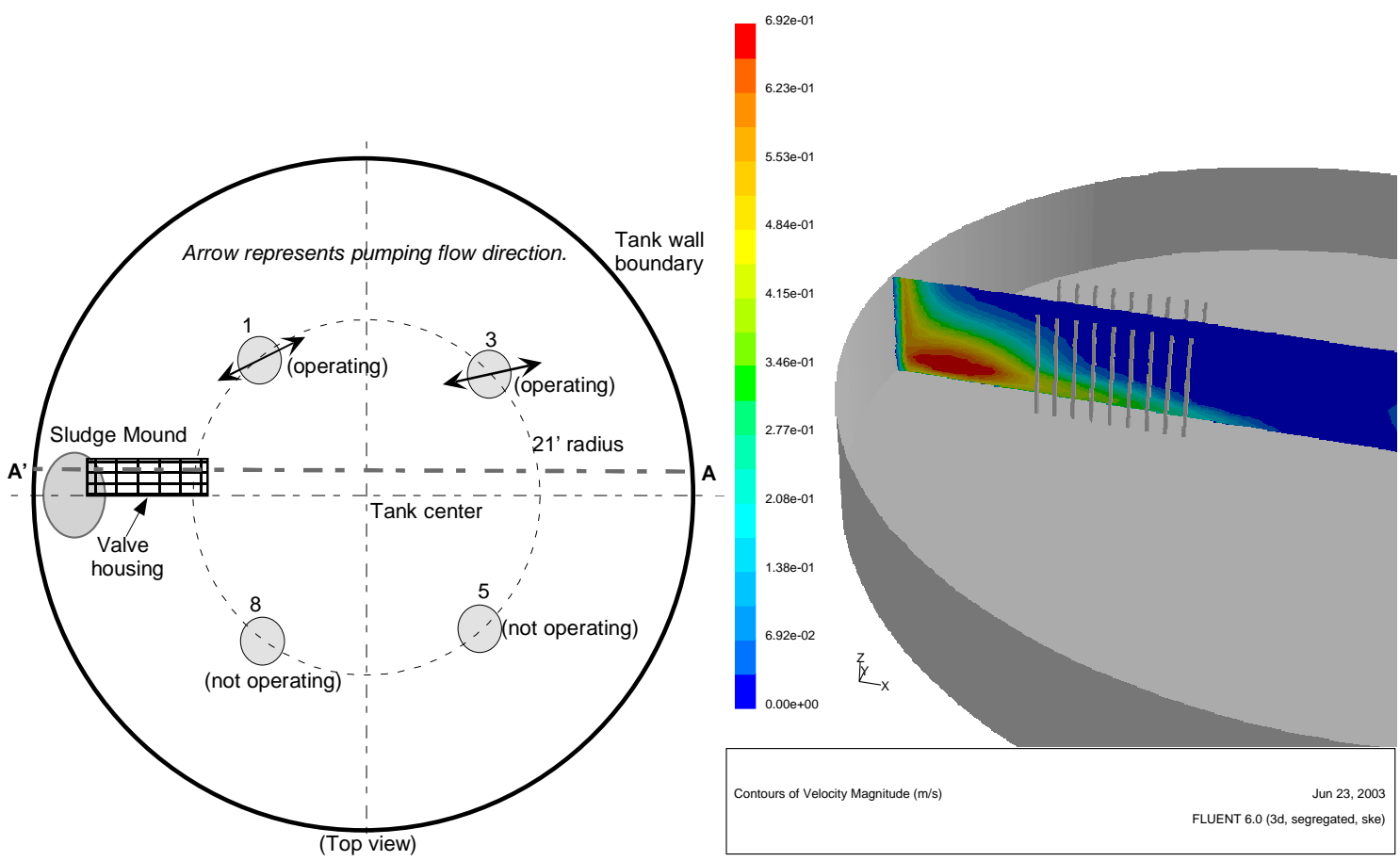

(Nominal reference speed: $1600 \mathrm{rpm}$ )

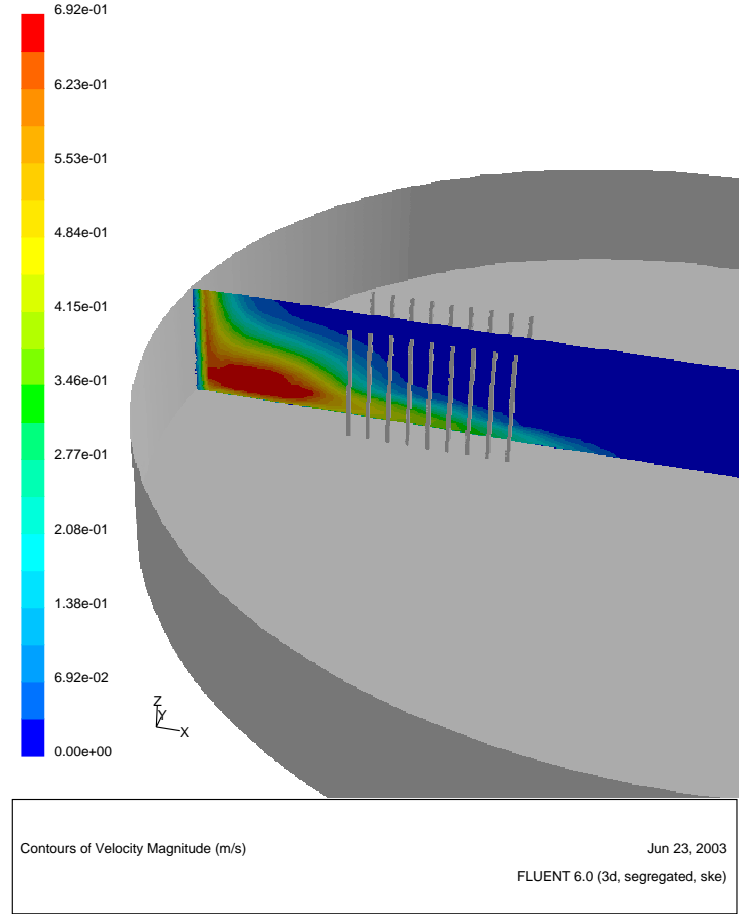

(1800 rpm)

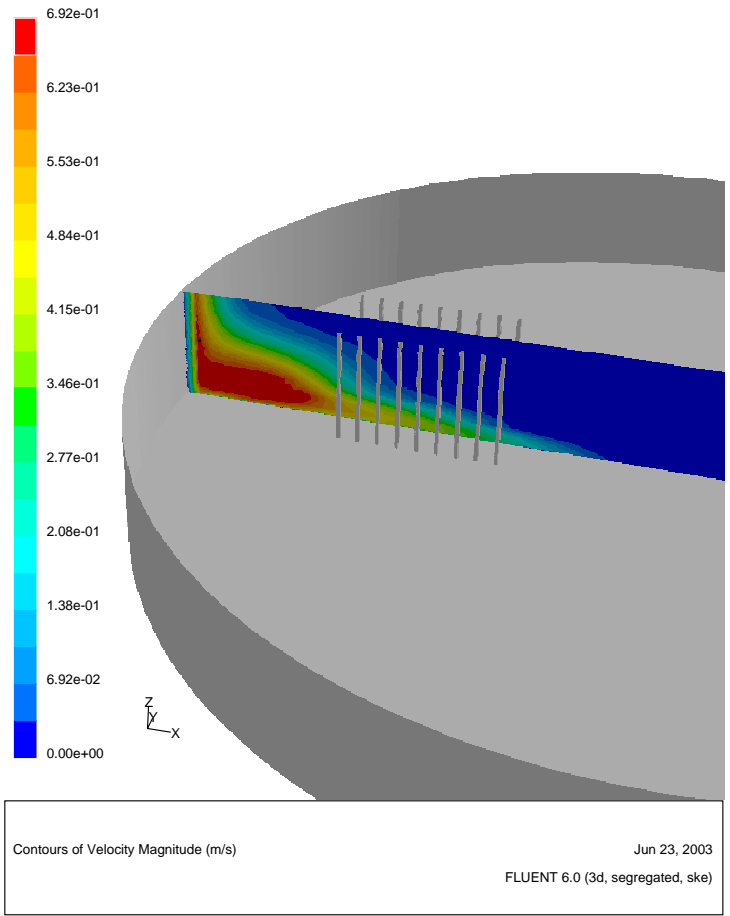

(2000 rpm)

Figure 29. Comparison of velocity contour plots at the vertical plane crossing the line $A^{\prime}-A$ predicted by the present model with two pumps running under the three different pump speeds showing that the red zone is the region higher than the minimum speed of sludge removal $(1 \mathrm{~m} / \mathrm{sec}=3.28 \mathrm{ft} / \mathrm{sec})$. 

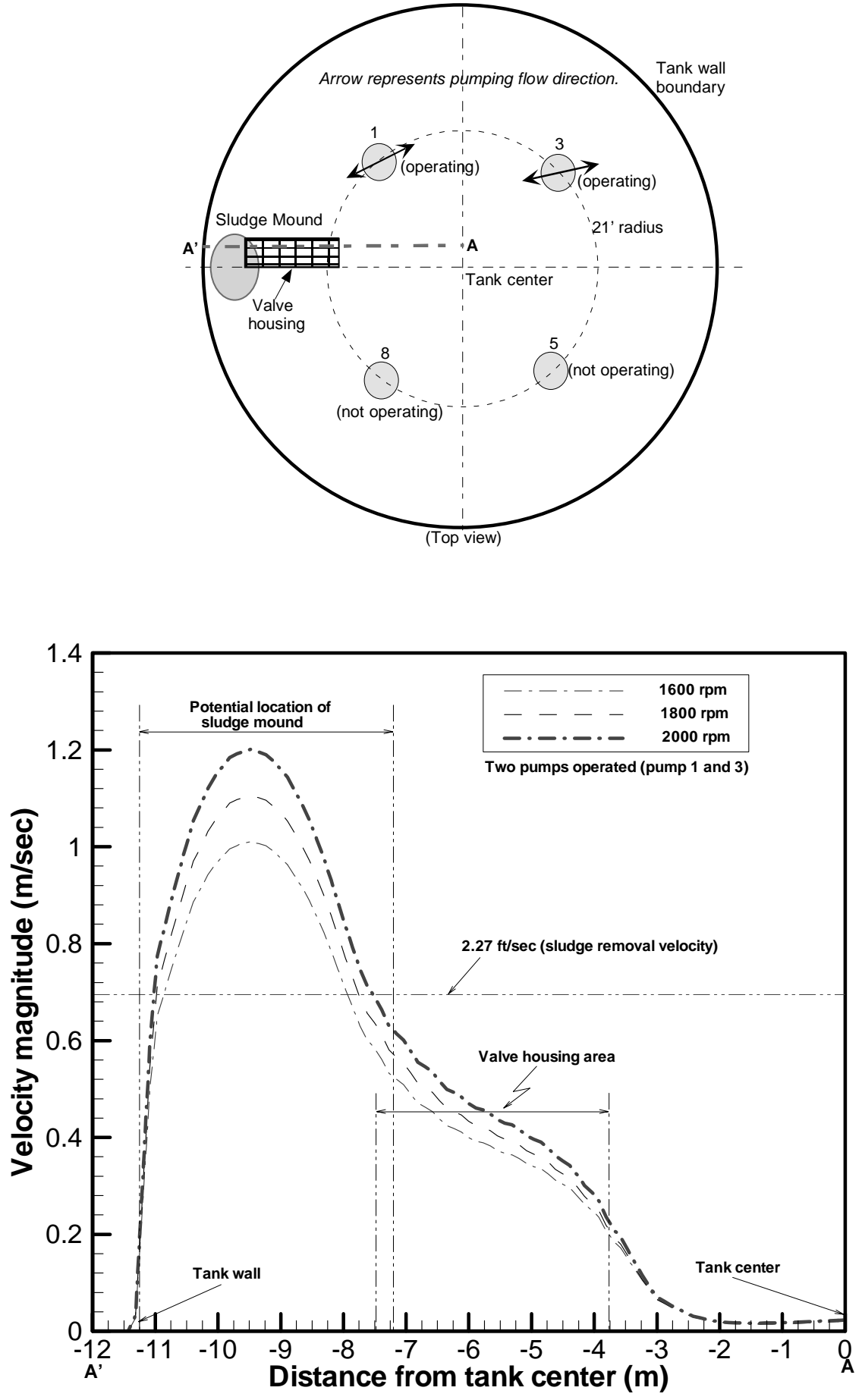

$(1 \mathrm{~m} / \mathrm{sec}=3.28 \mathrm{ft} / \mathrm{sec})$

Figure 30. Flow velocities along the line $A^{\prime}-A$ at the nozzle inlet plane using the present model with two pumps running under the three different pump speeds. 

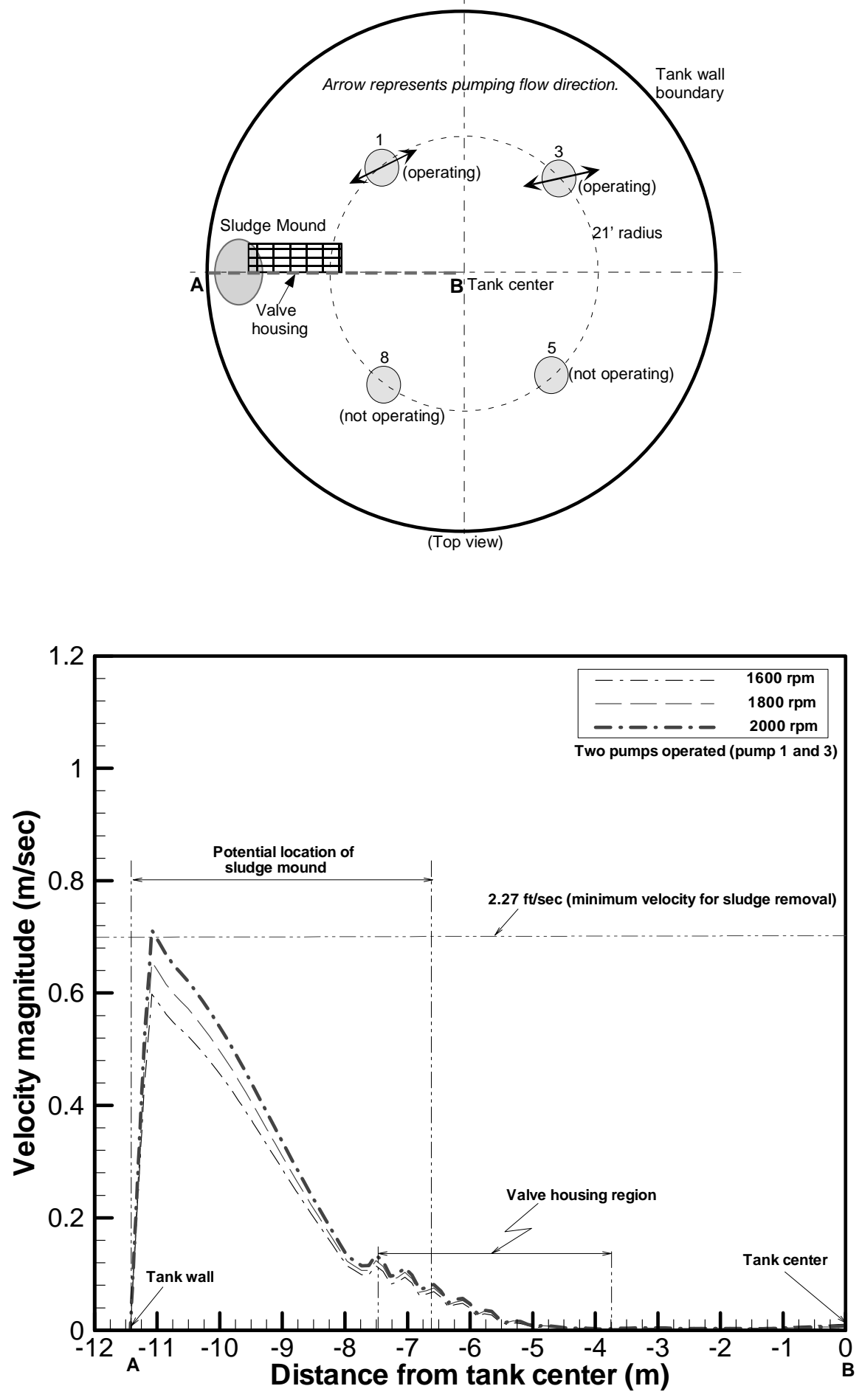

Figure 31. Comparison of velocity magnitude distributions along the line A-B of the pump discharge plane predicted by the present model with two pumps running under the three different pump speeds showing the minimum speed of sludge removal $(1 \mathrm{~m} / \mathrm{sec}=3.28 \mathrm{ft} / \mathrm{sec})$. 

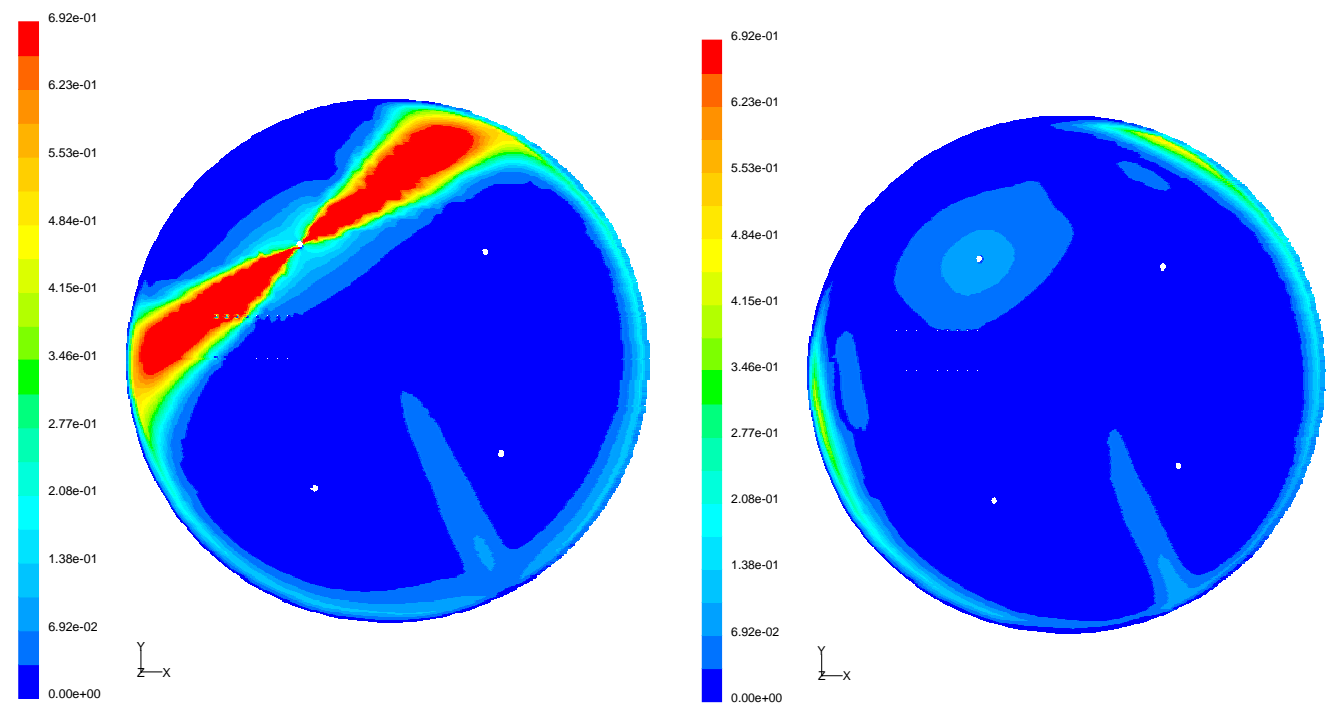

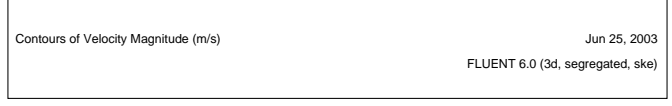

(Pump nozzle discharge plane)

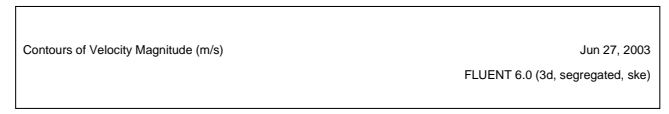

(Top surface plane)

(Flow patterns under 103 in liquid level)
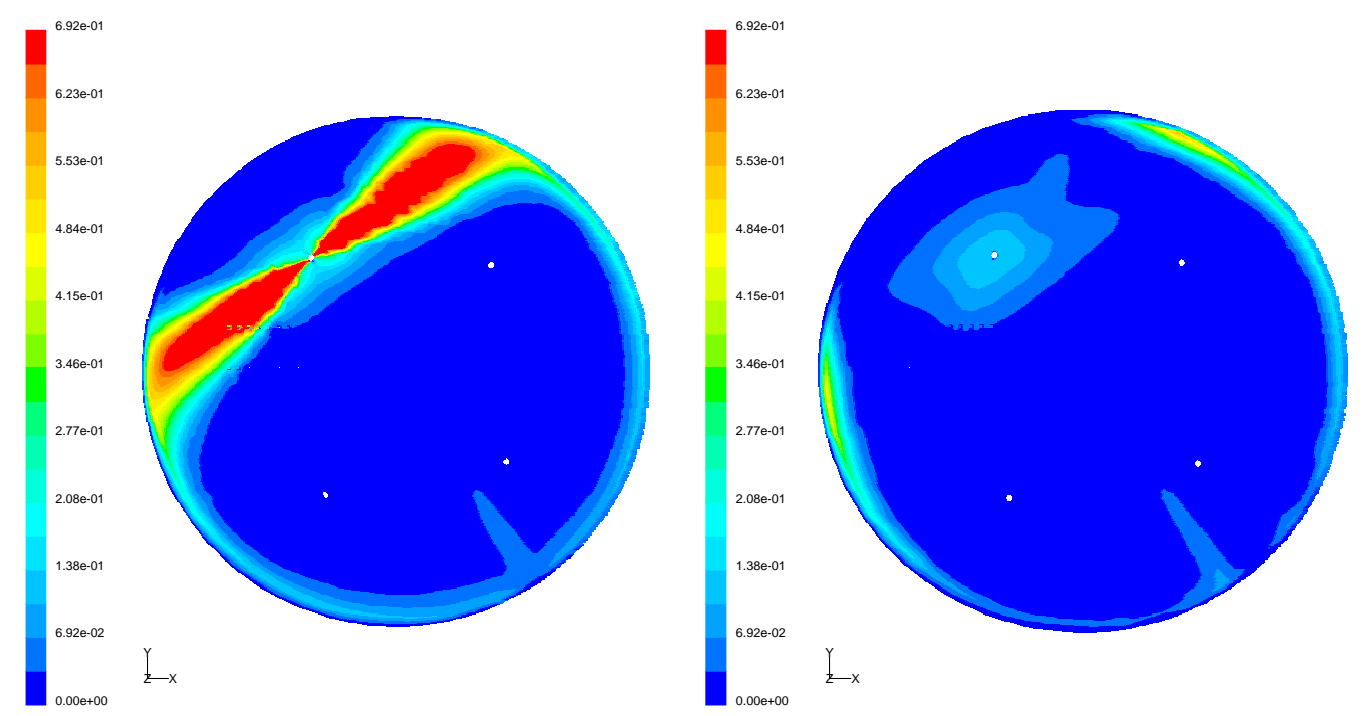

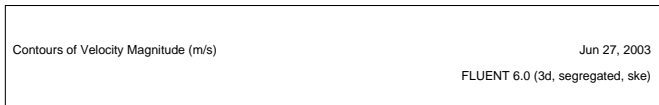

(Pump nozzle discharge plane)

(Flow patterns under 74 in liquid level)

$$
(0.69 \mathrm{~m} / \mathrm{sec}=2.27 \mathrm{ft} / \mathrm{sec})
$$

Figure 32. Comparison of flow patterns at the nozzle exit plane for the two different tank level (103 in and 74 in levels) under the referenced operating speed of one slurry pump (pump no. 1). 

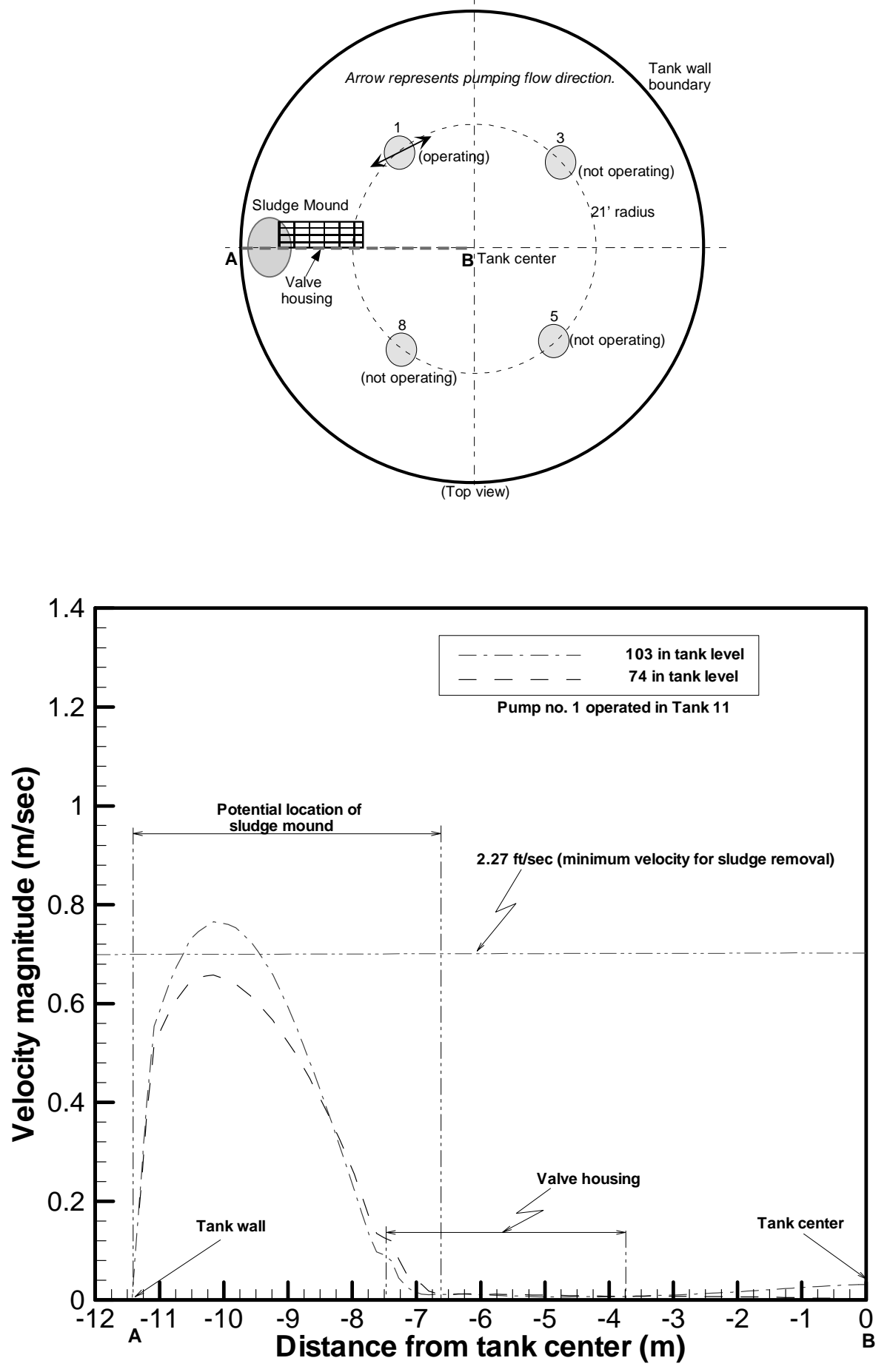

$(1 \mathrm{~m} / \mathrm{sec}=3.28 \mathrm{ft} / \mathrm{sec})$

Figure 33. Comparison of flow velocities along the line A-B at the nozzle exit plane between the 103 in and 74 in tank levels under the operating conditions of one slurry pump (pump no. 1 in Tank 11 as shown above). 

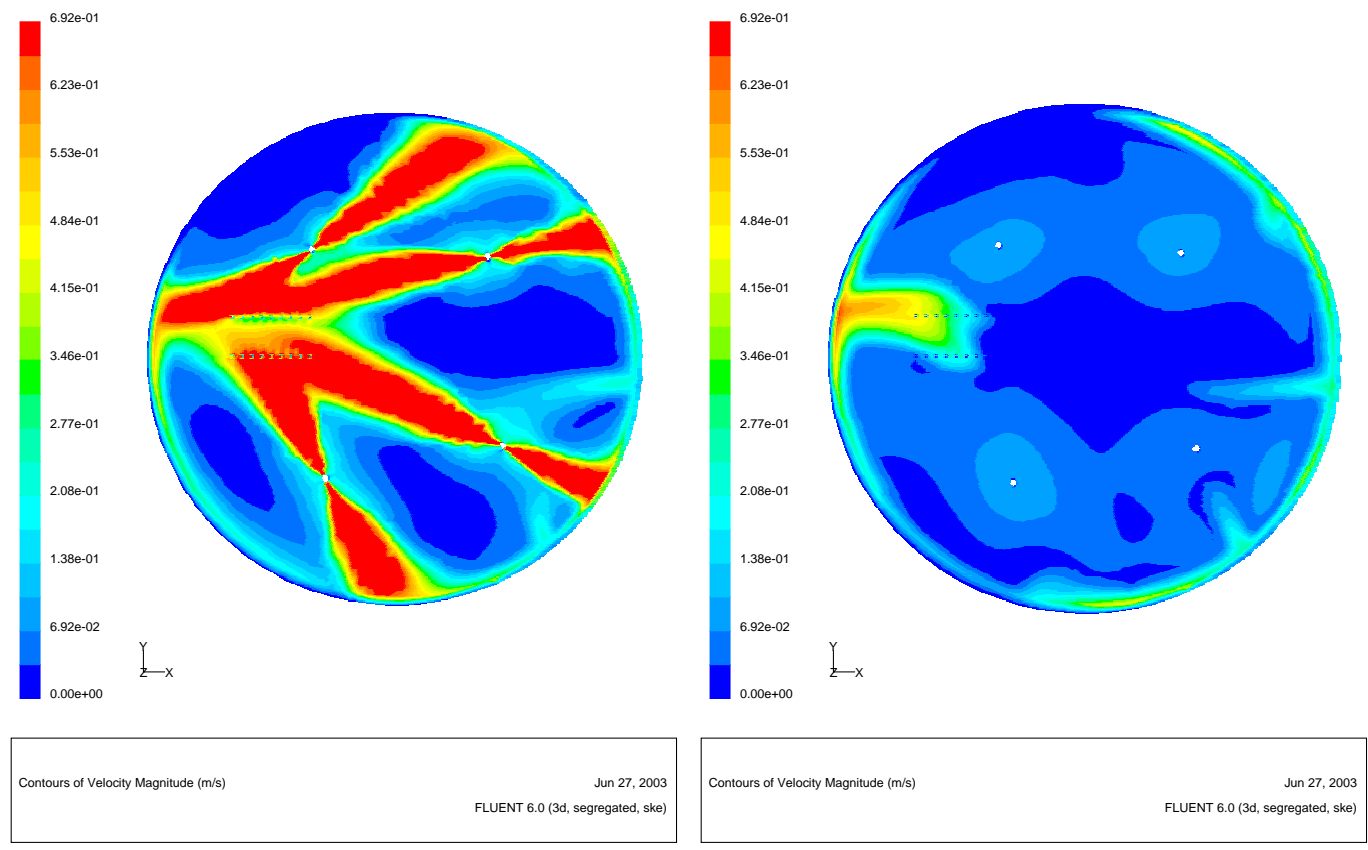

(Pump nozzle discharge plane)

(Top surface plane)

(Flow patterns under 103 in liquid level)

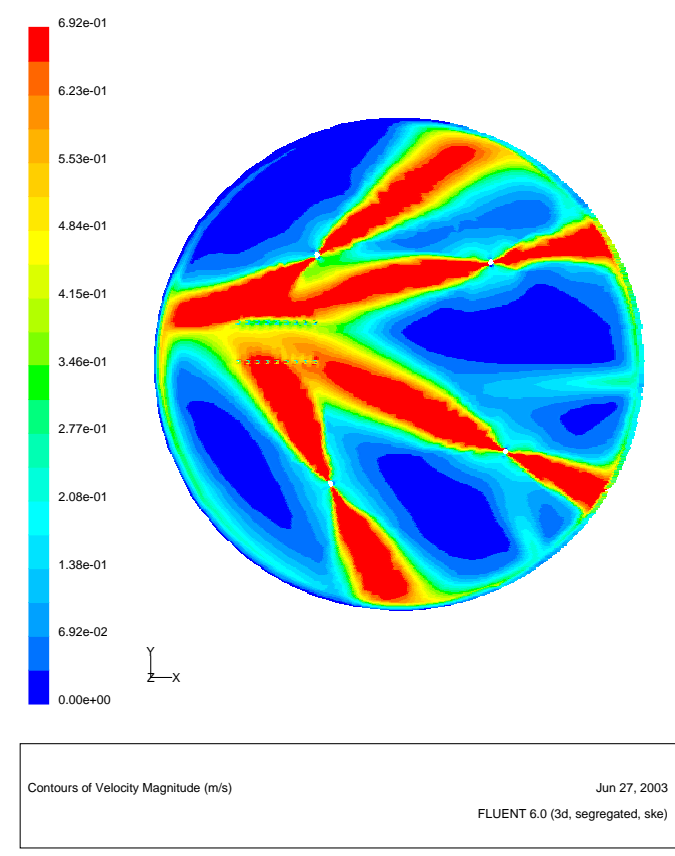

(Pump nozzle discharge plane)

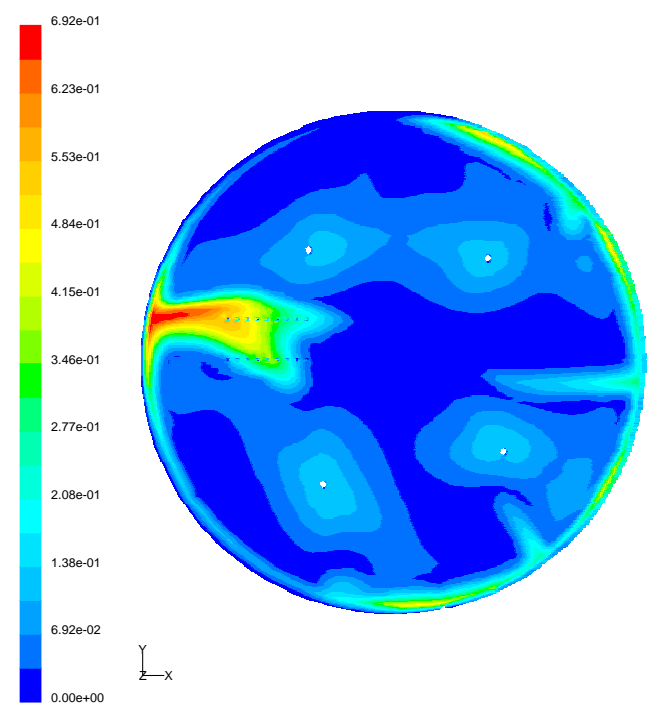

(Flow patterns under 74 in liquid level)

$$
(0.69 \mathrm{~m} / \mathrm{sec}=2.27 \mathrm{ft} / \mathrm{sec})
$$

Figure 34. Comparison of flow patterns at the nozzle exit and top planes for the two different tank level (103 in and 74 in levels) under the referenced operating speeds of four slurry pumps (pump no. 1, 3, 5, and 8). 
Report: WSRC-TR-2003-00308

Date: $\quad 10 / 6 / 2003$

Page: $\quad 62$ of 71
WESTINGHOUSE SAVANNAH RIVER COMPANY

SLUDGE HEEL REMOVAL ANALYSIS FOR SLURRY PUMPS OF TANK 11
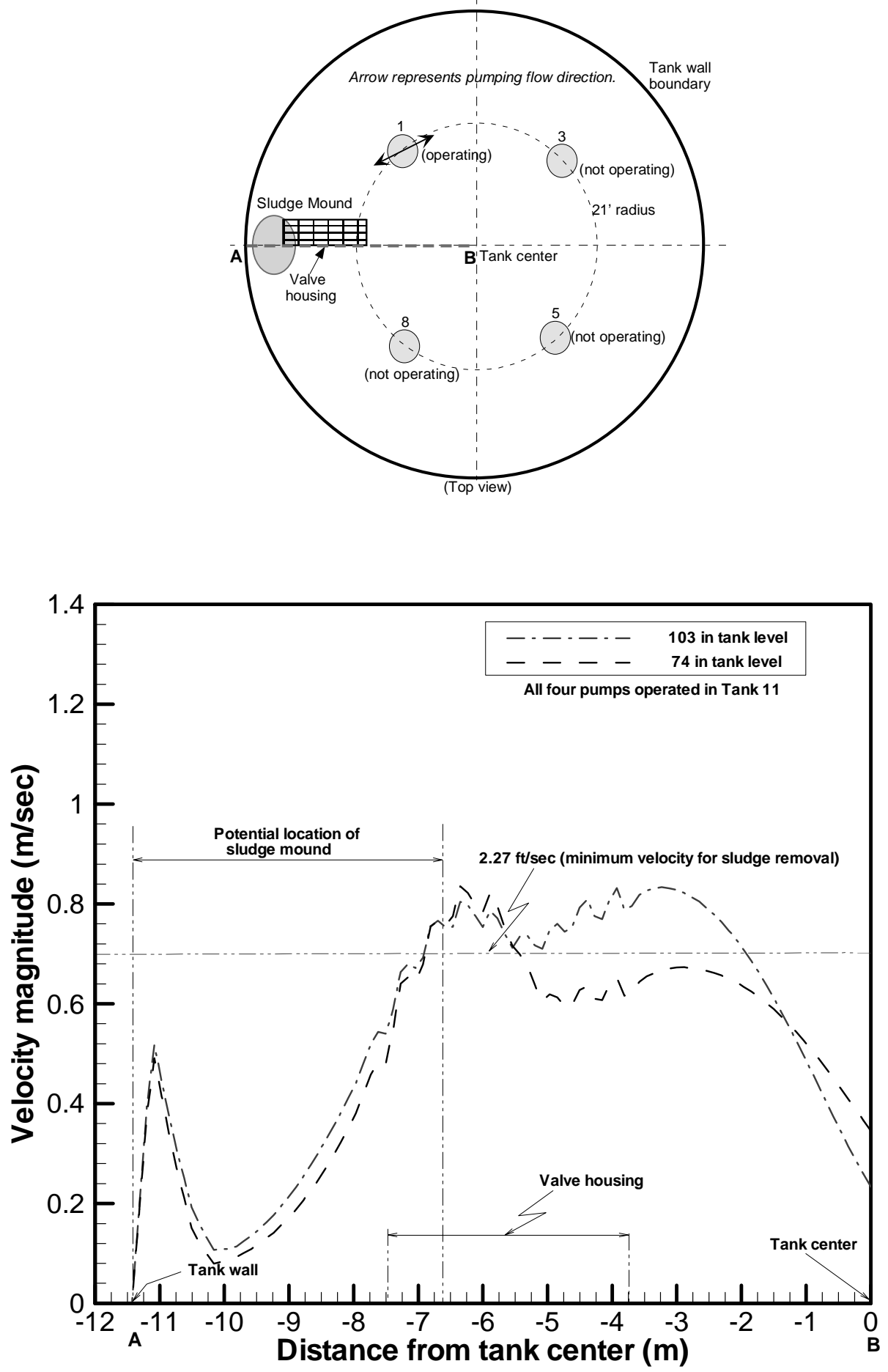

$(1 \mathrm{~m} / \mathrm{sec}=3.28 \mathrm{ft} / \mathrm{sec})$

Figure 35. Comparison of flow velocities along the line A-B at the nozzle exit plane between the 103 in and 74 in tank levels under the operating conditions of four slurry pumps (pump no. 1, 3, 5, and 8). 

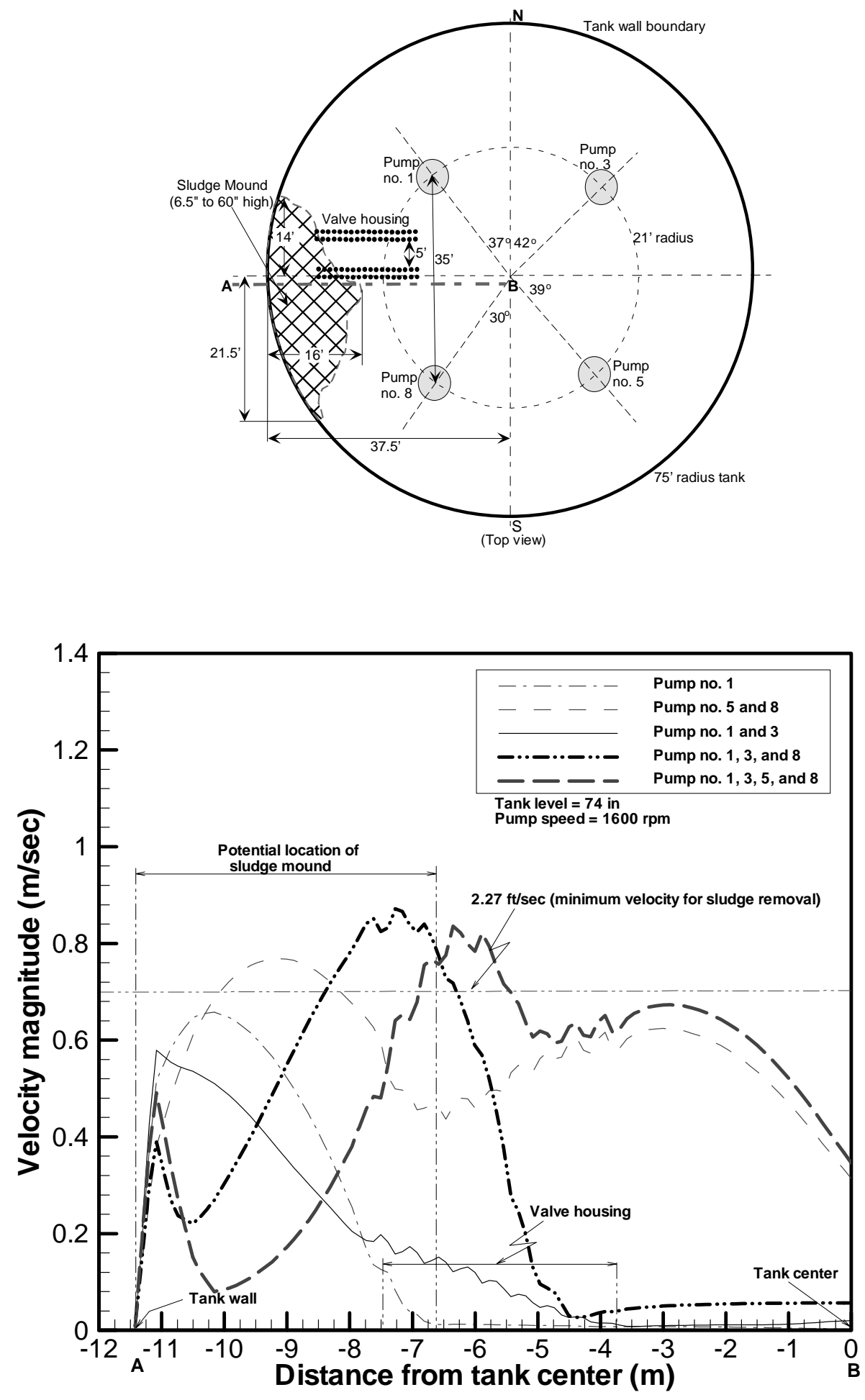

$(0.69 \mathrm{~m} / \mathrm{sec}=2.27 \mathrm{ft} / \mathrm{sec})$

Figure 36. Flow velocity results along the line $A-B$ near the sludge heel regions using selected numbers of operating pumps and aiming nozzle directions for the reference pump speed (1600 rpm) with lower tank level (74 in liquid level) 

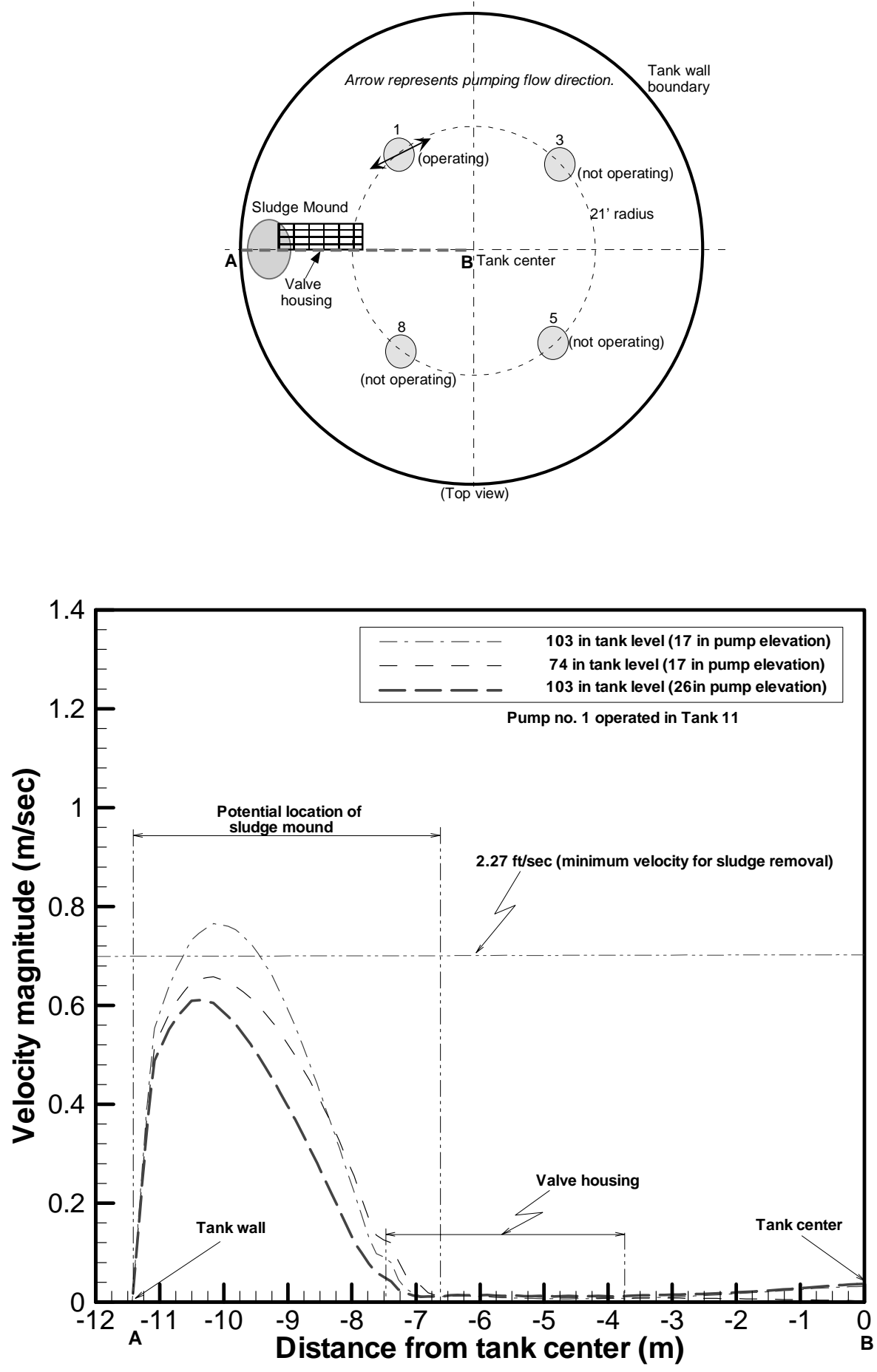

$(1 \mathrm{~m} / \mathrm{sec}=3.28 \mathrm{ft} / \mathrm{sec})$

Figure 37. Comparison of flow velocities along the line A-B of the nozzle exit plane among the different tank levels and pump elevations under the operating conditions of one slurry pump (pump no. 1 in Tank 11 as shown above) 

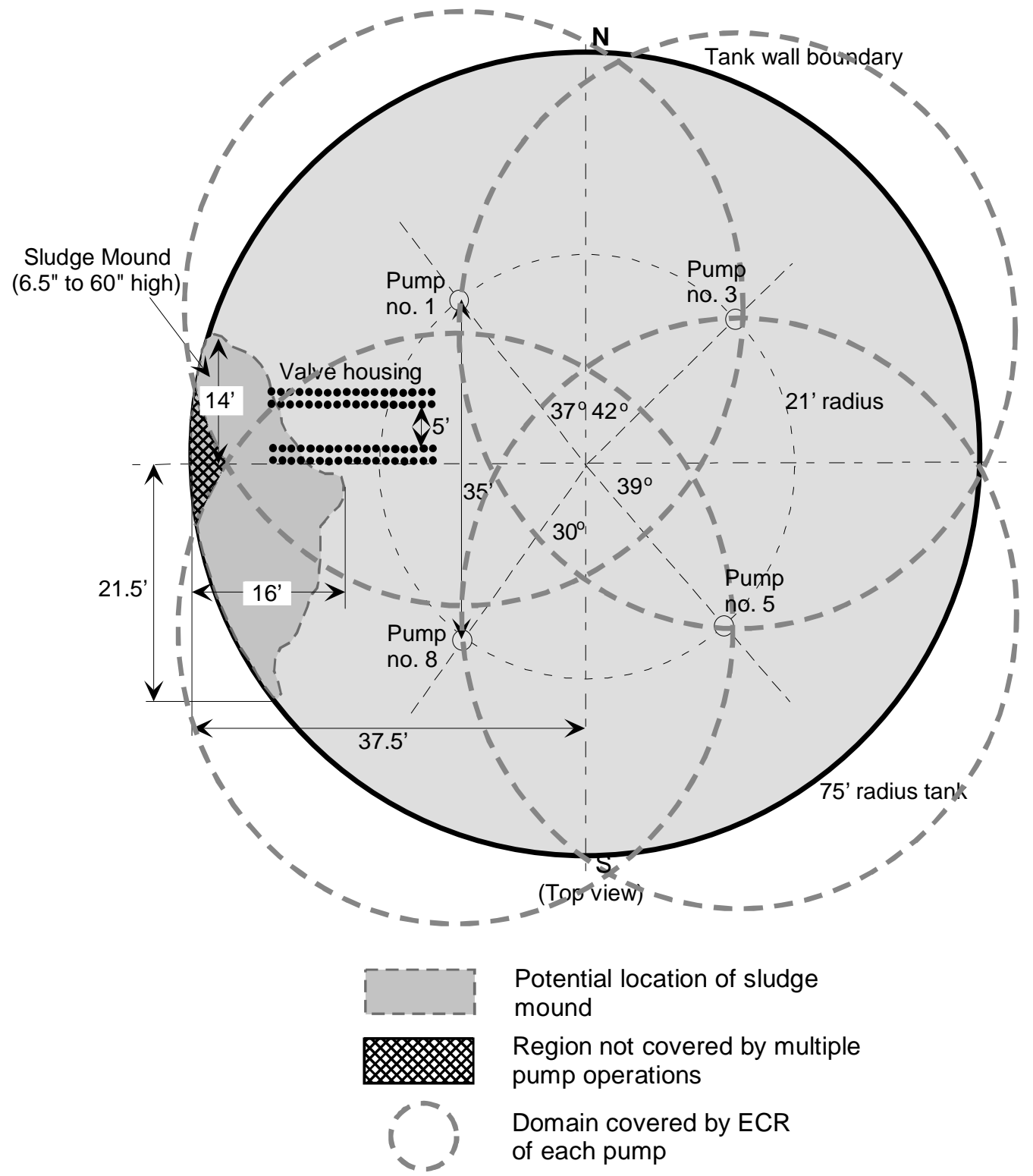

$(E C R$ for the reference operating conditions $=$ about $27 \mathrm{ft})$

Figure 38. Predictions of sludge removal domain provided by the recommendations of the indexed nominal operations of mixing pumps and the aiming nozzle directions for a given pump speed (1600 rpm) as shown in Table 7 
Page:

\section{Summary and Conclusions}

Tank 11 simulation models with submersible slurry pumps have been developed to provide operational guidance of slurry pumps for an efficient sludge removal. Sensitivity calculations have been performed for key operational parameters such as tank liquid level, pump elevation, and pump speed and to provide a recommendation for sludge heel suspension and removal operations in Tank 11. Reference design and operating conditions shown in Table 6 were used to perform the best estimate analysis of the tank sludge removal. In the analysis, the pump was assumed to be stationary as requested by the customer [2]. Solid obstructions including the pump housing, the 14" riser, and 72 -tube valve housing structure were included in the performance model. Free surface motion of the tank liquid was neglected for high tank liquid level using the literature information.

Steady-state analyses with a two-equation turbulence model were performed with FLUENT $^{\mathrm{TM}}$, a commercial computational fluid dynamics (CFD) code. All analyses were based on three-dimensional results. A recommended operational strategy was developed assuming that local fluid velocity can be used as a measure of sludge suspension and removal. For a minimum suspension velocity of $2.27 \mathrm{ft} / \mathrm{sec}$, the results indicated that the existing slurry mixers running at $1600 \mathrm{rpm}$ could remove the sludge heel from the tank with a 103 in liquid level. In this case, the exception is the region within about $2 \mathrm{ft}$ of the wall, which is located behind the valve housing structure. A recommended strategy is summarized in Table 7.

The length of time that the sludge is exposed to the liquid stream is also important in affecting the ability of the liquid stream to suspend sludge, and this effect is quantified in the present analysis by using the Tank 16 test results. The results show that about 40 hours' pump operation for an indexed pump orientation is required to remove the sludge mound based on the slurry jet spread angle computed by the Tank 11 CFD simulation models and the sludge cleaning rates observed by operations of the Tank 16 slurry pump.

The main conclusions are as follows:

- Internal obstructions can help increase local flow velocity in some regions, such as the valve housing structures where the sludge mound is located in Tank 11.

- Sensitivity results show that higher tank level and lower pump elevation result in better performance for suspending and removing the sludge for the given design and operating conditions of Tank 11. These are consistent with the results of the Tank 8 analyses and experimental observations of Tank 18 operations

- It is noted that the higher pump speed is generally more efficient than the lower in terms of sludge removal capability, but it is about the same in terms of flow circulation patterns. When pump speed is lower than $1800 \mathrm{rpm}$, the velocities near the wall region by the sludge mound are probably not high enough to suspend and mobilize the sludge.

The analysis results performed by the present models will be used to evaluate hydraulic cleaning capabilities for waste removal. This information will also assist in the operating plan for the Tank 11 waste removal and in identifying special operation requirements for the suspension and removal of the tank sludge heel. 
WESTINGHOUSE SAVANNAH RIVER COMPANY

SLUDGE HEEL REMOVAL ANALYSIS FOR SLURRY PUMPS OF TANK 11
Report:WSRC-TR-2003-00308

Date:

$10 / 6 / 2003$

Page:

67 of 71

(This Page Intentionally Left Blank) 
Page: $\quad 68$ of 71

\section{Recommendation}

The analysis reported here did not address overall pump operating strategy to suspend bulk of sludge waste, and the present models did not actually include the existence of the sludge mound on the computational domain so that all flow patterns were based on a flat-bottomed tank. Therefore, the recommended pump operation program is based on an assumption that it is best to attack the leading edge of the sludge mound first. With this in mind, the recommended pump operational program is shown in Table 7 and repeated here in the recommended order:

1. Case-A: Pump 1, $38^{\circ}$

2. Case-B: Pump 5, $22^{\circ}$

Pump 8, $43^{\circ}$

3. Case-C: Pump 1, 38

Pump 3, $16^{\circ}$

4. Case-D: Pump 1, 38

Pump 3, $16^{\circ}$

Pump 8, 54ำ

5. Case-E: Pump 1, $38^{\circ}$

Pump 3, $16^{\circ}$

Pump 5, $22^{\circ}$

Pump 8, 65

Pump orientations are as shown in Figures 16 through 24. The uncertainty in the minimum sludge suspension velocity becomes an issue for regions close to the wall and a pump speed of $1600 \mathrm{rpm}$. The higher speed (at least $1800 \mathrm{rpm}$ ) is expected to do a better job removing sludge, especially close to the tank wall. The required time duration for each case was estimated by using the experimental results of Tank 16. 
WESTINGHOUSE SAVANNAH RIVER COMPANY

SLUDGE HEEL REMOVAL ANALYSIS FOR SLURRY PUMPS OF TANK 11
Report:WSRC-TR-2003-00308

Date: $\quad 10 / 6 / 2003$

Page:

69 of 71

(This Page Intentionally Left Blank) 


\section{References}

1. Technical Task Request by G. B. Clendnen, HLE-TTR-2003-118, Rev. 0, July 10, 2003.

2. E-mail written by G. B. Clendnen, "Tank 11 Modeling Information", May 28, 2003.

3. E. J. Freed and P. S. Mukherjee, "Tank 8 Waste Removal Operating Plan", UESR-F-00009, Rev. 5, April 2001.

4. S. Y. Lee and R. A. Dimenna, "Heel Removal Analysis for Mixing Pumps of Tank 8", WSRC-TR-2002-00460 (September 2002).

5. S. Y. Lee and R. A. Dimenna, "Performance analysis for Mixing Pumps in Tank 18", WSRC-TR-2001-00391 (October 2001).

6. N. V. Chadrasekhara Swamy and P. Bandyopadhyay, "Mean and Turbulence Characteristics of Three-Dimensional Wall Jets", Journal of Fluid Mechanics, Vol. 71, Part 3, pp. 541-562 (1975).

7. FLUENT, Fluent, Inc. (1998).

8. S. Y. Lee, "Evaluation of Sludge Removal Capabilities for ADMP Mixer in Tank 18, WSRC-TR-2003-00166, April 2003.

9. J. M. Dallavalle, Micromeritics, $2^{\text {nd }}$ Edition, Pitman Publishing Corporation, New York (1948).

10. C. K. Madina and L. P. Bernal of F, "Interaction of a Turbulent Round Jet with the Free surface", Journal of Fluid Mechanics, Vol. 261, pp. 305-332 (1994)

11. Abramovich, G. N., "The Theory of Turbulent Jets", The MIT Press, Cambridge, MA, 1963.

12. H. Schlichting, Boundary Layer Theory, McGraw-Hill Book Company, New York (1967).

13. G. Tatterson, "Sludge Suspension in Waste Storage Tanks", DPST-89-257, January 6, 1989.

14. Graf, W. H., Hydraulics of Sediment Transport, McGraw-Hill Book Company, New York, 1971.

15. H. Tennekes and J. L. Lumley, A First Course in Turbulence, The MIT Press, Cambridge, MA, 1972.

16. B. V. Churnetski, "Effective Cleaning Radius Studies", Memorandum, DPST-81282, February 19, 1981.

17. J. H. Perry, Chemical Engineers' Handbook, Fourth Edition, McGraw-Hill Book Co, New York. 
WESTINGHOUSE SAVANNAH RIVER COMPANY

SLUDGE HEEL REMOVAL ANALYSIS FOR SLURRY PUMPS OF TANK 11
Report:WSRC-TR-2003-00308

Date:

$10 / 6 / 2003$

Page:

71 of 71

(This Page Intentionally Left Blank) 